\title{
Abstracts
}

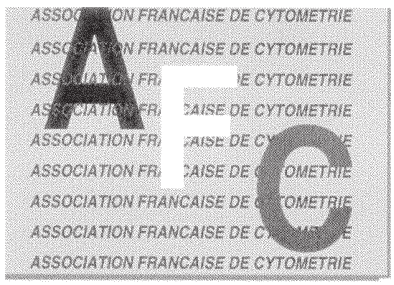

\section{Association Française de Cytometrie}

\author{
AFC Cytometrie 96 \\ Rouen, 16-18 Octobre 1996 \\ Organising and Scientific Committee
}

Alain Bernheim (AFC), Claudine Buffet-Janvresse (Rouen), Pierre Carayon (AFC), Jean-Luc D'Hautcourt (AFC), Jean Dufer (AFC), Christophe Duperray (AFC), Marc Feuilloley (Rouen), Jacques Hemet (Rouen), Sylvie Huet (AFC), Annie Laquerriere (Rouen), Olivier Lees (AFC), Bernard Lenormand (Rouen), Xavier Ronot (AFC), François Tron (Rouen), Philippe Vago (AFC) 


\section{AVANCÉES TECHNOLOGIQUES ET TRAITEMENT INFORMATIQUE DES DONNÉES}

Présidents de séance : P. Carayon, J.-L. D’Hautcourt

\section{Résumés 1 à 22}

Présentations orales : résumés 1 à 5 
1 HIGH RESOLUTION IMAGING IN VITRO AND IN VIVO STEPS TOWARDS A NEW CYTOMETRY

D.L. Farkas

Center for Light Microscope Imaging and Biotechnology

Carnegie Mellon University, Pittsburgh PA 15213, USA

Optical imaging excels in versatility, resolution, and range. In cytometry, subcellular and dynamic monitoring can add new dimensions, but necessitate improved microscopic approaches for quantitating morphology and function in cells, viewed as living microcuvettes. With the right combination of technologies, and the resulting greatly enhanced spatial and temporal resolution, new insights can be gained non-invasively. This talk will attempt to summarize our progress in (a) expanding the capabilities of light microscopy for cytometry by multimode and automated microscopy (1-4), emphasizing optimized image acquisition; (b) improving the axial resolution of cellular imaging by standing wave microscopy (5); (c) imaging with increased speed and spectral content (6) with an acousto-optic tunable filter microscope; (d) new approaches in vivo, with mesoscopic imaging (7). Selected biological results will also be presented, with emphasis on the medically important cytometry areas such as cancer (8) and transplant immunology.

(1) Farkas et al. (1993) Ann. Rev. Physiol. 55, 785-817 - (2) Farkas et al. (1994) Proc. SPIE 2137, 2-16 - (3) Taylor et al. (1996) Proc. SPIE 2678, 15-27 - (4) Focht and Farkas (1995) Cell Vision, 2 , 450-454 - (4) Bailey et al. (1993) Nature $\underline{366}, 44-48$ - (5) Farkas, D.L. et al. (1994) Proc. SPIE 2386, 138-149 - (6) Wachman et al. (1996) Applied Optics, in press - (7) Farkas et al. (1996) Proc. SPIE 2678, 200-209 - (8) Ballou et al. (1995) Cancer Immun. Immunother. 41, 251-263.

3 FULLY AUTOMATION OF AN IMAGE ANALYZER FOR DNA QUANTITATION OF ARCHIVAL TUMORS

P. Herlin (1), E. Masson, D. Bloyet (2), F. Duigou (1), B. Plancoulaine (3), J.P. Signolle (3), F. Angot (2), D. Deman, P. Belhomme (2) , J.B. Joret, T. Datry, A.M. Mandard (1)

(1) Dept. of Pathology, Centre Francois Baclesse, 14021 Caen Cedex, France - (2) URA CNRS 1526, GREYC-ISMRA, 14050 Caen Cedex, France - (3) IUT de Caen, 14032 Caen Cedex, France

(Pôle Traitement et Analyse d'Images de Basse Normandie)

Numerous retrospective studies have been done since the introduction of a method of preparing isolated nuclei for the DNA quantitation of archival tumors. Image analysis of deparaffined tumor samples, which allows nuclei labelling, has proved to provide a good alternative to flow cytometry. However, when interactively done, this technique is very time consuming and can give biased results (due to interactive field and cell choices) and is unable to give statistically significant results in an acceptable delay for clinical oncology. An analyser was developed and fully automated, focusing efforts on speed and accuracy of the measurements, full automation of field selection and cell sorting in order to collect many more events and to get a good histogram resolution. DNA ploidy data obtained from the different cell populations can be analyzed using MCycleAV software for $\mathrm{S}$ phase fraction evaluation and comparison with flowcytometry results. Such an automatic image cytometer can be routinely used to systematically control at least diploid DNA histogram profiles obtained by flowcytometry.

\section{HIGH SPEED CELL SORTING \\ Z. Mishal \\ Laboratoire de Cytométrie, CNRS-UPS 47, B.P. 8, \\ 94800 Villejuif, France}

Selection of viable sub population by flow cell sorting has become a standard technique in cell biology. The application in research field ranging from microbiology to hematology and immunology. For most of these applications several hours of sorting are necessary, as relatively a few number of cell is required. The isolation of rare cells requires longer sort times. For example, the sorting of pluripotent hematopoietic stem cells for in vivo transplantation in mice, which needs the analysis of many millions of cells may take 24 hours.

The application of this technique to human transplantation would require sort time of several days. In spite of the fact that other technique using magnetic beads, coupled with anti-CD34 monoclonal antibodies permits relatively rapid sorting of hematopoietic cells. The purity of these cells may not be sufficient. The new high speed cell sorters could sort the enriched CD34 cell fraction within few hours, for ordinary cell sorters it would take all day. When deciding on the type of cell sorting technique to use, the specific sort rate limiting parameters of the different available cell sorters should be identified and analyzed. Three stages in the cell sorting process can be described. The first stage is the measurement of the optical parameters of the particle which is analyzed by the laser beam. The second stage is the treatment of the signals emitted by the particle. The third stage is the final and most important limiting factor which is the sort decision.

OXYGEN EXCHANGE THROUGH THE HUMAN ENDOTHELIAL CELL MEMBRANE MONITORED BY THE FLUORESCENT PROBE, PYRENE DERIVATIVES: PRELIMINARY MEASUREMENTS BY FLUORESCENCE MICROSCOPE

D. Dumas, J.F Stoltz

Laboratoire d'Hématologie, EA 1728 Faculté de Médecine, BP 184 Brabois, 54505, Vandoeuvre-les-Nancy, France

The fluorescence intensity and lifetime of pyrenebutyric acid (PBA) decrease as the partial oxygen pressure increases according to: $F_{d} / F=1+K s v[02]$ and $t / t_{0}=1+K d[02]$ with $F_{0}, F, t_{0}$ and (respectively the fluorescence intensities and lifetime in the absence and in the presence of oxygen, Ksv and Kd the dynamic quenching constant. To validate the methodology with static fluorometry and time-related fluorometry, this study was conducted in a quartz circulation well that contained the endothelial cell suspension (ECV 304) after trypsin digestion. To transpose this method to fluorescence microscopy under undamaged conditions (no trypsin digestion), endothelial cells were grown on glass coverslips until confluent. Fluorescence emission was integrated for $0.1 \mathrm{sec}$ on the slow-scan cooling CCD camera and quenching constant was determined by the ratio of fluorescence intensities in the absence and presence of oxygen. P 26 Experiments showed a correlation between the PBA fluorescence quenching constant obtained with static fluorometry, fluorescence microscopy and by time-resolved fluorescence. Values of Ksv and Kd were nearly the same and remained constant, indicating process of PBA quenching by oxygen was purely dynamic. To conclude, this method using fluorescence quenching has all the characteristics to be transposed to fluorescence microscopy.

This work was partly supported by a grant of region de Lorraine 
5 INTERNET AND CYTOMETRY

C. Duperray

INSERM U291, Service Régional de Cytométrie en Flux, 34197

Montpellier Cedex 5, France

Internet history began in 1969 with ARPANET, a military program to allow communication during nuclear war. In 1970, American scientists were allowed to use this network. It became an international network in 1973 with a connection with UK and Norway. The Internet word appeared in 1982. At the end of 1995, forty millions of computers were connected.

There are multiple interests to use Internet in cytometry:

E-mail allows fast worlwide communications and file transfer to other cytometrists. Another way to use Email is the mailing list which allows debates on different subjects (for instance Purdue mailing list for flow cytometry). Electronic debates can also be done on Newsgroups but they do not work in the same way. Data analysis freeware or shareware for cytometry can be loaded on network using FTP (when you know Internet address), Archie (with the file name) or WWW. Many databases are accessible through Internet, some are free of charges like GENBANK, PIR others are not like MEDLINE. Lots of associations (AFC, ISAC...) or laboratories give information about congresses, techniques on their WWW servers.

The most important problem on Internet is to find good address with good information. Providers give you the opportunity to use their research tools, but will they stay free of charges?
CORICO STATISTICAL METHOD FOR DATA PATTERN DECODING, APPLIED TO THE STUDY OF NUCLEOLAR ORGANIZERS REGIONS IN 60 PITUITARY ADENOMAS C. Lesty*, J. Pléau-Varet, and M. Kujas Hematology*\& Histology lab., CHU Pitié, 75013 Paris-France

From the probability point of view, one say that the correlation coefficient $R$ between two variables $x$ and $y$, is the ratio of their covariance to their standard deviations. Notions of linearity, and of random deviations from linearity are implicit. From the geometry point of view, $\mathrm{R}$ is the cosine of the angle formed by the two standardized variables in the $\mathrm{N}$-dimensional space of the $\mathrm{N}$ observations. $\mathrm{R}$ define an angular distance. A null value of $\mathrm{R}$ means a $90^{\circ}$ angle, and is not synonymous with independence. Cyclic variables are an illustration. Each isolated $\mathrm{R}$ has no explanatory value: there are so many ways, for two variables not to be redundant with each other. As soon as a phenomenon depends on several variables, mathematical relations become inextricable; one graphic solution is required. Without any underlying assumption, Corico software made some 500000 total and partial correlations computations, to give a computer drawn diagram of the pattern of the interactions. The information is condensed without any lost, by the elimination of redundancy. The diagram distinctly reveals conjunctions of several phenomenons. The prognostic and mutual relations of cell kinetics markers(PCNA, Mib1, Mitoses, NORs) are analyzed through 26 clinical and biological variables obtained on 60 adenomas after surgical removal. Nine variables are linked to the recurrence.
7 NEIGHBORHOOD GRAPHS FOR THE QUANTIFICATION OF IMMUMOHISTOCHEMICAL LABELLING

F. Angot (1), A. Elmoataz (1), M. Revenu (1), P. Herlin (2)

(1) URA CNRS 1526, GREYC-ISMRA, 14050 Caen Cedex, France - (2) Dept. of Pathology, Centre François Baclesse, 14021 Caen Cedex, France

(Pôle Traitement et Analyse d'Images de Basse Normandie)

In tumor histopathology, image processing is a powerful tool for the quantification of immunohistochemical labelling of histological sections. It allows to appreciate the proportion of the proliferating cells of a tumor (through a nuclear staining; Ki67, PCNA, BrdU...) or the localization of hormonal receptors in the nuclei of breast cancer cells. For the moment, several problems give limits to the automation of the method, which is the first step toward a standardization of the measurements. Even if a satisfactory automatic segmentation of colored cell nuclei has been obtained with mathematical morphology tools, it is also necessary to restrict the analysis to clusters of epithelial tumoral cells, eliminating stromal and inflammatory compartment of the tumors. In order to fully automate this step, one has to combine intrinsic informations about nuclear structures (size, density,...) and neighborhood informations about cells (internuclear distances). The representation and handling of the histological images with the structure of neighborhood graphs is a suited solution to this problem. The localization of interesting parts of the tissue section were obtained by this way. In addition, this tool allows to analyze the topography of the nuclear labelling.
EPITHELIAL CELL NEST AUTOMATIC DELINEATION USING MATHEMATICAL MORPHOLOGY FOR QUANTITATIVE IMMUNOHISTOCHEMISTRY

S. Schüpp (1), A. Elmoataz (1), P. Herlin (2)

(1) GREYC URA CNRS 1526, 14050 Caen Cedex, France (2) Dept. of Pathology, Centre Francois-Baclesse, 14021 Caen Cedex, France

(Pôle Traitement et Analyse d'Images de Basse Normandie)

Automatic quantification of immunostained epithelial cancer cell nuclei on sections requires an automatic delineation of cancer cell nests, in order to rule out unwanted stromal and inflammatory nuclei compartment from the analysis. The most sophisticated commercially available image cytometers offer, up to now, interactive tool for this purpose; this solution penalizes time processing and prohibits automation. The use of Mathematical Morphology tools seems to be well adapted to this problem, as they are able to take into account features of the objects to extract (size, shape, connexity,...). The first results obtained using an original sequence of mathematical morphology operators are presented, as a very promising approach. 
9 IMAGE GALLERIES AND DNA PLOIDY MEASUREMENTS

P. Herlin (1), D. Deman (2), F. Angot (3), C. Boudry (4)

(1) Dept. of Pathology, Centre Francois Baclesse, 14021 Caen Cedex, France - (2) ENSI, 14050 Caen Cedex, France - (3) GREYC URA CNRS 1526, 14050 Caen Cedex, France - (4) LERMAT URA CNRS 1317, 14050 Caen Cedex, France

(Pôle Traitement et Analyse d'Images de Basse Normandie)

The introduction of image cytometers in clinical oncology asks for the development of fully automatic dedicated softwares. The "a posteriori" visualization of gallery of measured elements offers to the pathologist the comfort of a visual control of the automatically labelled cells. Several commercially available analysers already offer this functionnality. Nevertheless galleries of small images remain underemployed tools which can be used for various purposes: learning, screening, data processing, and image treatment. An illustration of their numerous uses will be given for DNA ploidy measurements by image analysis.
10 USE OF SNAKE MODEL FOR SEGMENTATION OF HISTOLOGICAL AND CYTOLOGICAL IMAGES

S. Schüpp (1), A. Elmoataz (1), P. Herlin (2)

(1) GREYC URA CNRS 1526, 14050 Caen Cedex, France (2) Dept. of Pathology, Centre Francois-Baclesse, 14021 Caen Cedex, France

(Pôle Traitement et Analyse d'Images de Basse Normandie)

Segmentation of objects to be measured is a very critical and difficult step in the analysis of histological images. The aim of this work is to illustrate performances obtained from a recently introduced method: the "snakes". Snake model is easy to implement as it is based on the solving of well-known partial differential equations. This method takes into account geometric informations of extracted objects. The obtained boundaries closely cling to the object outlines, with low sensitivity to the noise and contrast. This segmentation method is well suited to the delineation of isolated objects (cell nuclei and mitotic figures) and groups of objects (epithelial cancer cell nests). It can be easily extended for 3D-image analysis.
11 GLOBAL TREATMENTS BY MATHEMATICAL MORPHOLOGY TO ELIMINATE DEBRIS AND AGGREGATES FOR ICM-DNA PLOIDY QUANTITATION C. Boudry (1,2,3), M. Coster (1), P. Herlin (2), B. Sola (3), J.L. Chermant (1)

(1) LERMAT (URA CNRS 1317) - (2) Centre Francois Baclesse (Dept. of Pathology) - (3) University of Caen, Cycéron (URA CNRS 1829), Caen, France

(Pôle Traitement et Analyse d'Images de Basse-Normandie)

The preparation of samples for ICM-DNA ploidy quantitation generates undamaged nuclei to be measured as well as unwanted debris and aggregates. These debris and aggregates represent $60 \%$ of analysed elements and can be classified in four categories: small debris, sliced nuclei, damaged nuclei and aggregates. Small debris and aggregates introduce a great bias on DNA ploidy measurement and consequently must be automatically eliminated. Classically automatic sorting methods are parametric (multiparametric analysis, neural networks...). Mathematical morphology (MM) offers global treatments of images and object sorting without measuring parameters. Thus, we propose an automatic sorting method to eliminate aggregates and small debris from ICM-DNA ploidy quantitation. The results obtained illustrate the powerfulness and the efficiency of MM global treatement as sorting method.
12 COMPARISON OF PERFORMANCES OBTAINED BY SEVERAL METHODS OF DEBRIS EXTRACTION MCYCLEAV DNA HISTOGRAM MODELIZATION, AUTOMATIC IMAGE PROCESSING AND REFERENCE INTERACTIVE LABELLING

C. Boudry (1,2,3), P. Herlin (2), M. Coster (1), B. Sola (3), J.L. Chermant (1)

(1) LERMAT (URA CNRS 1317) - (2) Centre François Baclesse (Dept. of Pathology) - (3) University of Caen, Cycéron (URA CNRS 1829), Caen, France

(Pôle Traitement et Analyse d'Images de Basse-Normandie)

McycleAV software offers several possibilities for modelization and extraction of cell debris on DNA ploidy frequency histograms: sliced nuclei correction, clumping correction, exponential background correction. Up to now, the performances of these 3 methods were compared without reference. We propose to evaluate these 3 methods as well as 2 automatic image processing methods by reference to manual interactive sorting of cell debris. For the 6 methods, DNA ploidy abnormalities were evaluated after the elimination of debris, strictly in the same conditions thanks to McycleAV. Our results suggest that the utilization of the "sliced nuclei" option must be recommended for the S-phase fraction evaluation of deparaffined samples by flow cytometry and that automatic image labelling offers a reliable alternative tool to manual labelling for image cytometry. 
13 AUTOMATED INTERPRETATION OF ICM-DNA PLOIDY FREQUENCY HISTOGRAM

J.P. Signolle (1), O. Rougereau (1), B. Plancoulaine (1), P. Herlin (2), A. Osmont (1)

(1) Dept. of "Mesures Physiques", IUT de Caen, 14032 Caen Cedex, France - (2) Dept. of Pathology, Centre François Baclesse, 14021 Caen Cedex, France

(Pôle Traitement et Analyse d'Images de Basse Normandie)

Fully automated ICM-DNA measurement of deparaffined tumors can be obtained thanks to automatic microscopic field selection, automatic segmentation, IOD measurement and automatic labelling of cell nuclei. DNA frequency histograms got from a large collection of nuclei, after elimination of unwanted events (debris, stromal and inflammatory cell nuclei) must be automatically built and interpreted to provide standardized results. A program was developed in order to get automatic classification of values depending on the number of measured nuclei, automatic detection of peaks, automatic estimation of resting and proliferating fraction, as well as Auer typing.
14 "RECOB": A FAST PATTERN RECOGNITION OPERATOR SUITABLE FOR CYTOMETRY

B. Plancoulaine (1), J.P. Signolle (1), J. Chasle (2), P. Herlin (2), J.C. Baloche (1), A. Osmont (1)

(1) Département Mesures Physiques, IUT de Caen, 14032 Caen Cedex, France - (2) Dept. of Pathology, Centre Francois Baclesse, 14021 Caen Cedex, France

(Pôle Traitement et Analyse d'Images de Basse Normandie)

Classically image treatment addressed to a cell sorting involves several phases: image improvements, (smoothings....), segmentation of objects (interactive or automatic thresholding, contour or region segmentation...), measurement of parameters (size, texture, density...) and sorting (interactive or automatic cell sorting after training: multiparametric methods, neural networks, decision trees...). We propose a two step method which only relies on a learning of characteristic grey levels of stereotyped objects to be recognized. The efficiency of this method is illustrated by the automatic detection of normal spermatozoa as well as automatic labelling of reference cells for DNA ploidy measurement of solid tumors.
15 FACS-GAL: A FLOW CYTOMETRIC TECHNIQUE TO MONITOR THE TRANSFECTION EFFICIENCY WITH NON VIRAL VECTORS

V. Floch (1), E. Hardy (1), M.P. Audrézet (1), B. Mercier (1), J.F. Abgrall (2), C. Férec (1)

(1) Etablissement de Transfusion Sanguine de Bretagne Occidentale, B.P. 454, 29275 Brest Cedex, France - (2) Service d'Hématologie Clinique, CHU Morvan, 29200 Brest, France

The aim of our work is to study the ability to transfect with a novel family of synthetic vectors (phosphonolipids) both hematopoietic cell lines (K562, KG1), primary CD34+ cells, and epithelial cell lines (CFT1, Cos-7).

To carefully optimize our transfection conditions we have used a flow cytometric analysis (FACS-Gal), developed by Nolan. This technique is based on the measurement of the fluorescence of fluorescein produced by enzymatic cleavage of fluorescein-di-b-Dgalactopyranoside (FDG) in cells that express the reporter gene E. Coli lac $Z$ which encodes for b galactosidase.

This method is much more sensitive than staining with X Gal $(80$ to 100 folds). It permits the determination of the percentage of cells effectively transfected and the level of gene expression.

With this technique, we have been able to detect $30 \%$ to $50 \%$ of transduced cells in cell lines (KG1, K562, CFT1, Cos-7) and primary CD34+ cultured cells.

FACS Gal assay is a powerful and efficient technique to screen new vectors for gene transfection and could be used as a routine technique in the future in gene therapy protocols.
16 CLASSIFICATION OF CELL NUCLEI BY A NEURAI NETWORK ARCHITECTURE: APPLICATION TO DNA OUANTITATION OF SOLID TUMORS

H. Cardot, C. Boudry, P. Herlin, M. Revenu

Pôle Traitement et Analyse d'Images de Basse-Normandie, France

In order to remove unwanted data from DNA histogram, the classification of different cellular elements, such as normal cells, abnormals cells and debris, can be considered.

To that purpose, we propose an architecture composed of several neural networks. Each of them is specialized in the separation of one cell type from another one (for instance: epithelial / stromal or polymorphonuclei / debris). In our application, 11 cellular types must be classified and 55 neural networks are used. The final decision is taken by combining the results of these 55 neural networks.

This method appears to give better results than previously tested approaches on breast cancer. Especially debris, which are very difficult to classify due to their large variability, are now detected with a $95 \%$ rate. 
17 TOPOGRAPHICAL ANALYSIS OF APOPTOSIS DETECTED BY MULTIPARAMETRIC AUTOMATIC SCANNING

F. Wallet, C. Dussert

Laboratoire de cancérologie expérimentale, CJF INSERM 93-11, Bd P. Dramard, 13916 Marseille Cedex 20, France

We have developped a new method for in situ detection of apoptotic cells that preserves cell arrangement and allows topographical studies.

Apoptosis was provoked by hydroxytamoxifene. Fifteen densitometric and textural parameters were computed from Feulgen stained nuclei of a mammary epithelial cell line MCF-7, by a SAMBA 200 cell image processor. Factorial and decisional discriminant analysis using reference files of apoptosis and cell cycle phases, allowed the detection of apoptosis and reclassification of apoptotic and living cells in each cell cycle phase.

Topographical studies using minimal spanning tree graph allow us to determine the degree of order of apoptotic population and show that apoptosis begins at the periphery of the culture cell clusters by $S$ phase and then $G 2$ phase. G1 phase cells are the latest to enter in apoptosis.
18 MULTIPARAMETRIC IMAGE ANALYSIS AND TOPOGRAPHY OF MCF-7 CELLS UNDER ESTROGEN AND/OR ANTI-ESTROGEN TREATMENTS

J. Palmari (1), F. Wallet (2), Y. Berthois (2), P.M. Martin (2), C. Dussert (2)

(1) Département des Interactions Photons Matière, Faculté des Sciences de St-Jérôme, 13397 Marseille Cedex 20, France - (2) CJF INSERM 93-11, Faculté de Médecine Secteur Nord, 13916 Marseille Cedex 20, France

MCF-7 cells were submitted during a 6 days period to $10^{-9} \mathrm{M}$ estradiol (E2) or/and $10^{-7} \mathrm{M}$ hydroxytamoxifen (OH-TAM) treatments, 2 days after platting.

Discrimination of nuclear phenotypes of Feulgen-stained treated and untreated cells was investigated by multiparametric statistical image analysis. 14 parameters related to densitometry and texture of the chromatin allowed the discrimination. This analysis lead to the computation of a new parameter, the phase independent area (PIA), eliminating the variations of the nuclear size with the stage of the cellular cycle. PIA was used to emphasize the development of a subpopulation in the MCF-7 cell line under estradiol treatment. Moreover, the coordinates of the nuclei barycenters and the Euclidean distance were used to analyse the topography of the cells by means of a graph called the minimal spanning tree (MST). A time dependent progression from cluster repartitions to ordered distributions was observed for treated and untreated populations, but the behaviour of estradiol treated cells was different from the other ones.
19 A COMPARATIVE STUDY OF CELL COUNTING TECHNICS

C. Dussert (1), J. Palmari (2), C. Penel (1), Y. Berthois (1)

(1) CJF INSERM 93-11, Faculté de Médecine Secteur Nord, 13916 Marseille Cedex 20, France - (2) Département des Interactions Photons Matière, Faculté des Sciences de St-Jérôme, 13397 Marseille Cedex 20, France

Various widely used cell counting technics were compared: absolute technics in which cells are individualised (Malassez cell visual counting, Flow cell counter, Image segmentation and analysis), and relative ones (Global surface measurements by image processing, DNA content, Protein content). We used those methods on both an heterogeneous cluster forming cell line (MCF-7), and a well separated cell line (BT20). They were analysed in a wide cell density range and measured after 48 hours growth.

The comparison of the relative results of those methods as well as of the experimental conditions they imposed (minimal and maximal sample size, speed of the analysis) led to the conclusion that all of the technics are linear, although the Malassez cell and the cell counter often over- or under-estimate the results. Finally, only imaging technics gave good absolute measurement result, despite their lengthiness.
20 IMAGE ANALYSIS AND TELEPATHOLOGY: A PRELIMINARY STUDY

D. Schoëvaërt (1), J. Assailly (1), E. Martin (2), J.P. Rigaut (1) (1) AIPC Laboratoire d'Analyse d'Images en Pathologie Cellulaire, IUH, Hôpital Saint Louis, Paris, France - (2) Service Central d'Anatomie Pathologique, CHU Bicêtre, France

Measurements made on teletransmitted images can be used in telehistoprognosis and/or in the quantitative interrogation of banks of images. Morphometric and densitometric measures require precise calibration procedures and the definition of reference values. In addition, reductions in information content resulting from image compression inevitably affect the quality of the information. It is thus important to assess to what extent the quality of visual by acceptable transmitted images is sufficient to allow a valid and meaningful quantitation.

We will present results from a preliminary study undertaken to investigate the differences in estimates of parameters (e.g. form factor, ploïdy content, texture), before and after compression (JPEG). The measures are obtained on human hepatic cells (TRIIBUN Leica, SAMBA IPS Alcatel TITN). Studies such as this should lead to a better appreciation of the limits and constraints of quantitative telepathology and allow the definition of new quantitative tools adapted to the analysis of teletransmitted images. 
21 STRAWBERRYPLANT COMMUNICATION STRATEGY FOR CYTOMETRIC DATA

P. Weber, N. Paschoud

Fondation Radiobiologie 2000, 2 place Benjamin Constant, 1003 Lausanne, Suisse

Hôpital Cantonal Universitaire Vaudois, dépt. de Radio-Oncologie, 1011 Lausanne-Chuv, Suisse

Clinical laboratory data are usually processed by dedicated computers and results stored on hospital mainfraimes for further use. Data handling and correlative analysis of clinical data is usually impossible in an automatic process and tedious.

We devised a flexible Window-95® based environment for easy data handling automatic processing and storage. Moreover, the direct correlation with clinical data is possible using a versatile database, even in a remote-user mode, allowing the direct "on site" work for both clinical laboratory parties.

Work supported in part by The Swiss League against cancer, the Fondation San Salvatore.

22 IMMUNODETECTION BY ECL (ENHANCED CHEMILUMINESCENCE) OF RECOMBINANT ACID PHOSPHATE (APPA FROM E. COLI) IN MYXOCOCCUS XANTHUS BACTERIA

S. Barray

Laboratoire de Microbiologie, Faculté des Sciences, 76821 Mt St Aignan Cedex, France

The gene encoding a periplasmic $\mathrm{pH} 2.5$ acid phosphatase (appA from E.coli) was placed under the control of an inducible promoter and integrated into the chromosome of M.xanthus to study the mechanisms of protein secretion in this bacteria.

Western blotting after SDS/PAGE of total cell proteins was performed with both strains (E.coli and M.xanthus) and probed with an antiserum against AppA protein

ECL immunodetection system (allowing a higher sensitivity than standard immunodetection by peroxydase conjugate antibody) has shown that cell-bound AppA protein from recombinant M.xanthus strain was identical in size with the processed periplasmic protein from E.coli, supporting our claim that the cell-bound activity corresponds to a periplasmic localization of recombinant AppA protein in M.xanthus bacteria. 
Session $n^{\circ} 2$

\section{IMMUNOLOGIE}

\section{ET HÉMATOLOGIE FONDAMENTALES}

Présidents de séance : J. Dufer, F. Tron

Résumés 23 à 35

Présentations orales : résumés 23 à 27 
23 LYMPHOCYTE SUBSETS IN NORMAL AND HIV+ INDIVIDUALS: ANALYSIS BY FOUR COLOUR IMMUNOFLUORESCENCE AND FLOW CYTOMETRY ON WHOLE BLOOD

L. Boumsell, V. Schiavon, J.P. Farcet, A. Bensussan INSERM U448, Faculté de Médecine, 94010 Créteil, France

In order to precisely define human lymphocyte subsets, we used four color immunofluorescence analysis and flow cytometry. We report here the results of systematic studies performed on whole blood from 20 normal volunteers. This was performed using monoclonal antibodies recognizing 18 different $\mathrm{CD}$ molecules and analyzed here into 14 different 4-color immunofluorescence combinations. This showed that among $\mathrm{T}$ cells, the two major $\mathrm{CD} 3+\mathrm{CD} 8+$ and CD3+CD8- subsets differed greatly in the percentage of cells expressing CD26, CD27, CD28, CD38, CD45RA, CD45RO, CD57, S6F1, BY55, CD101 and their respective combination representing an array of subsets. Furthermore the minor NK subsets, i.e. CD2+CD3-CD8+, CD2CD3-CD8+, CD2+CD3-CD8-, CD2-CD3-CD8- also differed in percentages of cells expressing CD16, CD56, CD57, S6F1, BY55 and their combinations. Results of normal subjects will be compared with HIV+ individuals.
DOWN-REGULATION OF THE PERIPHERAL CB2 CANNABINOID RECEPTOR DURING B CELL DIFFERENTIATION

P. Carayon, D. Dussossoy, J. Marchand, S. Galiègue, O. Jbilo, A. Bord, G. Petitprêtre, P. Casellas

Laboratoire de Cytométrie, Sanofi Recherche, 34184 Montpellier Cedex 04, France

The quantitative distribution of the peripheral CB2 cannabinoid receptor was studied in human leukocyte subsets. Using anti-CB2receptor immunopurified polyclonal antibodies (Abs) and flow cytometry, we found that, in peripheral blood, CB2 receptor is mainly expressed in B and NK cells, the lowest level being found in T cell subsets. The preferential CB2 expression in B cells led us to study the modulation of this receptor during the different stages of differentiation from resting B lymphocytes to plasma cells. Dualcolor confocal microscopy performed on tonsillar tissues showed a clear $\mathrm{CB} 2$ receptor expression in mantle $\mathrm{IgD}+\mathrm{B}$ cells whereas some areas of germinal centers (GC) were weakly stained. These observations were confirmed when $\mathrm{CB} 2$ receptor expression was studied in B cell subsets both by a quantitative tricolor immunofluorescence flow cytometric analysis and by a quantitative PCR-based method carried out on highly purified B cell subsets. Both techniques confirmed a down-regulation of CB2 expression during $B$ cell differentiation when $B$ cells acquired the phenotype of centroblasts. Finally, CB2 receptor expression was restored at the terminal stages of differentiation in memory B cells and plasma cells. Taken together, these results suggest that $\mathrm{CB} 2$ receptor have biological relevance during $\mathrm{B}$ cell differentiation.
25 FLOW CYTOMETRIC ANALYSIS OF CELL SURFACE ANTIGEN MODULATION ON APOPTOTIC HUMAN T LYMPHOCYTES

J.P. Aubry, Y. Delneste, P. Jeannin, J.Y. Bonnefoy

Geneva Biomedical Research Institute, GlaxoWellcome, Plan les Ouates/Geneva, Switzerland

The aim of this paper is to identify by flow cytometry the T cell subsets which are affected during apoptosis. We have adapted a method based on the detection of differences in chromatin condensation with Hoechst 33342 in conjunction with PI staining (Belloc et al, Cytometry, 1994). We first applied this method to Jurkat $\mathrm{T}$ cells and four different populations were identified and sorted by flow cytometry: living, apoptotic, dead cells and debris. Subsequent to the sorting, labeling of DNA strand breaks confirmed the content of each population. We therefore applied this technique to studying the modulation of surface antigens when peripheral blood T lymphocytes become apoptotic. This was done in low concentrations of FCS in the presence of either PMA + ionomycin, con A or adenosine. The expression of various membrane proteins was evaluated on living and apoptotic cells: antigens expressed on T lymphocytes (CD3, 4, 8, 27, 28), adhesion molecules (CD11a, 11b, 11c, 58) and activation markers (CD40ligand, 25, 95). After 24 hours of activation, the proportion of cells expressing CD11c, 11b, 95, 25 and 58 was increased in the apoptotic compartment as compared to the living cells. The other markers studied were unaffected or slightly decreased on apoptotic cells.
26 CYTOQUANT $^{\text {TM }}$ Gp: A NEW CONCEPT IN PLATELET FUNCTIONAL EXPLORATION

I. Besson (1), L. Camoin-Jau (2), S. Miet (1), P. Poncelet (1), F. George (2), J.Sampol (2)

(1) BIOCYTEX, Marseille, France - (2) Laboratoire d'Hématologie, Hop. Conception, Marseille, France

The CYTOQUANT ${ }^{\mathrm{TM}}$ Gp (Diagnostica Stago, Asnieres, F) has been developed to assess platelet function using flow cytometry. The method allows to quantitate platelet surface glycoproteins GpIb, GpIIb/IIIa complex, GpIIIa and GMP140. The method uses immunofluorescence assay without any washing step. An internal calibrator is added to the assay allowing the transfer of arbitrary units of fluorescence (MFI) into absolute number of antigenic sites per cell. The test is performed on whole blood collected on sodium citrate or on PRP in the presence of an aggregation inhibitor (disintegrin). Quantitative phenotype is obtained on resting platelets and after ADP and arachidonic acid activation. In the proposed testing conditions, quantitation of GpIIb/IIIa complex, GpIIIa, GpIb and GMP140 on resting platelets is $10 \times 10^{3}$, $41 \times 10^{3}, 25 \times 10^{3}$ and $<500$, respectively. Activation leads to a decrease of GpIIIa and GpIb level and an increase of GMP140 expression whereas GpIIb/IIIa complex does not change significantly. The interlaboratory $\mathrm{CV}$ is less than $20 \%$. Thus, this method might be proposed as a standardization tool for platelet functional studies in thrombopathies, for platelet concentrates QC as well as in multicentric pharmacological studies. 
27 STUDY OF MULTIDRUG RESISTANCE MARKERS COEXPRESSION

J. Boutonnat, M. Mousseau, X. Ronot, D. Seigneurin

Laboratoire de Cytologie Quantitative, Institut Albert Bonniot, 38706 La Tronche, France

Cross resistance to several natural cytotoxic products is known as multidrug resistance and represents a major obstacle in myeloblastic acute leukemia (LAM). The main mecanism implied drug efflux from the interior of the malignant cell by PGP and MRP. A new protrein (LRP) is known to be associated with a pejorative outcome in LAM. We have developped an indirect labelling in flow cytometry to detect the coexpression of these proteins. The antibodies used were UIC2 for PGP, MRPm6 for MRP and LRP56 for LRP. These antibodies have different isotypes. We used Fab'2 coupled with FITC, PE or TC with isotype specificity to reveal the first antibodies. We mixed K562 cells (resistant to Adriblastine) only expressing PGP with GLC4 cells (resistant to Adriblastine) expressing MRP and LRP to have the three antigens in the sample assay. MRPm6 and LRP56 recognize intracellular epitopes. The mixture was fixed and permeabilized after PGP labelling. PGP and LRP were easily detected. MRP detection was more difficult because in the triple labelling the background was higher than in a single labelling. Despite the increased background in the triple labelling we are able to detect coexpression of PGP, MRP, LRP by flow cytometry. This method appears to be very useful to detect coexpression of markers in resistant leukemic cells. Such coexpression could modify the therapeutic approach with revertants known to be active only on PGP.

29 SWINE LYMPHOCYTE PROLIFERATIVE AND CYTOTOXIC ACTIVITIES MEASURED BY FLOW CYTOMETRY

L. Piriou, E. Albina

Unité de Virologie, Immunologie porcines, CNEVA, 22440 Ploufragan, France

Flow cytometry was used to quantify the proliferation of swine lymphocytes stimulated by phyto-hemagglutinine (PHA). Proliferating cells were characterized by their increased size (FSC) and DNA synthesis (FL3, as measured by the level of propidium iodide (PI) incorporated in permeabilized cells). Result was expressed as proliferation percentage: $\%$ of proliferating cells in PHA-stimulated culture minus $\%$ in non-stimulated culture. Variation of PHA concentration from 0 to $10 \mu \mathrm{g} / \mathrm{ml}$ resulted in a correlative increase of proliferation percentage. As expected, proliferation was impaired at higher PHA concentrations. Proliferation of swine lymphocytes was measurable after two days of PHA exposure.

Swine Natural Killer cytotoxic activity was also investigated by flow cytometry using pre-labelled-target cells (FL1) and enumerating killed cells stained with PI (FL3). FITC was first evaluated for labelling target cells. Discrimination between live or killed cells, target (T) and effector (E) cells was obtained. For an E/C ratio of 100 , up to $55 \%$ of target cells were killed. This activity decreased proportionally with lower $\mathrm{E} / \mathrm{T}$ ratio. However, reproducibility of the assay could be affected by the relative instability of cell labelling. Alternative protocols for target labelling are currently evaluated.
QUANTITATIVE PHENOTYPE OF HUMAN PLATELETS: NORMAL REFERENCE VALUES

I. Besson, P. Poncelet

Biocytex, 140 ch. Armée-d'Afrique, 13010 Marseille, France

The absolute number of surface glycoproteins (Gp) per platelet can be measured with a newly developed flow cytometric method. This simple no wash immunofluorescence assay is run directly on whole blood collected on sodium citrate. The presence of an internal calibrator allows to convert arbitrary units of fluorescence into absolute number of antigenic sites per cell. Here, we quantitate the expression of PECAM-1 (CD31), GpIV (CD36), GpIIb/IIIa (CD41a), GpIIIa (CD61), GPIb (CD42b), GpIX (CD42a), VNR (CD51), P-Selectin (CD62), Gp53 (CD63) on resting and ADP activated platelets in a series of healthy volunteers. On resting platelets, minimal expression of CD62, CD63 and VNR $(<300$ sites/plt) is observed. Similar densities are measured for GpIb and GpIX (30.000 sites/plt). Whereas CD41a MAbs recognize 50.000 $\mathrm{GpIIb} / \mathrm{III}$ a complex/plt, a density of 30.000 to $60.000 \mathrm{GpIIIa/plt}$ is measured with various CD61 MAbs. After ADP activation, these levels increase for CD62, CD63, GpIIIa, and decrease for GpIb and GpIX. GpIV and PECAM-1 show a lower expression level (20.000 sites/plt) and do not vary under stimulation. Using this new quantitative cytometric assay, different MAbs per CD have been compared and a reference quantitative phenotype of normal adult platelet established. This phenotype is usefull to study platelet $\mathrm{Gp}$ modifications in various physiological and pathological states.

EFFECTS OF ANTIINFLAMMATORY CYTOKINES ON HUMAN NEUTROPHIL OXIDATIVE BURST

H. Réglier, C. Elbim, M.A. Gougerot-Pocidalo

Laboratoire d'Immunologie-Hématologie, CHU X.Bichat, Paris, France

Human polymorphonuclear neutrophils (PMN) play a critical role in host defenses against invading microorganisms. In response to a variety of stimuli, e.g. pathogens PMN release reactive oxygen species which are essential for bacterial killing. However, in cases of excessive or misdirected responses, the oxygen derived species may be detrimental to the host. A fine regulation of PMN responses, in particular by cytokines is therefore necessary. We and others have previously reported that the priming effect of TNF GM-CSF and IL-8 is critical for triggering the PMN oxidative burst in response to formyl peptides (fMLP). However contradictory data concerning the effect of antiinflammatory cytokines on PMN oxidative burst have been published. This could be due to the fact that most studies have been performed on PMN isolated from their blood environment by various procedures which may differently modulate surface receptor expression and themselves alter cell responses. Therefore we used flow cytometry to study the effects of IL-10, IL-4, IL-13 and TGFb1 on PMN oxidative burst in whole blood. We found that none of the cytokines tested exerted direct or priming effect on $\mathrm{PMN} \mathrm{H}_{2} \mathrm{O}_{2}$ production. Moreover they did not modulate TNF priming of PMN oxidative burst in response to fMLP. Further studies are in progress to evaluate the fixation of these cytokines on PMN in whole blood by flow cytometry. 
31 QUANTITATIVE ANALYSIS OF LEUCOCYTE MEMBRANE ANTIGEN EXPRESSION: NORMAL ADULT VALUES

A. Bikoue (1), F. George (1), P. Poncelet (2), M. Mutin (1), G. Janossy (3), J. Sampol (1)

(1) Lab. Hématol., UFR Pharmacie, Marseille, France (2) Biocytex, Marseille, France - (3) Depart. Clin. Immunol., R.F.H., London, UK

The aim of this study is to define the normal ranges of expression of various differentiation antigens on the lymphoid, monocytic and polymorphonuclear blood populations in normal healthy individuals. The values expressed as antibody binding capacity (ABC) per cell are related to the density of antigenic sites expressed by these cells and have been measured by the quantitative immunofluorescence indirect (QIFI) assay. Results show: (1) The hierarchy of expression of the main leukocyte antigens (CD2, CD3, CD4, CD5, CD7, CD8, CD11a, CD11b, CD11c, CD13, CD14, CD16, CD18, CD19, CD20, CD21, CD22, CD24, CD33, CD35, CD36, CD 37, CD44, CD 45, CD46, CD54, CD55, CD58, $\mathrm{HLA} \mathrm{Cl} \mathrm{1).} \mathrm{(2)} \mathrm{The} \mathrm{values} \mathrm{for} \mathrm{occasional} \mathrm{antigens} \mathrm{that} \mathrm{are}$ expressed differently in adults and elderly or men and women. (3) Variations in $A B C$ values if different MAbs defining the same $C D$ are used. (4) The use of the QIFI test in 2-colour immunofluorescence for molecules expressed at different levels defining functionally different subsets. Therefore, using whole blood and well-characterised MAbs, we established values of antigen density in normal adult which can be regarded as control values for the various pathological conditions where $\mathrm{CD}$ antigen expression may be altered.

\section{FUNCTIONAL DETECTION AND \\ OF MODULATORS ON PGP AND MRP \\ J. Boutonnat, M. Mousseau, X. Ronot, D. Seigneurin \\ Laboratoire de Cytologie Quantitative, Institut Albert Bonniot, 38706 La Tronche, France}

Typical multidrug resistance is known to be associated to overexpression of MDR1 gene or MRP gene or both. We investigated the specificity and sensitivity of fluorescent probes (Rhodamine 123 (Rh123) and Daunorubicine (DNR)) in flow cytometry for detection of PGP and MRP and also compared the action of Cyclosporine A and Verapamil on MRP. We used the K562R cell line expressing PGP and the HL60R cell line expressing MRP. The cells were incubated one hour with the fluorescent probe with or without the modulators for accumulation detection. Efflux was tested as follows: one hour incubation with the fluorescent probe, washed twice and reincubated three hours without fluorescent probe in combination or not with modulators. If Rh123 is more efficient than DNR for the selection of PGP activity it might be surprising that we found Rh123 after one hour incubation to be higher in the HL60R than in the HL60S cell line. No efflux was detected after three hours. The DNR accumulation in HL60R was decreased and active efflux was shown. Cyclosporine A and Verapamil modulated PGP activity in K562R but were unable to inhibit MRP activity on HL60R cell line. The present study showed that Daunorubicine is more sensitive than Rh123 to detect MRP expression and that modulators as Cyclosporine A or Verapamil were not active on MRP. These findings promote the use of Rhodamine 123 and DNR to detect functionnal PGP and MRP.
33 DIFFERENTIAL EFFECT OF VERAPAMIL, QUININE AND S9788 ON THE NUCLEAR THP-DOXORUBICIN ACCUMULATION IN MULTIDRUG-RESISTANT CELLS

R. Belhoussine, H. Morjani, M. Manfait

Laboratoire de Spectroscopie Biomoléculaire, FR53, UFR de Pharmacie, 51096 Reims Cedex, France

Confocal laser microspectrofluorometry was used to investigate the restoration of nuclear THP-doxorubicin accumulation and sensitivity by verapamil, quinine and S9788 in a variant of the erythroleukemia K562 cell line and in two variants of the chinese hamster cell line LR73 selected for resistance to doxorubicin (LR73D) and transfected with the $m d r l$ gene (LR73R). All this cell lines present a multidrug resistance (MDR) phenotype. At a concentration of $1 \mu \mathrm{M}$ of THP-DOX, verapamil and S9788 were able to restore the nuclear accumulation of THP-DOX in resistant cells to the level of sensitive cells. On the other hand, this was not observed with quinine. We have measured the nuclear THP-DOX accumulation at the IC50 of THP-DOX in the presence or not of modulators. In K562R cells, verapamil, S9788 and quinine reduced the nuclear concentration of THP-DOX required for $50 \%$ growth inhibition. Only quinine reduced strongly this parameter to the level of sensitive cells, while the effect of verapamil and S9788 was limited. In LR73D and LR73R cells, verapamil and S9788 did not reduce the nuclear accumulation of THP-DOX at its IC50. However, quinine reduced strongly this parameter. Quinine does not interact with P-gp, we believe that it modifies the molecular environment of anthracyclines and/or its binding to a possible cytoplasmic target leading to different cell death.
4 EXPRESSION OF CD82 ON LEUKAEMIC CELLS

S. Leprêtre, F. Jouen-Beades, D. Fradelizi, H. Conjeaud, M.P. Callat, J.F. Lesesve, B. Lenormand, F. Tron

Laboratoire d'Hématologie et d'Immuno-Pathologie Expérimentale, CHU Rouen, INSERM U283, Hôpital Cochin Paris, France

The mononuclear cell surface protein IA4, recently classified a CD82, is a member of the transmembrane 4 superfamily. Its role has not been fully elucidated, but some studies indicate that CD82 is involved in T-lymphocyte activation and differentiation. However, CD82 is expressed on a large variety of cell lines like Bcells, T-cells, NK-cells, monocytes and granulocytes.

In this report, we studied the expression of CD82 on T and $\mathrm{B}$ leukaemic cells isolated from different patients, using fluorescence flow cytometric methods. Twenty four blood samples or bone marrow aspirates, from 8 T-ALL, 5 B-ALL, 1 indifferentiated-AL, 6 B-CLL, 2 T-CLL, 1 NK-lymphocytosis and 1 T-lymphoma, were analyzed. As defined by the GEIL, the positive threshold of the marker was $30 \%$ for B- and T-cells. Two samples were negative (1 T-ALL and 1 NK-lymphocytosis). All others were positive with a median of $75 \%$ (respectively $59 \%$ for T-leukaemic cells and $91 \%$ for B-leukaemic cells). The median of fluorescence intensity was 10 (respectively 6.4 for T-leukaemic cells and 13 for B-leukaemic cells).

So far CD82 was demonstrated to play a role in T-lymphocyte activation, this marker did not appear to be specific of T-leukaemic cells since it was expressed at a higher level and percentage in Bleukaemia cells. 
35 CONSTRUCTION OF ASTROCYTE LINES OVERPRODUCING THE TYPE 2 COMPLEMENT RECEPTOR

A. Menet (1,2), M. Fontaine (2), C. Buffet-Janvresse (1)

(1) Virology, CHU Charles Nicolle, 76000 Rouen, France -

(2) INSERM U 78, 76230 Boisguillaume, France

CR2 is the receptor of C3 fragments of complement. It is mainly found on the surface of B lymphocytes where it forms complexes with other surface molecules. These complexes have been implicated in B cell function. The complexes containing CR2, and their involvement in transduction pathways have been characterised. CR2 was recently identified on the surface of astrocytes, and its function in these cells is unknown. However, the amount of CR2 produced by astrocytes is small. CR2 cDNA was therefore inserted into a plasmid under the control of the SV40 promoter, and the plasmid used to transfect the astrocyte cell lines T98 and T93. Cells overproducing CR2 were selected by various methods: selection on geneticin, panning on petri dishes, with magnetic beads and FACS. Transfectants were visualised by immunofluorescence using anti-CR2 monoclonal antibodies: HB5, OKB7, and confirmed by ELISA using biotinylated HB5. The two transfected astrocyte lines could be used to detect surface markers involved in complexes on the astrocyte surface. This may allow new transduction pathways involving complement receptors to be identified. 


\section{CELLULE VIVANTE, VÉGÉTAUX ET MICRO-ORGANISMES \\ (première partie)}

Présidents de séance : C. Duperray, X. Ronot

Résumé 36

Présentation orale : résumé 36 
36 ASSESSMENT OF SUBSET SPECIFIC ACTIVATION RESPONSES IN MIXED IMMUNE CELL POPULATIONS K. Muirhead, D. Carpenter, B. Ohlsson-Wilhelm Zynaxis, Inc. Malvern, PA 19355 USA

Understanding the nature and sequence of interactions among $\mathrm{T}$ cells, B cells and antigen-presenting cells is crucial to development of effective vaccines for disease prevention (e.g. infectious agents) and treatment (e.g. cancer, allergy, auto-immunity). Selective expansion of certain cell types in response to stimulation is a key feature of immune responses but bulk assays such as ${ }^{3} \mathrm{H}-\mathrm{TdR}$ incorporation or MTT fixation do not allow assessment of subset specific responses. Stable membrane binding dyes are partitioned quantitatively between daughter cells during division (1), and division related decreases in fluorescence intensity of the red cell tracking dye, PKH26, have been used to monitor subset specific proliferative responses to mitogens (2). Such "dye dilution" assays can be combined with assessment of cytokine secretion, costimulatory ligand expression and/or apoptosis to provide a much more complete picture of cellular interactions in mixed immune cell populations, and are also expected to be useful in identification and isolation of responder or non-responder cell types for characterization at the molecular level. Examples of specific methodological issues and additional applications will be discussed.

(1) Horan et al., Methods in Cell Biology 33: 469-490 (1990). -

(2) Yamamura et al., Cell. Mol. Biol. 41: S121-144 (1995). 


\section{CELLULE VIVANTE,}

VÉGÉTAUX ET MICRO-ORGANISMES

(deuxième partie)

Présidents de séance : C. Buffet Janvresse, D. Schoëvaërt

Résumés 37 à 49

Présentations orales : résumés 37 à 40 
37 CHANGE IN MITOCHONDRIAL MEMBRANE POTENTIAL FOLLOWED BY RHODAMINE 123 IN INTACT HEPATOCYTES

B. Sibille, C. Filippi, C. Keriel, X. Ronot (1), X. Leverve

Laboratoire de Bioénergétique, UJF, 38041 Grenoble Cedex 9, France (1) EPHE, Institut Albert Bonniot, 38706 La Tronche Cedex, France

Mitochondrial uncouplers, such as 2,4 dinitrophenol (DNP), increase the cellular respiration by decreasing mitochondrial membrane potential $(\Delta C)$. However, this respiratory stimulation is transient when reducing equivalents are provided from the cytosol and sustained with NADH from the mitochondrial matrix (octanoate). Moreover we have observed that the strong decrease in the ATP/ADP ratio by DNP is restored to some extent by octanoate. We have used a cellular incorporation of rhodamine 123 (R123), monitored by flow cytometry, in order to follow $\Delta C$ in living hepatocytes. R123 is a positively charged dye, so its accumulation in matrix depends on the $\Delta \mathrm{C}$. Classical inhibitors or uncouplers are used to investigate the efficiency of this method. Myxothiazol $(3,6 \mu \mathrm{M})$, an inhibitor of the b-c1 complex of the respiratory chain decreases $\Delta C(62 \%)$, while oligomycin $(6 \mu \mathrm{g} / \mathrm{ml})$, an inhibitor of the F0F1-ATPase increases it (22\%). DNP induces a decrease of $\Delta \mathrm{C}(68 \%)$, which is affected apparently by octanoate addition, moreover respiration and the ATP synthesis are enhanced. This result is surprising but was also found with radioactive probes, the classical reference method. This cellular staining by $\mathrm{R} 123$ has been validated by corroborative results using the usual $\Delta \mathrm{C}$ method of determination. It provides a dynamic and fast tool to monitor the $\Delta \mathrm{C}$ evolution in living hepatocytes.

\section{LEUCOTOXIN BINDING DETERMINATION BY FLOW CYTOMETRY}

D. Colin, O. Meunier, L. Staali, S. Sire, G. Prévost, H. Monteil Institut de Bactériologie, 67000 Strasbourg, France

Numerous toxins which recognize cell membrane receptors are secreted by bacteria. In particular, S. aureus secrete a family of two components protein toxins which form pores through the membrane of leucocytes. The binding of these leucotoxins were first studied by the use of iodinated toxins. In order to avoid the use of radioactivity we have developed flow cytometric technics for binding kinetics determination suitable for all sensitive cells. For this purpose, we have inserted a cystein in the sequence of the toxins and fixed one fluorescein-5-maleimid on this cystein which does not modify the toxic activity. The specific fluorescence was determined by spectrofluorometry on the target cells themselves and transposed to the flow cytometer. The comparisons of the different experiments were achieved by calibrating the flow cytometer with fluorescent microspheres. Furthermore, the binding kinetics could be simultaneously obtained from several different target cells. This technic presents the advantage to utilize few cells, few toxin molecules and to work in conditions were the number of bound molecules doesn't modify the unbound concentration. Moreover, when both components are utilized, the toxic effect can be simultaneously followed.
38 MULTIPARAMETRIC INVESTIGATIONS FOR STUDYING TIME-EFFECT OF ADRIAMYCIN ON SEVERAL HUMAN LEUKEMIC LYMPHOBLASTS E. Rocchi, J. Vigo, P. Viallet, J.M. Salmon

Group of Quantitative Microfluorometry, Laboratory of Physical Chemistry, University of Perpignan, Perpignan, France

Rationale investigations of the cytotoxic processes of drugs on heterogenous cell populations point out the need to get informations on individual cells. Such informations, including both dose-effects and time-effects, can be obtained through a multiparametric approach involving multiwave length microfluorometry and numerical image analysis. For that purpose, cells can be simultaneously stained with Hoechst 33342 (nuclear staining), Rhodamine 123 (mitochondrial staining) and Nile Red (cell contour delineation). As a first step, that protocol was used to look for differences between a sensitive lymphoblastoid cell line (CEM-WT) and two related resistant ones (CEM-VLB and CEMVM1) which differ both by their resistance level and by the nature of the mechanism involved in the drug-resistance. Adriamycin was used to check both dose and time effects. Changes in the biological parameters accessible from Rh123 and Ho33342 labelling were found more informative than changes in morphometric parameters. They allow the monitoring of the time-dependent cellular modifications induced by the cytotoxic process. Moreover the different mechanisms involved in the cellular resistance can be differenciated.
40 IN SITU HYBRIDIZATION IN LIVING CELLS : DETECTION OF RNA MOLECULES

S. Paillasson, M. Robert-Nicoud, X. Ronot

UPR-ES EA 2021, INSERM U 309, Institut Albert-Bonniot, Université Joseph-Fourier, 38706 la Tronche Cedex, France Laboratoire de Neurobiologie du Développement, E.P.H.E., 34095 Montpellier Cedex 05, France

In situ hybridization is a widely used technique for the sequencespecific detection of nucleic acids in fixed cells. The aim of the present work is to design new in situ hybridization techniques for RNA detection in cells that are maintained alive. Due to its high expression level in cells, the 28S ribosomal RNA was retained as a target model. First a non perturbing permeabilization procedure has been developped for Hela cells using streptolysin $O$. This procedure was used to introduce fluorochrome labelled DNA probes specific for the $28 \mathrm{~S}$ ribosomal RNA. Two different kinds of probes were used: a 20-mer oligodeoxynucleotide and a $2.1 \mathrm{~Kb}$ plasmid. The results showed that: i) no significant cell death or growth perturbation was observed after permeabilization, ii) $28 \mathrm{~S}$ RNA specific probes provided bright nucleoli and low cytoplasmic signal, and iii) negative controls did not lead to any fluorescent staining.

These results indicate the feasibility of specific hybridization of labelled nucleic acid probes under living conditions. Such a technique will provide new tools to study dynamic processes such as RNA transport from transcription sites to translation sites in intact living cells by means of fluorescence microscopy. 
41 MITOCHONDRIAL BIOENERGETICS: POSSIBILITY OF A SEMI-QUANTITATIVE APPROACH BY FLOW CYTOMETRY

M. Goubern, M.F. Chapery, M. Andriamihaja, P.X. Petit CGM, CNRS, 91198 Gif-sur-Yvette, France

LNSA, INRA, EPHE, 78352 Jouy-en-Josas, France

The aim of this study is to show some relationships between two essential classical bioenergetics measurements and flow cytometric measurements (FCM) on isolated mitochondria, particles as small as $0.6 \mathrm{~mm}$.

Liver mitochondria exhibit linear osmotic behavior (water content vs inverse medium osmolarity). Mitochondrial volume can be followed by forward scatter (FS peak) in FCM as well as the spectrophotometric changes of inverse absorbance $(520 \mathrm{~nm})$ of a mitochondrial suspension. No changes of the FCM "structural" side scatter is observed.

Membrane potential is measured in liver or brown adipose tissue mitochondria and modulated either by rate of the respiratory chain, ATP synthesis or partial uncoupling. It is possible to highly correlate membrane potential of mitochondrial suspension measured with a selective TTP+ electrode and FCM fluorescence of RH123. Compared to DiOC6(3) or JC1, the sensitive potential dye RH123 is the most appropriate marker for mitochondria FCM in spite of its known but limited side effects. Possibility of measuring mitochondrial function or alteration by FCM constitutes an important feature for studying mitochondrial related pathological cellular events including programmed cell death.

\section{CHROMATIN ORGANIZATION AND CELL MIGRATION DURING IN VITRO WOUND HEALING}

A. Doisy, F. Germain, P. Tracqui, M. Robert-Nicoud, X. Ronot UPR-ES EA 2021, INSERM U 309, TIMC-UMR CNRS 5525 \& EPHE, Institut Albert-Bonniot, 38706 La Tronche, France

The chromatin organization of eucaryotic cells changes as a function of cell status during processes such as proliferation, differentiation and migration. Cell migration plays a crucial role in several physiological or pathological processes such as embryogenesis, tumour invasion and wound healing. Thus, it appears of major interest to investigate chromatin dynamics in combination with cellular migration. In this context, we have used an optimized, non perturbant, DNA specific method using the fluorescent vital bisbenzimidazole probe Hoechst 33342 which was developped on living L929 and Hela cells. Cell migration was assessed on a mechanically wounded monolyer. Computer-assisted image analysis was used to follow migratory activity and chromatin organization during in vitro wound healing. Cells and nuclei movements were analyzed using optical flow technique, which consists in the calculation of the velocity field of cells and nuclei movements in the frame. We can conclude that: i) Hoechst 33342 does not perturb in vitro wound healing, and ii) this system allows the correlation of cell migration and position in the cell cycle. It makes it possible to study chromatin dynamics using a quantitative analysis of DNA reorganization and correlate it with migration caracteristics. This present model would be of interest for investigating cell-extracellular matrix interactions by using different substrata and migratory response to chemotactic factors.
42 INTERACTIONS BETWEEN SAMPLE AND INTERNAL STANDARD IN GENOME SIZE ESTIMATION IN PLANTS M. Noirot, P. Barre, C. Duperray, J. Louarn, S. Hamon LRGAPT, ORSTOM, Montpellier, France

The use of an internal standard led to a bias in the estimation of genome size by flow cytometry in plants. Bias depended on species in mixture and varied between 0 to $30 \%$. Some intraspecific variation that was emphasized using internal standard vanished when standard was external.

Various experiments (heating treatments, dilutions) suggests that bias should be due to variation of chromatine condensation in nuclei leading to changes in fluorochrome accessibility to DNA.

FLOW CYTOMETRIC ANALYSIS OF CARBOHYDRATES INTERACTIONS UPON THE BINDING OF FIBRINOGEN FIBRONECTIN AND LAMININ TO THE CONIDIA OF ASPERGILLUS FUMIGATUS

M. Sanchez (2), J.Ph. Bouchara (2), G. Renier (1), F. Carrere (1), A. Chevailler (1), D. Chabasse (2)

Laboratoires d'Immunologie (1) et de Parasitologie (2), CHU, 49033 Angers Cedex 01, France

During the last few years, we have investigated the binding of fibrinogen, fibronectin and laminin to Aspergillus fumigatus conidia. Inhibition experiments have shown that this binding was specific and suggested that the ligands may share a common receptor.

Aliquotes of a conidial suspension were incubated for 30 minutes at $37^{\circ} \mathrm{C}$ with purified FITC-labelled fibrinogen, laminin, or fibronectin in the presence of $200 \mathrm{mM}$ or $20 \mathrm{mM}$ solution of various sugar residues (selected among the components of fibrinogen and laminin), or of mucin or asialo-mucin. After washing they were resuspended in $500 \mu \mathrm{l}$ of $1 \%$ formaldehyde in PBS and analyzed by flow cytometry.

Among the various sugars tested, only N-acetyl-Neuraminic acid and sialyl-lactose gave an inhibition similar to that of the native protein. Mucin and asialo-mucin also were potent inhibitors and interestingly, mucin gave stronger inhibition than asialo-mucin. These results suggest that Aspergillus conidia may express lectin type receptors binding the terminal sialyl-lactosamin residues found on oligosaccharide chains of fibrinogen, fibronectin and laminin glycoproteins. 
FACS ANALYSIS OF INTEGRIN PROFILE EXPRESSED BY AIRWAY EPITHELIAL CELLS

P. Roger (1), J. Cohen (2), E. Puchelle (1), S. de Bentzmann (1) (1) INSERM U314 and (2) Laboratory of Immunology, CHR Maison Blanche, REIMS, France

The cell migration which occurs during respiratory epithelial wound repair after injury is dependent on the modifications of the cell-matrix interactions, in which integrins are involved. The active role of the a5b1 integrin receptor in the repair of airway epithelium has been previously described We analyzed the expression of $b 1$, a3, a5 integrin subunits and a5b1 integrins by airway epithelial cells. Cells were obtained from human nasal polyps and grown up to confluency and in sparse islets mimicking intact and repairing respiratory epithelia, respectively. Cells were detached, pelleted and incubated with Mabs against $\mathrm{b} 1, \mathrm{a} 3, \mathrm{a} 5$ and a5b1 integrin at $4^{\circ} \mathrm{C}$ to favour membrane labelling. Bound Mabs were revealed by incubation with fluorescein (FITC)-conjugated secondary antibody at $4{ }^{\circ} \mathrm{C}$. Cells were fixed in ethanol $70 \%$, treated with RNAse A and further stained with propidium iodide for $10 \mathrm{~min}$. Stained cells were analyzed on a Becton Dickinson FACScan over 20,000 events. FITC-surface integrin fluorescence was measured on propidium iodide intense peak population which contained intact cells. Repairing and confluent airway epithelial cells express b1, a 5, a3 integrin subunits and a 5b1 integrins. More intense labelling was observed for repairing cells compared to confluent cells, suggesting that $\mathrm{a} 3, \mathrm{a} 5$ and $\mathrm{b} 1$ integrins are overexpressed at the surface of repairing epithelial cells during respiratory wound repair. These results showed that airway epithelial cells engaged in the repair process are able to upregulate their integrins to favour their spreading and migration and their contact with the extracellular matrix.

77 USE OF A FLUORESCENT REDOX PROBE AND FLOW CYTOMETRY FOR THE VISUALISATION OF DESHYDROGENASES ACTIVITY IN BACTERIA SUBMITED TO TOXICS

M. Vergne, P. Leprat, C. Jayat-Vignoles, R. Julien

Institut de biotechnologie, Faculté des Sciences,

123 avenue Albert Thomas, Limoges, France

The biological sensors used in toxicity tests of environmental pollutants must respond to several criteria such as sensitivity, reproductibility, ability to supply a reliable statistical analysis and provide effects on a dose-dependent manner. Flow cytometry (FCM), which allows multi-parametrical analysis and offers the possibility to vary the biological sensors, has been considered as an appropriate technique for toxic effect assessment. Escherichia coli and different toxic compounds (phenol, nitrates, heavy metals) have been chosen to adjust FCM methodologies and to validate them concurrently with techniques commonly used for investigation of environmental pollutant toxicity : growth inhibition tests and tests using the bacterial bioluminescence (ATPassay and Microtox test).

Deshydrogenases activity measured by the use of 5-cyano-2,3ditolyl tetrazolium chloride is the most suitable parameter to supply reproductible IC50, the concentration of toxic that causes a $50 \%$ inhibition in measuring parameter. Moreover, the use of a fluorescent redox probe coupled with FCM has proved its efficiency in terms of rapidity, reproductibility and reliable statistical analysis.
DETERMINATION OF THE SIZE OF THE M E B R A NE OUS POR ES MA DE BY THE STAPHYLOCOCCAL LEUCOTOXINS

O. Meunier, G. Prevost, H. Monteil, D.A. Colin

Institut de Bactériologie, 67000 Strasbourg, France

Staphylococcus aureus secretes numerous toxins and among them a family of leucotoxins. These leucotoxins are constituted by the synergistic combination of a "classS" protein (LukS-PV, HlgA and $\mathrm{HlgC}$ ) and a "classF" protein (LukF-PV, and HlgB). All the 6 combinations create membranous aspecific pores.

Flow cytometry was used to determine the pore forming activity of the six leucotoxin couples and their particular human leucocyte specificity. Ethidium bromide was used as a fluorescent marker of pore forming capacities of the leucotoxins. The ethidium fluorescence was registered from FL3 as an indicator of leucotoxins activity on gated cells. The mean FSC value of the gated cells was used as an indicator of cell size. The pores formed by leucotoxins provoke an osmotic schock and a swelling of the sensitive cells. The swelling can be prevented by osmotic protectants which do not penetrate into the cells. The use of osmoprotectants of different sizes such as polyethylene glycol (PM $1000,1500,2000,3000,3350,4000$ ) allows us to evaluate the size of the pore formed by the leucotoxins whose radius was shown to be comprised between 1 and 1,2 $\mathrm{nm}$.

48 ANALYSIS OF CELL DEFORMATION USING DEFORMABLE ACTIVE MODELS: APPLICATION TO THE STUDY OF EFFECTS OF PHARMACOLOGICAL SUBSTANCES ON ENDOTHELIAL CELL IN CULTURE

E. Sohm (1), D. Schoëvaërt (1), M. Pouchelet (3), H. Lu (2)

(1) Lab. d'Analyse d'Image en Pathologie Cellulaire - (2) U 353 INSERM, Hôpital Saint Louis, Paris, France - (3) SC. Audiovisuel INSERM, Le Vésinet, France

We propose a method to quantify the deformation of living cells based on the analysis of image sequences, which provides good results in contour detection and motion tracking. Image sequences are acquired by high resolution microcinema at ten minutes interval and digitized on a computer equipped with a MATROX PIP 1024 card. After preprocessing of the first image of the sequence, a recursive Deriche filter is applied in order to extract reference points of the cell contour, these points are used to initialize the process of contour tracking on the following image. A spline function is used to modelize this contour. The reference points are attracted to the real edge of the cell using principles of physics in order to obtain reference points on the new contour. The process is iterated for all images in the sequence. On each iteration we compute difference of surface between two adjacent modelized cell contours. We normalize the sum of differences all over the iterations by the number of the iterations. This method has been applied to human umbilical endothelial cell during migration stimulated by bFGF. First results indicate that ATF-HSA inhibits the cell migration. 
49 IN VITRO ANALYSIS OF THE MOTILITY OF INDIVIDUAL OSTEOCLASTS

E. Antoine (1), D. Brugère (1), C. Bardelay (1), G. Colliot (2)

(1) Roussel UCLAF - (2) Biocom S.A., 91940 Les Ulis, France

The osteoclast is unique in its ability to resorb bone and excessive osteoclastic activity plays an important role in osteoporosis. Cell shape and motility reflect osteoclast resorbing activity. We therefore developed a quantitative method to study these parameters in individual osteoclasts.

In vitro osteoclast cell shape and motility can be analysed using both light microscopy combined with digitisation and computer analysis of stored images (1). The use of TrakCell software (Biocom) makes it possible to record sequences of digitised osteoclast images in several fields in parallel. These sequences can be visualized using a digital video recorder (MagNum).

Osteoclast motility determined both by, cytoplasmic movement and change in position of the centre of gravity and osteoclast cell area have been measured before and after the addition of the test compounds and correlations have been observed with the activities of several growth factors.

(1) O.A. Adebanjo et al., J. of Endocrinology, 1994, 143, 375-381.
UNSUPERVISED TEXTURED IMAGES SEGMENTATION USING MARKOVIAN ANALYSIS.

APPLICATION TO THE STUDY OF LIVING CELLS.

F. Depermentier*, A. Hebbache*, D. Schoaëvaërt**

* Faculté des Sciences, Reims, France

** Laboratoire d'Analyse d'Image en Pathologie Cellulaire,

Hopital Saint-Louis, Paris, France.

Vital markers utilization for living cells analysis risks to alterate their morphology. Then, the segmentation of their images, acquired by high resolution microcinema and digitalized on a computer equiped with a Matrox PIP 1024 card, is not reliable. Now, instead of using markers, if we use a Nomarsky or Hauffmann filter, we get contrasted but strongly textured images, which are difficult to segment with classical methods.

So, we propose a method which use textural features and Markovian fields to realize this segmentation.

After preprocessing (contrast reinforcement, Deriche smoothing filter, histogram equalization), the image is considered as the realization of a Markovian field: The value of each pixel depends only on his neighbourhood (5x5 windows are used). For each window, several textural features are computed from gray level spatial co-occurrence matrices. Then, we calculate an energy from those features and we use the simulated annealing process to segment the image.

This method has been applled with succes to several cell images (from H. Lu, U 353 INSERM, Hôpital Saint-Louis, Paris). 
Session $n^{\circ} 5$

\section{STANDARDISATION,}

\section{ASSURANCE DE QUALITÉ}

Présidents de séance : M. Bergeron, J.-L. D’Hautcourt

Résumés 50 à 59

Présentations orales : résumés 50 et 51 
50 EVOLUTION OF THE CANADIAN QUALITY ASSURANCE PROGRAM (QAP) FOR CD4 T-CELL ENUMERATION. M. Bergeron, F. Mandy, *R. L. Somerjai and 43 Canadian participating laboratories.

National HIV/AIDS Laboratory for Analytical Cytology, Health Canada, Ottawa, Canada; * Institute for Biodiagnostics, National Research Council, Winnipeg, Canada

A Quality Assurance Programme for CD4 T-cell enumeration was initiated by Health Canada in 1989. The aim of the QAP is to improve and maintain the performance of the laboratories that provide immunophenotyping services for the Canadian Clinical Trial Network for HIV/AIDS therapies (CTN).

The programme, in operation for 6 years, comprises of two components. The first one includes regular sendout of HIV positive and negative specimens. The second one deals with effective communication among members of CTN and provides workshop to transfer pertinent biotechnology to all participants.

The most profound impact of this QAP has been the inverse relationship between the frequency of participation and the size of the aggregate standard deviation for the participating group.
51 SECOND PHASE OF THE AFC QUALITY CONTROL PROGRAM ON FLOW CYTOMETRIC DNA CONTENT AND S-PHASE FRACTION

J.L.D'hautcourt, F. Spyratos, A. Chassevent, P. Vago

On behalf of the Association Française de Cytométrie (AFC), BP 5, F34830 Jacou, France

The first phase of the AFC quality control program emphasised the importance of training in the correct use of DNA software: because $31 \%$ of the results had to be rejected in the first trial. These second phase consisted of sending 20 list mode files derived from analysis of various human tumour samples, with a standardised analytical protocol to 47 European laboratories. By using three software: CellFit (401), MultiCycle (440) and ModFit (299), 1140 responses were obtained. Twenty percent of responses were excluded for the following four reasons: A) 11 contained no data , B) 86 DNA ploidy classification errors, C) 109 without cycle results, D) 20 incomplete cell-cycle calculation or errors exceeding $2 \%$ in the sum of the 3 phases. From this preliminary study we concluded that errors due to numerical data processing by the operator were slightly minimised in this second phase; $1 \%, 7.5 \%, 9.5 \%$, and $2 \%$ versus, respectively $4.8 \%, 8.4 \%, 8.9 \%$, and $2.5 \%$ for the first phase. The results of this last trial will be discussed.
52 FLOW CYTOMETRY ANALYSIS OF CD2, CD4, CD8 AND CD 20 WHOLE BLOOD ABSOLUTE COUNTS SIMULTANEOUSLY DETERMINED BY USING COULTER "FLOW-COUNT" AND BECTON DICKINSON "TRUE COUNT" ASSOCIATED TO THEIR RESPECTIVE QUALITY ASSURANCE CONTROLS

P.J.M. Philip

Unité d'Exploration Fonctionnelle Cellulaire et Tissulaire (UEFCT) Laboratoire Central d'Hématologie, CHU, Nice, France

Coulter "Flow-Count" (FC) as well as Becton Dickinson "TrueCount" (TC) are based on fluorescent microsphere reagents used for direct determination of absolute counts in flow cytometry. The aim of this study was: $1 /$ to analyze on the same flow cytometer (XL-MCL Coulter, Hialeah, FL, USA) the whole blood CD2, CD4, CD8 and CD20 antigenic absolute values by using simultaneously these both absolute count systems: $2 /$ to evaluate all the procedures recommended by each manufacturer for controlled their absolute values as well as the the assayed concentration of their fluorospheres. Flow cytometric referenced CD absolute counts were prepared 5 times for each of the 3 whole blood investigated MoAbs incubated, red cell lysis, then each samples analyzed 5 times on the cytometer (MCL-XL, Coulter) at different times. In a second analysis, 30 whole blood samples were prepared from an identical patient, MoAbs incubated, red cell lysis, then both absolute counts determined in order to control and to compare the reproductibility and the precision of the recommended procedures for these both absolute count systems. Our results provide the comparative analysis obtained between these both systems and the validity of the quality assurance controls proposed when flow cytometry absolute values observed were not correct.
QUALITY CONTROL IN IMMUNOCYTOMETRY: A MULTICENTRIC STUDY

A. Mercadier (1), S. Marion (2), C. Brunet (3), C. Malcus (4), M. Colin (5), C. Elbim (6)

(1) Bobigny, France - (2) Villejuif, France - (3) Marseille, France (4) Lyon, France - (5) St Martin, France - (6) Paris, France

The need for quality assurance of cytometry data has been emphasized this last decade and several quality assurance testing programs have been described. We present here a multicentric study which tested a stabilized whole blood preparation Ortho Absolute Control* (OAC) which may be treated exactly like routine analysis as a full process control.

Material: 6 centers used OAC lots during the last year. 2 groups are individualized: Group 1: 4 centers equiped with Ortho Cytoron Absolute and Ortho trio $(\mathrm{CD} 4,8,3)$ sample preparations. Group 2: 4 centers of group1 and 2 centers equiped with Coulter XL, Becton Dickinson FACScan and Ortho or Immunotech trio sample preparations.

Method: All results are collected as percent and absolute count values for group1 and only $\%$ values for group 2.

Results: 1 lot tested in all centers of group 1. CV of CD4, 8, 3 lymphocytes subsets populations values are as follow:

$\begin{array}{llll} & \text { CD4 (FITC) } & \text { CD8 (PE) } & \text { CD3(Cy5PE) } \\ \text { Percent } & <7 \% & <8 \% & <4 \% \\ \text { Absolute Count } & <9 \% & <10 \% & <7 \%\end{array}$

Comparative results of percent $\mathrm{CV}$ are observed when the lot is used in the all centers of groupe 2 .

This study demonstrates low variance for percent positive cells, and suggests OAC as a useful quality control. 
54 NORMAL ABSOLUTE VALUES OF LYMPHOCYTE SUBSETS FROM HEALTHY DONORS DETERMINED BY ORTHO TRIO PANEL

C. Brunet (1), C. Gastal (2), F. George (1), J. Sampol (1)

(1) Laboratoire d'hématologie CHU Conception, Marseille, France

- (2) Ortho-Clinical Diagnostics France

Lymphocyte immunophenotyping has now an important role in immune monitoring in AIDS and other immunological disorders as well as in the follow-up of patients undergoing immunotherapy and anti-viral therapy. Flow cytometry has became the reference method for lymphocyte immunophenotyping, which has progressed so rapidly in recent years that the need for quality control and standardization is self-evident. The aim of this study was to define normal values of $\mathrm{T}(\mathrm{CD} 3+, \mathrm{CD} 4+, \mathrm{CD} 8+), \mathrm{B}$ (CD19+) and NK (CD16+ CD3-) subpopulations using a new concept for absolute determinations based on Immunocount II algorithms (Ortho Diagnostic Systems Software) in conjonction with a flow cytometer that directly measures absolute counts (Cytoron Absolute). This study was conducted on whole EDTA anticoagulated blood. Samples were stained with TRIO panel (CD4FITC/CD8PE/CD3Cy5PE and CD16FITC/CD19PE/ $\mathrm{CD} 3 \mathrm{Cy} 5 \mathrm{PE}$ ) and the procedure contains no centrifugation steps. Normal values (cells per microliters) obtained from a preliminary series of 60 healthy donors are reported in following table: CD3+: 14857374

$\mathrm{CD} 3+\mathrm{CD} 4+: 8707246$

CD19+: 2507100

CD3+CD8+: 4937182

CD16+CD3-: $<500$
STANDARDIZATION OF ACUTE LEUKEMIA FLOW CYTOMETRY ANALYSIS THROUGH QUANTIFICATION OF CD10 AND CD34: THE GEIL'S MULTICENTRIC EXPERIENCE

P.J.M. Philip, F. Baudouin, C. Sartiaux, M.C. Bene and the Groupe d'Etude Immunologique des Leucémies (GEIL)

Secrétariat: Lab. d'Immunologie, Fac. Med. Nancy, France

The GEIL is a federation of 41 laboratories (France and Belgium) interested in the immunophenotype of human leukemias. This group led several multicenter workshops assessing the validity and reproductibility of cell labelling with various types of analyzers. The development of fluorescent beads allowing antigenic quantification led the group to set up a new workshop. Aliquotes of 3 fluorescent beads "Immunobrite" and a fluorescent standard bead "standardbrite" (Coulter) were distributed to all participants simultaneously to the CD10 and CD34 monoclonal antibodies for a multicentric study of more than 200 Acute Leukemias. Using abacus and calculations taking into account the specificity of each cytometer parameters, a calibration curve was thus established for each laboratory and all histograms centralized. Quantification of CD10 and CD34 expression was translated into numbers of molecular equivalent standard of fluorescein-like (MESFL). Our results showed that the CV of MESFL determinations for the standard bead was less than $7 \%$ within the group for any quantimetric study. Moreover, CD10 and CD34 quantimetric analysis of AL demonstrated that various epitopic levels could be characterized among the AL for the same MoAbs. Thus, quantimetry could be used as a new tool for dissecting leucocytic cell disorders and identify new prognostic factors.

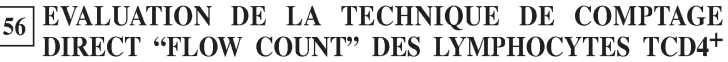
CIRCULANTS

P. Drevot, I. Pagès, JP Vendrell

Laboratoire d'Immunologie, Hôpital Lapeyronie, CHU Montpellier

The determination of CD4 and CD8 T-cell subpopulations constitute an important biological parameter for therapeutic follow-up of HIV-1 infected patients. We have conducted a study to quantify the CD4 and CD8 lymphocytes using standard fluorescent beads for the absolute count (Flow Count System provided from Coulter). We have compared these results with those obtained with standard CD4 and CD8 method used routinely in our laboratory. Briefly, the lymphocyte population was characterized by three-color immunofluorescence with CD3-ECD, CD4-FITC and CD8-PE MAbs and number of CD4 per microliter of blood was determined as the product of the absolute lymphocyte counts and percentages of the cell subset.

The lymphocytes of 142 samples of blood from infected patients were determined using these two methods, staining and counting samples were performed within four hours of venepuncture. For 53 samples of blood, CD4 counts were subsequently performed at 16 and 24 hours. Statistical difference between the two assays was assessed by the Wilcoxon signed rank test and association between variables was measured by non parametric Spearman's correlation.

A statistical difference was observed between the two methods $(p=0,001)$ but significant correlation was found $(0.977)$. Moreover, results of two determinations realized at different times (4 and 24 hours) by direct count assay did not show any statistical difference. The results demonstrate that the FLOW COUNT assay system can be used to count the T-cell subpopulations in the follow-up of the HIV-1 infected patients. The time of storage of blood samples during 24 hours did not modify significantly the count of CD4 lymphocytes.
COULD FLOW CYTOMETERS BE USED FOR QUANTIFICATION OF FLUORESCENCE ? J.P. Delville (1), C. Alonso Vega (1), V. Deneys (2), J.L. D'hautcourt (3), H. De Geyter (4), P. Capel1, O. Pradier (1) (1) ULB-Hôpital Erasme, 1180 Bruxelles; Belgique - (2) UCLHôpital St Luc, 1200 Bruxelles; Belgique - (3) CHR-Hôpital de Warquignies, 7300 Boussu; Belgique - (4) NALIS SA, 5000 Namur, Belgique

Quantification of fluorescence intensity of cell markers requires cytometer stability in time. In order to estimate the reliability of our results, a calibration was performed with our flow cytometers using calibrated fluorescent beads (Quantum 1000®, FCSC) run each week. Performance Parameters calculated by the Quickcal ${ }^{\circledR}$ software (FCSC), allowed us to compare the performances of our instruments during five months. The MESF of the beads were stable within the time (CV for MFI values of FACScalibur: $<1.8 \%$ (FITC), $<6.3 \%$ (PE) and FACScan; $<2 \%$ (FITC) and $<2.4 \%$ (PE)) Moreover, the $\mathrm{CV}$ for MESF values, between 5 instruments in 4 centers (CytoronAbsolute ${ }^{\circledR}$, Epics XL $®$, FACScan and FACScalibur ${ }^{\circledR}$ ) was $<3 \%$ for FITC and $<5 \%$ for PE with $\mathrm{R}^{2}>0.99$ The mean average residual percent, the detection threshold (in MESF), the mean coefficient of response was respectively $3 \%$, $<650,62.5$ for FITC and 5\%, <544, 65.6 for PE. The number of $\log$ decades range from 3.9 to 4.3 (FITC) and 3.7 to 4 (PE) and the zero channel value was 225 (FITC) and 154 (PE). In conclusion cytometers are stable within the time and can be used for fluorescence quantification and results can be compared between laboratories using the same calibration material. 
58 INTER-LABORATORY STUDY OF COULTER INDEX DNA CONTROLS

A. Chassevent, J.L. D'hautcourt, M. Pagniez, P. Vago

On behalf of the Association Française de Cytométrie (AFC), BP 5 , 34830 Jacou, France

Standardization of flow cytometry DNA analysis led three laboratories to test 2 commercialized cell suspensions. These fixed cells consist of: NC) Normal Control, non-cycling diploid cells and AC) Abnormal Control, mixture of diploid and cycling aneuploid cells. By using different DNA staining methods and various DNA softwares, 28 analyses were performed for each group of cell suspensions.

It is worth noting that:

1) before staining, the preliminary protocol must be improved;

2) $\%$ debris was very low for $\mathrm{NC}$ and $\mathrm{AC}$;

3 ) the aneuploid CV seemed to be high, twice those of diploid one (mean percents were respectively 5.3 and 2.5 );

4) $\% \mathrm{~S}$ and $\% \mathrm{G} 2+\mathrm{M}$ depended on batches;

5) the binding of fluorescent dye to DNA was modified by cell fixation; therefore, $\mathrm{NC}$ cannot be used as diploid standard.

Taking these points into consideration, we conclude that COULTER DNA controls could be used for studying intra- and inter-laboratory reproducibility.
59 QC WINDOWS $®$ TO ESTABLISHING THE COMMON WINDOW OF ANALYSIS. IS IT AN IMPROVED SETTING PROCEDURE FOR FLOW CYTOMETRY?

J.L. D'hautcourt

C.H.R. Hôpital de Warquignies, 7300 Boussu, Belgique

Since a few years flow cytometry becomes very important tool in clinical laboratories. Standardisation procedures are required to ensure that correct results are obtained. Reference standards with matching spectral properties are now available (QC3 $3^{\mathrm{TM}}$ and Certified Blank ${ }^{\mathrm{TM}}$ microbeads; FCSC) allowing us to perform standardisation. Unlike procedure previously described, OC Windows ${ }^{\circledR}$ establishes the position of the fluorescence intensity Window of Analysis allowing data comparison independent of instrument make. The aim of this study was to compare the results obtained with this new method of optimisation and those proposed by B. Brando (Resolution Index) and by M. Loken (Unstained lymphocytes in first decade). QC Windows ${ }^{\circledR}$ beads, Quantum ${ }^{\mathrm{TM}}$ beads and human lymphocytes were run at different PMT voltage settings and QuickCalc software were used to evaluate the data. Regardless the fact that the setting obtained by these three methods are quite similar, the sentence "Instruments that have been adjusted to a common window of analysis produce histograms that are nearly identical" is not proved from either the theoretical aspect or the practical one. We can concluded that a standardised procedure to optimise flow cytometer setting is still needed. 
Session $n^{\circ} 4$

\title{
MICROSCOPIE CONFOCALE
}

\author{
ET 3D
}

Présidents de séance : M. Feuilloley, D. Ploton

Résumés 60 à 67

Présentations orales : résumés 60 à 63 
60 THREE-DIMENSIONNAL ORGANIZATION OF THE CELL STUDIED BY CONFOCAL MICROSCOPY D. Ploton

U 314 INSERM et IFR 53,CHR Maison-Blanche, 45 rue Cognacq-Jay, 51092 Reims- Cedex, Reims

Nowadays, cell- biologists forget too often that cells are volumic entities in which functions are confined within well-defined subvolumes limited or not with a membrane. The fact that cells are considered as flat objects is due to limitations of classical microscopes which frequently oblige to squash the cells or to physically cut them.

Hopefully, recent developments, both in microscopy and in computers were performed. In this field, the confocal microscope plays a crucial role by performing optical sections characterized with high resolution and contrast and produces a lot of data. However, to our opinion, these data are insufficiently used to understand the cellular organization.

Thus, during the last three years, our group used or developped various methods applied to the investigation of the volumic organization of cellular components (mainly nuclear domains and mitotic chromosomes). In this talk I will show that very efficient software are extremely helpful to rapidely create animated threedimensionnal reconstructions with a high resolution and that our view of the structural and functionnal organization of the cell is now completely changing.
61 3D CONFOCAL MICROSCOPY AND VOLUME RENDERING STUDY OF THE NUCLEOLUS . NUCLEOLIN COLOCALIZATION WITH UBF AND WITH DNA

C. Klein, L. Lucas, D. Ploton

INSERM U314, 45 rue C. Jay, 51092 Reims Cedex, France

The nucleolus is a nuclear domain in which active ribosomal genes are clustered, rRNA is synthetized and processed. It is thus considered as a good model in the study of the three-dimensional (3D) organization of gene expression.

The aim of this work was to investigate the 3D organization of nucleolar components containing nucleolin (Nin), a nucleolar protein associated with rRNA, in confocal microscopy.

Nin was first colocalized with Chromomycin A3 stained DNA secondly with UBF, an RNA polymerase I transcription factor associated with rDNA. In order to understand the complex volumic arrangement of labelled nucleolar domains it was necessary to analyse the data obtained by $3 \mathrm{D}$ reconstruction and $3 \mathrm{D}$ visualization (animated series).

During interphase Nin is localized in a ribbon like structure coiled in the nucleolus. UBF is present in small beads arranged in the nucleolus as a so called "nucleolar necklace" embeded in the Nin labelling. Nethertheless UBF and Nin are not colocalized. In addition we demonstrate in which way the 3D position of Nucleolar Organizing Regions during mitosis plays a role in the 3D organization of early interphase nucleoli.

This work demonstrate the usefullness of $3 \mathrm{D}$ visualization in the analysis of the 3D organization of the nucleolus.
62 PHENOLIC MATERIAL DISTRIBUTION IN CEREAL GRAIN AS PROBED BY MICROSPECTROFLUOROMETRY

A. Saadi, S. Charonov, M. Manfait

Laboratoire de Spectroscopie Biomoléculaire, FR53, UFR de Pharmacie, 51096 Reims Cedex, France

Microspectrofluorometry which is a proven technique to follow the behaviour of drugs in living cells, can be useful to study the spatial distribution of phenolic material in wheat kernel.

Cross-sections of wheat kernel were used, and fluorescence emission analysis was done from microvolumes of each of them. Spectral data were stored in the work-station and permitted a spectral fluorescence image to be established. Spectral fluorescence imaging allows to locate spectral parameter indicators of phenolic acids with a colour gradient onto the fluorescence image. To characterise each histological section, the analysis of images obtained showed that the exterior layers of grain were strongly auto-fluorescent, compared with the endosperm centre. A close study, more particularly on the aleurone walls, showed that significant differences occurred between the anticlinal walls and the inner and outer periclinal walls.

Results obtained on the surface of wheat cross-sections by the present technique correlate with data that have been found by other methods such as epi-illuminating.

To cartograph total phenolic material present in the grain, the whole spectral data obtained from the cross-section forming the grain are collected, and superimposed to reconstitute one 3D model of wheat kernel.
CHARACTERIZATION OF FLUORESCENT HUMAN PAPILLOMAVIRUS DNA IN IMAGE SEQUENCES OF HELA CELLS

E. Kahn (1), G. Lizard (2), F. Frouin (1), P. Roignot (3), Y. Chardonnet (4), D. Schmitt (4), R. Di Paola (1)

(1) INSERM U66, CHU Pitié Salpétrière, 75634 Paris, France -

(2) INSERM CJF93/10, Hôpital du Bocage, 21034 Dijon, France -

(3) Centre de Pathologie, IRMB, 21000 Dijon, France -

(4) INSERM U346, Hôpital E.-Herriot, 69003 Lyon, France

Factor analysis of biomedical image sequences (FAMIS) was applied to fluorescent in situ hybridization (FISH) HeLa cell preparations to characterize 10 to 50 copies per cell of human papillomavirus (HPV) DNA type 18 integrated in cellular DNA Targets labelled by Fast Red (FR) in the nuclei stained by thiazole orange (TO) were used as a biological model. Three methods were used to characterize this model: multispectral analysis, dynamic studies, and $3 \mathrm{D}$ analysis. The investigation was performed on $2 \mathrm{D}$ and $3 \mathrm{D}$ image sequences obtained on a single photomultiplier (PM) detector of a confocal microscope (Sarastro1000, Molecular Dynamics), by selection at emission through $10 \mathrm{~nm}$ interference filters in the range of $500-780 \mathrm{~nm}$, by confocal scanning with constant excitation time, and by z displacement. Results showed that spectra and kinetics, and estimated images corresponded to FR stained targets as well as to TO stained nuclei, and that 3D emission profiles and estimated images provided improved visualization and localization of HPV DNA sequences inside the nuclei. 
64 MULTICOLOR ANALYSIS AND LOCAL IMAGE CORRELATION IN CONFOCAL MICROSCOPY D. Demandolx, J. Davoust

Centre d'Immunologie CNRS-INSERM de Marseille-Luminy, Case 906, 13288 Marseille, France

Multiparameter fluorescence microscopy is often used to identify cell types and subcellular organelles according to their differential labelling. On thick objects, the quantitative comparison of multiply-labelled specimens requires the three-dimensional (3-D) sampling capacity of confocal microscopy, which can be used to generate pseudocolour images. To analyse such 3-D data sets, we have created pixel fluorogram representations which provide a powerful means of analysing image acquisition noise, fluorescence cross-talk, fluorescence photo-bleaching and cell movements. To identify true fluorescence co-localization, we have developed a novel approach based on local image correlation maps. These maps discriminate the coincident fluorescence distributions from the superimposition of non- correlated fluorescence profiles on a local basis. We believe that the pixel fluorograms are best suited to the quality control of multifluorescence image acquisition. The local image correlation methods are more appropriate for identifying co-localized structures at the cellular or subcellular level. The thresholding of these correlation maps can further be used to recognize and classify biological structures according to multifluorescence attributes.
DYNAMIC CHARACTERIZATION OF TUNEL-CARD FLUORESCENT DNA BREAKS IN IMAGE SEQUENCES E. Kahn (1), G. Linares-Cruz (2), F. Frouin (1) H. Bruzzoni-Giovanelli (2), F. Calvo (2), R. Di Paola (1) (1) INSERM U66, CHU Pitié Salpétrière, 75634 Paris, Paris (2) Laboratoire de Pharmacologie (IGM), 75010 Paris, France

Factor analysis of biomedical image sequences (FAMIS) was applied to fluorescent in situ hybridization (FISH) and TdTmediated dUTP-biotin nick end labelling-(TUNEL) tyramide preparations to characterize fragmentations of DNA in nuclei of human tumoral and reverted cell lines. Targets labelled 1) by FITC in the nuclei stained by propidium iodide, and 2) by TRITC in the nuclei stained by chromomycin A3, were used as a biological model. To characterize this model, dynamic studies were used. The investigation was performed on 2D-image sequences obtained on a single photomultiplier (PM) detector of a confocal microscope (Sarastro1000, Molecular Dynamics), 1) by $488 \mathrm{~nm}$ filtering selection of the argon laser excitation, and 2) either by succesive acquisitions through $457 \mathrm{~nm}$ laser excitation then through $514 \mathrm{~nm}$ laser excitation, or without filtering selection at excitation. At emission, acquisitions were performed by scanning the same localization at constant excitation time. Results showed that kinetics and estimated images corresponded to FITC and TRITC stained targets as well as to propidium iodide and chromomycin A3 stained nuclei. It was possible to distinguish targets, taking into account differences in photobleaching of the different fluorochromes.
66 DEPTH ANALYSIS OF PROBES IN CYTOGENETIC FLUORESCENT PREPARATIONS FROM IMAGE SEQUENCES

E. Kahn (1), F. Frouin (1), C. Philippe (2), M. Pelegrini (1), R. Di Paola (1), A. Bernheim (2)

(1) INSERM U66, CHU Pitié Salpétrière, 75634 Paris, France - (2) CNRS URA 1967, 94805 Villejuif, France

Factor analysis of biomedical image sequences (FAMIS) was applied to fluorescent in situ hybridization (FISH) preparations to characterize depth differences in flattened human nuclei. We used cosmids as probes (DNA labelled by biotin, revealed with FITC conjugated avidin) and the nuclei were counterstained with propidium iodide. The investigation was performed on this model and on couples of beads, by 3D sequences of images obtained on a single photomultiplier (PM) detector of a confocal microscope (SARASTRO CLSM 1000 Molecular Dynamics) by selection at emission over $500 \mathrm{~nm}$ and by $\{z\}$ displacement. Estimated images showed depth differences in the beads and staining impregnation inside them, and depth differences in FITC stained targets inside propidium iodide stained nuclei. These informations could not be visualized by conventional 3D reconstructions. In conclusion, we can verify that it is possible to characterize differences in the depth of fluorescent probes, staining impregnation, and study 3D architecture of flattened preparations.
67 ARTEFACTS DUE TO SHIFT VARIANT AND QUASIMONO-CHROMATIC IMAGE FORMATION IN 3-D RECONSTRUCTION BY OPTICAL SECTIONING MICROSCOPY

A. Dieterlen, C. Xu, A. Chomik, J.J. Meyer, G. Jung, S. Jacquey LAB. EL U.H.A., 68093 Mulhouse Cedex, France

Widefield microscope optical-sectioning is a powerful tool to study living structures in the field of biology. The biological specimen is stepped through focus by a controlled displacement of the microscope stage. A series of two dimensional section images are acquired. To get a faithful 3-D estimate of the specimen, reconstruction should be applied in order to reduce the loss of informations (due to the missing cones) and to compensate for low optical axial resolution. Taking into account experimental parameters such as refractive index variation and the spectral bandwidth of the fluorescent emission, the image formation process can no longer be considered shift invariant nor monochromatic. Using the Gibson-Lanni theoritical point spread function (PSF) model and varying the wavelength and the position of the reference source, we use it to reconstruct a $3 \mu \mathrm{m}$ calibrated fluorescent bead. In this way, we show experimently the artefact and the distorsions of the 3-D reconstruction if spatial variance and quasi-mono- chromaticity are neglected. The results are then compared with the "ideal" (spatially invariant and monochromatic) reconstruction. In this way, we stress on the possible 3D reconstruction errors. 
Session $n^{\circ} 6$

\section{ADN, ONCOLOGIE CLINIQUE}

Présidents de séance : A. Laquerrière, D. Seigneurin

Résumés 68 à 81

Présentations orales : résumés 68 à 72 
68 CLINICAL CYTOMETRY OF DNA CONTENT: STATE OF THE ART

P. Vago

INSERM U254/CRIC, 34000 Montpellier, France

In oncology, both flow (FCM) and image (ICM) cytometry are used to analyze DNA content for DNA ploidy characterization and Sphase fraction evaluation. This information is clinically useful in predicting patient prognosis and response to treatment. One critical aspect for the clinical applications of these measurements is the use of standardized procedures to prepare and analyze clinical samples, and to analyze and interpret cytometry data. Guidelines have been provided for FCM (Cytometry 14: 472-477, 1993) and ICM (Anal Cell Pathol 8: 67-74, 1995; Cytometry 26: 101-107, 1996). In 1996, the cytometry community is focusing its attention on i) the intratumoral heterogeneity in DNA ploidie and proliferation associated antigens and ii) the combination of FCM and ICM for DNA pattern assessment. With regard to the second aspect, it has been established that the agreement between FCM and ICM is - $90 \%$. Disagreements are due to the specificity of each method. More interesting is that ICM reveals the presence of a DNA diploid peak in addition to the DNA aneuploid peak in $180 \%$ of DNA aneuploid tumors. This feature introduces a bias in the FCM Sphase evaluation when only the DNA aneuploid cycle is considered. These different aspects of clinical cytometry of DNA content will be discussed.

PROGNOSTIC SIGNIFICANCE OF DNA ANEUPLOIDY IN THE RISK OF COLORECTAL ADENOMA RECURRENCE M. Cottier, P. Brulet, I. Maubon, O. Sabido, C. Barthelemy, J.C. Audigier, J.L. Laurent

Unité de recherche bioclinique Cytométrie en Flux et Pathologie Digestive, Faculté de Médecine, 42023 Saint-Etienne, France

We previously reported our results about flow cytometric DNA analysis in colorectal adenomas. The prevalence of DNA aneuploidy was $17,2 \%$ and DNA aneuploidy correlated with size and dysplasia. The aim of this study was to investigate the prognostic significance of DNA aneuploidy and cell proliferation in the risk of recurrence of colorectal adenomas and to compare DNA content with clinicobiological prognostic parameters. The database included 299 patients with one or more adenomas at the initial colonoscopic examination. From these patients we analyzed 517 adenomas (histopathologic characteristics, DNA ploidy). Only 157 patients had at least one follow-up colonoscopic examination (follow-up period between 6 months and 6 years and 10 months). Seventy-seven patients had at least one adenoma recurrence. Kaplan-Meier actuarial method, univariate and multivariate analysis (Cox proportional hazards model) (BMDP programs) are used to evaluate 1) the relationship between adenoma recurrence and DNA ploidy and others clinicobiological parameters, and 2) the independent significance of prognostic covariables.
69 IMAGE CYTOMETRY OF THYROID NEOPLASMS: METHODOLOGICAL ASPECTS

F. Liautaud, J. Dufer, M.J. Delisle, P. Coninx

Institut Jean Godinot, B.P. 171, 51056 Reims Cedex, France

The smears obtained by fine needle aspiration biopsy of thyroid cold nodules and Feulgen stained were analysed by a SAMBA 2005 cell image processor. 33 benign and 11 malignant nodules were included in a database. Discrimination was based on nuclear features, essentially textural parameters. Reproducibility of their measurements was associated with the process of cell selection. It appeared to be \pm twice higher when nuclei were selected at random rather than by the pathologist. In order to discriminate between the cells from benign and malignant nodules, two methods were used, either based on the Tchebycheff inequality without hypothetising on the frequency distribution, or on the basis of a norma distribution after ArcSinus $=+$ transformation of data. Both produced the same results. Sensitivity (Se) and specificity ( $\mathrm{Sp}$ ) of image cytometry were as high as $92 \%$ and $88 \%$, respectively for the cases from the database. Prospectively validation was obtained for 25 benign and 12 malignant nodules with a Se and a Sp of $91.6 \%$ and $80 \%$ respectively.

\section{STUDY OF DNA HETEROGENEITY IN BREAST} TUMOURS

M. Lorenzato, M. Abboud (1), B. Visseaux-Coletto, C. Quereux (1), J.J. Adnet

Labo Pol Bouin, (1) Service de Gynécologie, CHRU Maison Blanche, Reims, France

We explored tumour DNA heterogeneity on Feulgen stained imprints of 58 breast tumours with at least 3 years follow up, for which DNA content had already been measured by classical image cytometry (CAS 200 Becton Dickinson). Each slide was then reanalyzed with the help of the DISCOVERY system (Becton Dickinson), an automated image analyzer ensuring a rapid screening and detection of rarely occuring abnormal cells. The program starts by measuring 200 at least diploid cells, then the analysis automatically shifts to the measurement of 50 at least tetraploid cells. Finally, the program searches for rarely occuring nuclei with DNA content above 5C, until about 10.000 nuclei are examined. The results are compared with those obtained with classical DNA measurement.

Discordance between both analysis was observed in $55 \%$ and was more important in the $<50$ years old group $(\mathrm{p}<0.01)$. Moreover the presence of $5 \mathrm{C}$ exceeding cells was observed in $92 \%$ of multifocal tumours (vs $69 \%$ in unifocal lesions). The results are also confronted with the patient follow up. 
72 HETEROGENEITY IN DNA PLOIDY AND S PHASE FRACTION OF BREAST TUMORS STUDIED BY FLOW CYTOMETRY

F. Duigou, P. Herlin, J.J. Michels

Dept. of Pathology, Centre Francois Baclesse, 14021 Caen Cedex, France

32 tumors were studied by flow cytometry in order to estimate the frequency of heterogeneity in DNA ploidy content and S phase fraction. A thin slice of each tumor was sampled in small subfractions. Each individualized subfraction was mechanically dissociated and its nuclei suspension stained by propidium iodide. Acquisition and data analysis were performed in accordance to American Consensus Conference (1993). Only homogeneous DNA ploidy cases were studied for the $\mathrm{S}$ phase evaluation. $50 \%$ of breast tumors exhibited heterogeneity in DNA ploidy and $38 \%$ in S phase fraction. No correlation was established between clinical factors or histological types and the heterogeneity of the DNA ploidy content or $\mathrm{S}$ phase fraction. DNA ploidy heterogeneity cannot be only explained by the proportion of stromal or inflammatory compartment in the subfractions: two neighbouring subfractions with the same tumoral representativeness can exhibit either a diploid DNA or aneuploid DNA histogram. These investigations put forward an outstanding question related to the value of $S$ phase fraction evaluation in the aneuploid DNA cases, when $S$ phase value of diploid DNA stemline is not taken into account.
73 ESOPHAGEAL SQUAMOUS CELL CARCINOMA AND PREOPERATIVE CHEMORADIOTHERAPY. DNA FLOW CYTOMETRIC AND KI67 EXPRESSION ANALYSIS

P. Gosset, B. Vandenhaute, M. Lecomte-Houcke, J.P. Triboulet Services d'anatomie-pathologique A et de chirurgie générale et endocrinienne, CHRU de Lille, 59000 Lille, France

Aims: Reports on preoperative chemoradiotherapy are conflicting. We examined resected esophagus to asses the value of a set of pathologic factors, flow cytometric DNA analysis, Mib1 (Ki67) expression and the efficiency of the chemoradiotherapy. Methods: Forty-two patients with an esophageal squamous cell carcinoma were randomized. Nineteen (group 1) were treated with surgery alone and 23 (group 2) with a preoperative chemoradiotherapy (cisplatin). Results: Preoperative treatment had no significant effect on survival curves in spite of an effect on tumor volume $(p=0.049)$. Mib1 overexpression was correlated with high $S$ phase fraction for the group 1 and with lower survival for both groups $(\mathrm{p}=0.044)$. Ploidie was correlated with TNM staging $(\mathrm{p}=0.037)$. For the 2 groups there was no significant difference for differentiation, invasion depth, lymph node statue, vascular emboli, stroma reaction, Mib1 expression, ploidie. Nuclear pleomorphism was more frequent in group $2(\mathrm{p}=0.049)$. Conclusion: The proliferative fraction (Mib1) and extension parameters (depth of invasion, vascular emboli and node statue) were equivalent in both groups. This could explain, in this study, the lack of efficiency of preoperative treatment on survival.
74 EVALUATION OF PLOIDY AND POTENTIAL DOUBLING TIME (Tpot) IN VIVO BY BROMO-DEOXY-URIDINE

P. Doutrelant (1), N. Wattez (1), P. Gosset (2), A. Delobelle (2), J.L. Lefebvre (3)

(1) Laboratoire d'hématologie - (2) Laboratoire d'anatomiepathologique - (3) Département d'ORL, Centre Oscar Lambret 59020 Lille, France

We used Flow Cytometry to calculate cell ploidy and Potential Doubling Time (Tpot) in a series of 100 patients with head and neck tumors. Bromo-deoxy-uridine (BUdr) is injected in vivo and a part of the tumor, taken by biopsy 6 to 8 hours later, is processed to obtain a single cell suspension. An anti-BUdr, FITC-conjugated (Becton-Dickinson), is used in combinaison with Propidium Iodide as staining procedures. The cellular suspension is analysed with a FacScan flow cytometer (Becton-Dickinson, San Jose, CA) to assess labelling index (LI), duration of DNA-Synthesis (TS). The 2 parameters are introduced in Begg's algorithm to calculate Tpot values. Ninety samples are informative and of these 90 tumors, a total of $56(62 \%)$ yield DNA diploid histograms, the remaining 34 $(38 \%)$ are DNA aneuploid. The tumours from patients with diploid tumors are characterised by a mean LI of $6 \%$ and a mean Tpot of 11.6 days. The mean LI and mean Tpot from aneuploid tumors are respectively $14.4 \%$ and 5.6 days. Otherwise, the mean total \% S Fraction is $11.3 \%$ for the diploid group compared to $28.4 \%$ for the aneuploid group. Evaluation of LI by immunohistochemistry and correlations between cell cycle parameters and clinical responses are in progress.
CONTRIBUTION OF AUTOMATIC IMAGE ANALYSIS TO THE EVALUATION OF CELL HETEROGENEITY IN TUMORS: EXAMPLES FROM PARAFFIN EMBEDDED BREAST TUMORS

P. Herlin, F. Duigou

Dept. of Pathology, Centre Francois Baclesse, 14021 Caen Cedex, France

Some examples have been chosen in order to illustrate cell heterogeneity of invasive breast carcinoma. Flow cytometry (FCM) and automatic image analysis (AI) were performed in order to estimate the DNA ploidy content from the same deparaffined samples. Frequency histograms obtained from these two techniques were analyzed and compared using the same software (MCycleAV). Three main situations lead to cellular heterogeneity and to the different conflicting results from CMF and AI: large inflammatory and stromal compartments, abundant residual normal acini, presence of several clones of cancer cells. Contaminating normal cells can biase $\mathrm{S}$ phase fraction evaluation of DNA diploid samples and hide small DNA aneuploid cell populations.

Flow cytometry is unsuitable for DNA ploidy analysis of such samples as specific labelling of fixed cellular elements is impossible. Fully automated image analysis allows objective cell sorting and is able to provide statistically significant results from a large collection of cancer cells. 
76 COMPARISON OF PROLIFERATING FRACTION EVALUATION IN BREAST CARCINOMA BY IMMUNOCHEMISTRY (MiB1) AND FLOWCYTOMETRY

L. Collet (1), C. Jeanne-Pasquier (1), C. Lebeau (1), F. Duigou (1), J. Marnay (1), J.-J. Michels (1), N. Leclerq (1), M. Henry-Amar (2), A.-M. Mandard (1)

(1) Dept. of Pathology - (2) Dept of Clinical Research, Centre Francois Baclesse, 14021 Caen Cedex, France

158 cases of lymph node negative breast carcinoma (Scarff and Bloom grade II, $1-3 \mathrm{~cm}$ diameter) were studied in order to estimate the fraction of proliferation.

Two methods were used: screening and counting of immunostained nuclei on sections (MiB1) and DNA ploidy histogram modelization of fresh tumor samples studied by flowcytometry (DNAPrep) MiB1 quantification was carried out as several cell countings (100 to 1000) in order to estimate the extent of standard error (SE). According to the american consensus guidelines, $\mathrm{S}$ phase fraction evaluation was calculated on 100 cases using MCycleAV software. The results obtained by the two methods are presented as well as the correlations between $\mathrm{S}$ phase fraction and $\mathrm{MiB} 1$ rate.
77 CYTOKERATIN LABELLING CONTRIBUTION IN SPF DETERMINATION AND DNA CONTENT ANALYSIS OF BREAST CARCINOMAS. FCM STUDY

A. Gallais, C. Duval, J. D'Anjou, P. Bertrand

Centre Henri Becquerel, 76038 Rouen Cedex, France

For a more precise S-Phase fraction (SPF) determination of tumor cells, we used a two-color method: FITC conjugated cytokeratin (CK) / Propidium Iodide (PI) to label epithelial cells only.

We compared intraduct (IDC) and grade I carcinomas to high grade carcinomas. Fresh or frozen samples mechanically dissociated from 429 carcinomas were studied (from 1992 to 1994). Unfixed cells were analysed on Coulter Cytometer and histograms by M-cycle Software.

$\mathrm{CK}+$ cells \% in tumors: -significantly decreased from low to high grade (69 \% in IDC, $73 \%$ in Gr. I, vs $54 \%$ in Gr. III). - was always higher in diploïd than in aneuploïd tumors, but only significantly in IDC (77\% vs $67 \%$ p $6.10-5$ ).

In diploïd tumors: SPF was significantly higher in CK-gated cells than in ungated cells for all grades (3.72 and 5,02 vs 3.76 and 3.99 for IDC and Gr. I).

In aneuploïd tumors: aneuploïd populations \% was always significantly higher in $\mathrm{CK}+$ cells compared to total cell population. But for the aneuploïd cells, SPF was significantly higher in $\mathrm{CK}+$ cells only in high grade.

$\mathrm{CK}+$ labelling permitted 3-10\% aneuploïd populations detection and $10 \%$ aneuploïd population SPF determination. This improvment in SPF determination and aneupl. populations detection may be useful in pronostic factors study.
78 QUANTIFICATION OF DNA IS A GOOD METHOD TO COMPLETETE CYTOLOGY OF THE URINARY SEDIMENT

C. Desplechain, H. Egloff, F. Franck, N. Goujon, M. Mosnier-Damet

Groupe des urologues d'Auvergne Cristal, 18, av. Léonard de Vinci, 63063 Clermont-Ferrand Cedex, France

Cytology examination of urinary sediment is highly accurate in tumors of the urinary bladder. The authors relate their experience of 7 years study with quantification of DNA by the Cell Analysis System (Cas 100 and 200) using the Feulgen's method. We study 1063 urinary sediment with DNA quantification: - If many cells are present in the sediment. - If there is "bizarre" cells. - If there is a tumor known in the past. In 710 cytology, no modification of the DNA content is found. In 199 cases, the quantification of DNA is superior to $5 \mathrm{C}$. In 170 cases, we quantify an aneuploïd clone and in 71 cases the aneuploïd content is near tetraploidy.

RESULTS and CONVICTIONS: If there is a clonal aneuploidy cellular content, it is always an urothelial tumor. The clones above $5 \mathrm{C}$ associated with a high proliferative index are suspicious of infiltrating tumors. Clones about $4 \mathrm{C}$ are papillary tumors of grade II or III with no prediction to infiltration. The present of more of $5 \%$ of the cell expressing more of $5 \mathrm{C}$ content without clonality are suspicious of a tumor existence and necessite further investigation. Even so the presence of a high number of cells engaged in the cellular cycle in spite of no clinical manifestations (Regeneration, infection...) must be considered as suspect.

CONCLUSION: The mesure of DNA is an adequate method for the pathologist. This is a complement for the cytologic diagnostic in studying urinary sediment.
INFLUENCE OF RXTHERAPY ON TUMORAL CELL KINETICS IN RECTAL CARCINOMA: VARIATIONS OF IN VIVO BRDU LABELLING INDEX

J. Hemet (1), P. Michel (2), A. Laquerrière (1), A. François (1), P. Ducrotte (2), M. Parésy (1), B. Doublet (1)

Services d'Anatomie Pathologique (1) et des Maladies de l'Appareil Digestif (2), CHU Rouen, France

Aim: The efficacy of p-irradiation as adjuvant therapy in rectal carcinoma is now recognized. The aim of this study was to evaluate the influence of such treatment on tumoral cell growth using CMF, by means of LI measurements after in vivo BrdU incorporation. Methods: Seven patients were included in this preliminary study. A total irradiation of $34.5 \mathrm{~Gy}$ was delivered within three weeks. Eight to ten biopsies were performed on rectal tumors, four hours after an intraveinously given $250 \mathrm{mg}$ BrdU solution before and after Rxtherapy. Biopsy material was processed for CMF analysis. LI was calculated using Begg's method.

Results: Among the seven cases studied, 4 were DNA diploïd and 3 DNA aneuploïd. For both groups, mean LI values did not significantly vary before therapy between diploid (7.00 7 1.99) and aneuploid tumors (7.03 7 2.86). After Rxtherapy, LI exhibited a $50 \%$ decrease in DNA diploïd tumors $(3.6870 .27$ ), contrary to DNA aneuploïd tumors $(6.9372 .02)$. Our results suggest that Rxtherapy may exert a different effect on tumoral cell kinetics in rectal carcinoma according to their ploïdy. 
80 COMBINATION OF FLOW AND IMAGE CYTOMETRY FOR DNA PATTERN ASSESSMENT IN BREAST CARCINOMA

V. Réclar (1), P. Vago (2), M. Radal (1), N. Lequeux (1), J. Simony (1)

(1) Anatomie Pathologique, CRLC, 34000 Montpellier, France (2) INSERM U254/CRIC, 34000 Montpellier, France

Both flow (FCM) and image (ICM) cytometry were used to asses the DNA pattern of 120 breast carcinomas. For FCM, frozen samples were mechanically dissociated and propidium iodide stained. For ICM, fresh cytological prints were Feulgen stained. FCM revealed a diploid DNA pattern in 40 (33.3\%) of the cases, an aneuploid DNA pattern in $75(62.5 \%)$ of the cases, and a multiploid DNA pattern in $5(4.2 \%)$ of the cases. Agreement between FCM and ICM was $87.5 \%$. Disagreements were as follows: 1$)$ in $8(20 \%)$ of the 40 FCM DNA diploid cases, ICM revealed i) the presence of both a DNA diploid and a DNA tetraploid peak (3 cases) or ii) that the $\mathrm{G}_{0} / \mathrm{G}_{1}$ peak was near-diploid (5 cases); 2 ) in $6(8 \%)$ of the $75 \mathrm{FCM}$ DNA aneuploid cases, the ICM DNA pattern was diploid; 3 ) in 1 $(20 \%)$ of the 5 FCM DNA multiploid cases, only 1 of the 2 DNA aneuploid peaks was detected by ICM. These disagreements were due to i) the presence of non tumoral cells for FCM false negatives, and ii) a weak representation of the DNA aneuploid cells for ICM false negatives. Another major feature of interest was that ICM revealed the presence of a DNA diploid peak in addition to the DNA aneuploid peak in $56(81.2 \%)$ of the 69 FCM and ICM DNA aneuploid cases. We conclude that a combination of both techniques is suitable for DNA pattern assessment
81 PROLIFERATION ASSOCIATED ANTIGEN ANALYSIS BY IMAGE AND FLOW CYTOMETRY : METHODOLOGICAL AND BIOLOGICAL ASPECTS

V. Réclar (1), J. Simony (1), N. Lequeux (1), M. Radal (1), P. Vago (2)

(1) Anatomie Pathologique, CRLC, 34000 Montpellier, France (2) INSERM U254/CRIC, 34000 Montpellier, France

The expression of the proliferation associated antigens $\mathrm{Ki}-67$ PCNA, P105, and P120 in 22 human breast carcinomas and MCF7 tumor cell line was investigated under various conditions using either image (ICM) or flow (FCM) cytometry. For ICM, paraffinembedded tissue sections of breast carcinomas were stained using monoclonal antibodies obtained from Coulter Immunology or Immunotech and a standard streptavidin-peroxydase technique. For FCM, frozen samples of breast carcinomas were mechanically dissociated and permeabilized using lysolecithin, paraformaldehyde, and nonidet P-40; the proliferation associated antigens were indirectly FITC labeled using the same monoclonal antibodie; DNA was counter-stained by propidium iodide. The same procedure of permeabilization and staining was used for fresh samples of MCF7 cell line. The percentage of positive cells, as determined by ICM or FCM, showed a very heterogeneous distribution between the different investigated antigens within a same tumor or the MCF7 cell line. The methodological and biological reasons for such a heterogeneous distribution will be discussed and procedures for the ICM or FCM clinical investigation of these antigens will be proposed. 


\section{HYBRIDATION IN SITU}

\section{ET CYTOGÉNÉTIQUE}

Présidents de séance : A. Bernheim, E. Kahn

Résumés 82 à 91

Présentations orales : résumés 82 à 89 
82 FISH ON CHROMOSOMES: SOME INTRODUCTORY REMARKS

A. Bernheim

Laboratoire de Cytogénétique et Génétique Oncologiques (URA 1967 CNRS), Institut Gustave Roussy, 39 rue Camille Desmoulins 94805 Villejuif Cedex, France

Morphological cytogenetics has been transformed in molecular cytogenetics by the introduction of FISH techniques. The nucleus content and organisation can be analysed during all the cell cycle, either on condensed chromosome, intact nuclei, section of nuclei, whole DNA streched DNA.

The FISH techniques are rapidly expanding with various probes: - unique DNA segments from few hundred base pair to several megabase; -repeat sequences for centromeric probes, telomeric allowing even the use of oligonucleotides for PRINS;

whole or partial chromosome for painting

- total DNA for comparative in situ hybridization which allows to demonstrate chromosomal losses or gains from tumoral DNA;

- stretched DNA or chromatin which allows a resolution as low as few $\mathrm{kb}$. Digital imaging by cooled single or color CCD cameras and image processingare more and more used. Recently Schrock et al (Science 1996) used an interferometer to determine the full spectrum of light emited by each stained chromosome. If a combinatorial approach is used by labeling the painting probes for each chromosome with a different assortment of fluorochromes, as few as five dyes can give enough combinations to give one for each human chromosome type.

Among an exponentialy growing amount of applications, determination of the very complex chromosomal abnormalities in cancer cells are one which may help to understand the genetic change leading to cancer and may provide roads to therapy.

84 ANALYSIS OF t (11;14) (q13; 932$)$ IN LYMPHOMAS BY CHROMOSOME 11 PAINTING: VALIDATION IN INTERPHASIC NUCLEI

B. Laudier, D. Feneux, C. Leonard, G. Tertian, G. Tchernia Laboratoire d'Hématologie et de Cytogénétique, 94275 KremlinBicêtre Cedex, France

Chromosome 11 painting has been proposed for diagnosis of $\mathrm{t}(11 ; 14)$ (q13:q32) in interphasic nuclei (1).

In order to assess this technic, we analyzed cells from 5 lymph node biopsies with various karyotypic abnormalities: hyperdiploïdy $(1), \mathrm{t}(14 ; 18)$ with and without additional chromosome 11 (3), and isolated $t(11 ; 14)$ (q13;q32) (1).

A lymph node biopsy with normal karyotype and normal blood cell cultures were used as controls.

Fluorescent spots were obtained after independent 11 and 14 chromosomic hybridization and visualisation by FITC/IP coloration. We scored the number of spots (sure (s), doubtful (d) and diffuse). We find a good association between the observation of 3 spots and the presence of chromosome 11 structural or numerical abnormalities: $18,8 \%$ and $17,7 \%$ respectively versus $<1,7 \%$ in other cases $(s+d)$. However, the discrimination could not be achieved between chromosome 11 structural or numerical abnormalities.

Independent chromosome 14 painting did not bring additive information. A centromeric analysis is mandatory to further define chromosomal abnormalities. In these conditions, chromosome 11 painting could be useful in this indication.

(1) Zucca et al. British Journal of Haematology, 1995, 89, 665-668.
83 FISH SIGNAL AMPLIFICATION SYSTEMS

K. Truong (1), Z. Maciorowski (1), J. Klijanienko (1), P. Vielh (1), J. Boenders (2), B. Dutrillaux (1), C.A. Bourgeois (1)

(1) Institut Curie, UMR 147 and Cytopathology, Paris, France

(2) Becton Dickinson Cellular Imaging Systems, Leiden, The Netherlands

Working with automatic image cytometers requires an optima signal-to-noise ratio, especially when detecting FISH spots in interphase nuclei. Therefore, we have developed and adapted different detection systems: in the current study, we present the results obtained on human blood lymphocytes using the biotinylated centromeric probes for both the 3 and 16 chromosomes. The probe's revelation was performed by: either two antibodies, the second one being linked to FITC or Rhodol Green; or an amplifiction based in one case on a biotin-streptavidin system linked to Rhodol Green, in another case we used the Tyramide Amplification System (TSA) (1). Firstly, the signal itself was quantified using STAT 2005 software (Alcatel-TITN), then the FISH spots for each nucleus were scored by a Becton-Dickinson DISCOVERY system.

The most appropriate detection system was then applied on breas cancer fine needle samplings.

Our results show with regard to diagnostics of aneuploidy, an important marker of breast cancer, that amplification systems are necessary although time consuming.

(1) Bobrow, M. N., Litt, G.J., 1993, United States patent

85 P R INS DEVELOPED FOR CYTOGENET IC INVESTIGATIONS ON SOMATIC HYBRIDS, CELL LINES AND TISSUE SECTIONS

P. Coullin (1,3), J.J. Candelier (1), B. Andréo (2), A. Bernheim (3), F. Pellestor (2)

(1) INSERM U178, 94807 Villlejuif, France - (2) CNRS UPR9008, 34033 Montpellier, France - (3) CNRS URA 1967, 94805 Villejuif, France

As an alternative to FISH, PRINS is a method very well adapted for the characterization and the periodic controls of interspecific hybrid cell lines. Full karyotypes were performed using Alu specific primers generating the painting of all human material associated with R-like banding. The representativity of individual human chromosome was established using primers specific for discriminent a-satellite DNA sequences providing specific signal on the centromeres of the targeted chromosome and corresponding spots in interphase nuclei. This family of primers represents attractive tools for studying aneuploïdies particularly in case of instable cell lines and in case where few metaphasis could be available. We tested the method with the colon cancer cell lines Caco2 and HT29 and with preparations from neuroblastoma patients. The methodology was adapted to tissue sections which may be useful for cytogenetical analysis in pathological samples particularly from cancers. 
86 PRELIMINARY EVALUATION OF A NEW FLUORESCENCE METAPHASE FINDER

L. Roy $(1,2)$, I. Sorokine-Durm (1), F. Soussaline (2), P. Voisin (1)

(1) Institut de Protection et de Sûreté Nucléaire, Département de Protection de la santé de l'Homme et de Dosimétrie, Section Autonome de Radiobiologie Appliquée à la Médecine, IPSN, B.P.6, 92265 Fontenay-aux-Roses Cedex, France - (2) IMSTAR, 6 rue Notre-Dame-des-Champs, 75006 Paris, France

The observation for diagnostic purpose of stable and unstable chromosome aberrations in peripheral blood lymphocytes can be greatly improved by automatic metaphase finding. A new system for conventional and fluorescence searching was developed by IMSTAR Company in collaboration with our laboratory. It consists of a fluorescence microscope equipped with a motorised multistage (8) and a CCD high resolution, digital, accumulation camera coupled with a computer unit. Our multifinder was firstly evaluated by comparison with the Cytoscan 3CS2 (Applied Imaging) system using the same metaphase Giemsa stained slides. Our system finds 4.5 times more metaphases with a false positive rate of $15 \%$ (compared with a false positive rate of $5 \%$ for Cytoscan). Moreover, our system can also perform fluorescence metaphase finding with a DAPI dye reprocessing. It has performed a similar efficiency in fluorescence metaphase finding than in conventional one. Also the system, using a 2-D imaging, gives better accuracy and allows complete image analyses to be performed on the same microscope-camera-computer set-up.
87 USE OF FISH AND PRINS TO DETECT CLONAL CHROMOSOMAL ABNORMALITIES IN CULTURED HEMATOPOIETIC PROGENITORS

J.M. Dupont (1), S. Fichelson (2), M. Fontenay-Roupie (3), D. Le Tessier (1), O. Dupuy (1), A. Lebarr (1), D. Rabineau (1), F. Dreyfus (3)

(1) Laboratoire de Cytogénétique - (2) Laboratoire d'Hémobiologie - (3) Laboratoire d'Hématologie, GH Cochin, 75014 Paris, France

We investigated the use of different FISH probes and techniques to study chromosomal abnormalities (monosomy 7 , trisomy 11 and a $5 q$ deletion) in clones obtained from methylcellulose cultured hematopoietic progenitors from 3 myelodysplastic patients. Clones were picked up after 14 days and cytocentrifuged on glass slides for FISH studies.

We used two different centromeric probes, both generated and labeled by PCR. A chromosome 7 specific probe was made from total human genomic DNA with primers specific for the alpha satellite subset of this chromosome. A chromosome 11 specific probe was made with human alphoid consensus primers on somatic cell hybrids containing chromosome 11 as sole human DNA.

Monosomy for chromosome 7 could also be detected in some clones by the PRINS technique.

Finally, we could also detect a $5 q$ deletion on interphase nuclei with a probe specific for the $5 q 31$ region. In order to visualize such a small probe, we used the HNPP-Fast Red kit from Boehringer which gives a bright red fluorescence and enhances the signal strenght.
88 IN SITU RT-PCR FOR THE DETECTION OF RESPIRATORY SYNCYTIAL VIRUS (RSV)

I. Mendel, V. François, J.M. Dupré, J. Lescoarnec,

C. Buffet-Janvresse

Virology, CHU Charles Nicolle, 76000 Rouen, France

We have developped an in situ PCR assay for the detection of RSV on cell cultures. MRC5 cells were infected with the RSV strain Long and fixed with formaldehyde $2 \%(\mathrm{v} / \mathrm{v})$ and ice acetoneethanol without any previous enzyme digestion. The slides were treated with a RNAse-free DNAse solution and then the cDNA was synthetised. A hot-start PCR procedure was carried out directly on the slides in a reaction mixture containing primers specific for the $\mathrm{N}$ gene of the viral genome and digoxigenin-dUTP. After washing, the slides were incubated with antidigoxigenin antibody-alkaline phosphatase conjugate and the hybrids were revealed with NBTBCIP as purple-blue spots around the nuclei. Numerous controls were included to check the specificity of the signal (incubation with RNAse, omission of the RT step, omission of Taq polymerase, use of "non sense" primers and southern blot from the amplified products on the slides)

These results suggest that in situ RT-PCR is well suited for RSV detection in cell cultures and we will subsequently test this technique for paraffin-embedded tissues.
MOLECULAR COMBING: A NEW APPROACHE TO MOLECULAR CYTOGENETICS AND PHYSICAL MAPPING

A. Bensimon, X. Michalet, C. Schurra and J. Herrick. Laboratoire de Biophysique de l'ADN, Institut Pasteur, Paris, France

In a process called "molecular combing" DNA molecules attached at one end to a solid surface are extended and aligned by a receding air-water interface and left to dry on the surface.

It turns out that the force the interface exerts on the DNA is strong enough to extend the molecule but to weak to break the bond between the molecule and the surface. The local action of the interface is the same on each of the molecules in solution: they are identically stretched.

Simple, controlled and reproducible optical mapping on purified DNA molecules, individual sorted chromosomes and total genomic DNA is made possible by applying Fluorescence in situ hybridisation (FISH) to combed DNA. The utility and accuracy of FISH on combed molecules are illustrated by several examples. (i) mapping of lambda DNA restriction fragments along linearized $49 \mathrm{Kbp}$ long lambda phage DNA molecules with $1 \mathrm{Kbp}$ precision; (ii) mapping of cosmid clones along a $470 \mathrm{Kbp}$ yeast artificial chromosome (YAC) with $5 \mathrm{Kbp}$ precision and estimation of the gaps and the overlaps between them, and (iii) ultrahigh resolution comparative nucleic acid hybridisation to combed DNA molecules. This has allowed us to study, in a relatively simple manner, chromosomal rearrangements, insertions and deletions of different genetic disorders with high precision. 
90 IN SITU IDENTIFICATION OF HUMAN CENTROMERES USING FLUORESCENT NUCLEOTIDES

P. Coullin (1,2), I. Barbounaki (2), J.J. Candelier (1,2), F. Pellestor (3), A. Bernheim (2)

(1) INSERM U178, 94807 Villejuif, France - (2) CNRS URA 1967, 94805 Villejuif, France - (3) CNRS UPR 9008, 34033 Montpellier, France

A simple method of identification of the human centromeres on metaphasic and interphasic nuclei based on in situ hyridization of labelled nucleotides is proposed. Its efficiency was demonstrated on cytogenetic preparations from human heteroploïd and human $\mathrm{x}$ hamster hybrid cell lines and also on frozen tissue sections. The tests were performed using oligonucleotides respectively labelled with 1,4 or 10 fluorescein molecules and specific of the a-satellite DNA of chromosome 1. The use of different fluorochromes and eventually the combination with an elongation in $5^{\prime}$ of the oligonucleotides give ways for the realization of a multicolors method.
91 PCR GENERATED CENTROMERIC PROBES FOR FISH: A SIMPLE AND RELIABLE TECHNIQUE

J.M. Dupont, O. Dupuy, D. Le Tessier, P. Auvinet, D. Rabineau Laboratoire de Cytogénétique, GH Cochin, 75014 Paris, France

The extended use of FISH with centromeric probes in many cytogenetic laboratories is often impaired by the cost of this technique. PCR constitutes a simple way to generate and label such centromeric probes at reasonable cost.

Two types of human DNA source can be used: 1- somatic hybrid cell lines containing a unique human chromosome. The specific amplification of the human subset of alphoid DNA is realised with a primer pair specific for the consensus region of human alpha satellite sequence. 2- Total human DNA. This time, a primer pair specific for the alpha satellite DNA of the chromosome of interest must be designed.

These probes, labelled during the PCR reaction by direct incorporation of modified dUTP, are actually widely used in our laboratory, alone or mixed with other probes (painting or locus specific probes). The first solution is the simplest one as a single published primer pair is sufficient, but its major drawback is the lack of specificity for certain chromosomes of the probe when used in FISH. The second solution is the most reliable once the specific primer pair is designed, but it needs a preliminary work to find out and compare the chromosome specific sequence with the published alpha consensus sequence. 
Session $n^{\circ} 8$

\title{
IMMUNOLOGIE ET HÉMATOLOGIE
}

\author{
CLINIQUES (première partie)
}

Présidents de séance : J.P. Aubry, P. Carayon

Résumé 92

Présentation orale : résumé 92 
92 FLOW CYTOMETRY ANALYSIS OF INTRA-CELLULAR

CYTOKINE PRODUCTION IN HIV INFECTION

B. Autran, Li Ts, L. Peries, C. Blanc, G. Carcelain, P. Debré

Lab. d'Immunologie, URA CNRS 625, CH Pitié-Salpétriêtre

Analysis of cytokine production by $\mathrm{T}$ cells has recently been improved by the ability to detect intra-cellular cytokine content in various $\mathrm{T}$ cell subsets by using multiparameter flow cytometry analysis. Indeed, development of new reagents allow to quantify the numbers of CD4 and CD8 T cells producing various cytokines either spontaneously or after in-vitro stimulation with different stimuli. Applications of these methods to pathologies such as HIV infection, where both a major CD4 T cell defect and a cytokine dysregulation occur, appear of considerable importance for the evaluation of the immune deficiency. IL-2, IL-4 and IFN-g production in CD4 and CD8 naive and memory T cells have been evaluated both in normal individuals and in HIV-infected individuals at distinct stages of the HIV infection. Modifications of the cytokine production patterns under the new combinations of anti-retroviral drugs will be presented and illustrate the interest of these methods for the immunological evaluation of therapeutic strategies. 


\section{PROLIFÉRATION, RÉGÉNÉRATION,}

\section{DIFFÉRENCIATION, APOPTOSE}

Présidents de séance : F. Belloc, S. Huet

Résumés 93 à 105

Présentations orales : résumés 93 à 96 
93 PROLIFERATION-ASSOCIATED MARKERS: BIOLOGICAL AND CLINICAL SIGNIFICANCE.

P. Galand

(Laboratory for Cytology and Exptl. Cancerol. Free Univ. Brussels)

Approaches were recently developed to gain information about some aspects of cell proliferation in human tissues without resorting to incorporation of a chemically or physically labelled precursor. They are based on the immunocytochemical detection of the pKi-67 antigen or of PCNA (auxiliary protein to DNA polymerase d) respectively by the Ki-67 or MIB-1 or by the $19 \mathrm{~A} 2$ or PC10 monoclonal $\mathrm{Ab}$ ). It is stressed that none of the above endogenous markers ( nor, by the way, any other one) should be expected to be exempt from any risk of unscheduled, expression, or of false negativity or positivity.

An extensive review of the literature confirms the actual potential under well-defined conditions - of those markers as predictive indicators of clinical outcome in a wide variety of tumour types. As to the biological significance of the positive labelling with those markers, (and from this its clinical interpretation) it is proposed that their combined use might clarify ambiguous or paradoxical findings, such as an apparent excess of PCNA-positive nuclei reported in one study.

It is concluded that prospective studies should now be performed in order to complete and confirm the above indications, obtained up to now from archival material only.

94 STUDY OF DRUG-INDUCED APOPTOSIS IN LEUKEMIC CELL LINES (KG1a AND HL60) BY TUNEL ASSAY N. Perek, O. Sabido, C. Bouchu, D. Guyotat, L. Campos Laboratoire d'Hématologie, Centre Commun de Cytométrie en Flux, Faculté de Médecine, Saint-Etienne, France

Most chemotherapeutic agents are effective by inducing apoptosis in target cells. Detection of apoptosis after drug exposure may thus be a method of choice to assess in vitro sensitivity of cancer cells We studied the effects of the topoisomerase II inhibitors cytosinearabinoside (araC), daunorubicine (DNR) and etoposide (VP16) on two human leukemic cell lines (HL-60, considered sensitive to apoptosis, and KG1a, considered resistant). Cells were incubated with increased drug concentrations (0 to $6 \mathrm{mM})$ and exposure times ( 0 to $24 \mathrm{H})$. Determination of the percentage of apoptotic cells was performed by flow cytometry using the TUNEL method.

HL-60 cells were more sensitive than KG1a cell line to VP16 and araC. Both lines exhibited the same sensibility to DNR. Maximum apoptosis ( $50 \%$ for DNR, $35 \%$ for VP16 and $25 \%$ for araC) was obtained with 3 to 6 hours of contact at low concentrations (1 to $5 \mathrm{mM}$ ). For concentrations higher than $10 \mathrm{mM}$ and incubation times longer than $10 \mathrm{~h}$, cells became necrotic without exhibiting features of apoptosis.

This method is currently tested in patient leukemic cells in order to define an index of chemosensitivity that could be predictive for response to therapy.
95 APOPTOTIC CELLS ARE IDENTIFIED BY PHAGOCYTES BEFORE BEING IDENTIFIED BY FLOW CYTOMETRY F. Durrieu, F. Belloc, L. Lacoste, P. Dumain, C. Jaloustre, F. Lacombe

Laboratoire d'Hématologie, Hôpital Haut Lévêque, 33604 Pessac, France

In the past few years, several methods were described to label and identify apoptotic cells. All of these were claimed to detect early apoptosis but, in our hands, all of them failed to detect apoptosis in clinical samples from AML patients under chemotherapy. A culture period was usually necessary to reveal cells which were primes in vivo. We developed a model of in vitro phagocytosis using $\mathrm{CHO}$ cells as phagocytes. Apoptosis was induced on HL60, U937 and K562 cells by treatment with $400 \mathrm{nM}$ daunorubicine for $1 \mathrm{~h}$. The cells were then incubated in wells seeded with $\mathrm{CHO}$ or in control wells. Every hour, the amount of apoptosis was assessed by flow cytometry, using several probes: DiOC6(3) for mitochondrial potential, TdT and F-dUTP for DNA fragmentation, F-annexin V for phosphatidyl serines, Hoechst 33342 for chromatine condensation and anti-BAX antibodies for BAX expression. None of these probes was able to detect apoptosis before apoptotic cells undergo phagocytosis. Moreover, with K562, CHO cells were able to phagocyte DNR treated cells while apoptotic features were never detected using conventional probes. We conclude that this model could be useful to search for a marker able to detect early apoptotic cells before they became target for phagocytes.
96 DIFFERENTIAL RADIOSENSITIVITY OF P53 (-) AND P53 (+) CELL LINES

F. Teyssier, O. Sabido, S. Ait El Mkadem, J.N. Talabard, J.C. Healy

Laboratoire de Biophysique, Centre Commun de Cytométrie en flux, Service de Radiothérapie, Faculté de Médecine, CHRU, Saint-Etienne, France

The p53 tumor suppressor gene is the most commonly mutated gene in cancer.

Two wild type p53 cell lines (Colo 685, Y79) and PBL, five mutated-type or deleted p53 cell lines ( Colo 320, K562, Daudi, KG1a, HL60) were subjected to 8 Gy of X-irradiation.

Radiosensitivity was tested by clonogenic assay, cell cycle analysis, p53 protein quantification (Quifikit assay), and quantification of apoptotic population (TUNEL assay).

Clonogenic assays show a radioresistance of p53 (-) cells by contrast to $553(+)$ cells. The radiosensitivity is dependent on wildtype 553 .

Radiosensitivity is correlated to an increase of p53 protein level, G0/G1 arrest and induction of apoptotic way.

On the opposite, p53 (-) cell lines express high level of p53 protein but do not show G0/G1 arrest neither a significant signal of apoptosis. However, cells exhibit a transitory $\mathrm{G} 2+\mathrm{M}$ accumulation. Wild type p53 is required to induce G0/G1 arrest and cell death by apoptosis in response to ionizing radiation.

Now, the aim of the study is to make radiosensitive, radioresistant cell lines and to potentialize effect of ionizing radiation by hyperthermia. 
97 DETECTION OF APOPTOTIC CELLS BY FLOW CYTOMETRY (FCM) AND IL-2 IMMUNOASSAY IN HUMAN IMMUNODEFICIENCY VIRUS (HIV) INFECTED PATIENTS

L. Charroin, C. Malcus-Vocanson, C. Malcus, F. Poitevin-Later, M.O. Rotagnon, F. Touraine-Moulin

Lab. d'Immunologie, Hôp. Neurologique, 69003 Lyon, France

Apoptosis is either a physiological cell suicide process or a disease associated occurence such as in AIDS. Apoptosis is displayed in HIV-infected patient lymphocytes and could explain both the early dysfunction and the late depletion of CD4+ T cells. In this context, we have studied peripheral blood mononuclear cell apoptosis, after $48 \mathrm{~h}$ phytohemagglutinin activation, using FCM (Coulter, USA) TUNEL method. Concurrently, we have assayed IL-2 secretion in culture supernatants by immunoenzymometric kit (Immunotech, France). According to their CD4 lymphocyte subpopulation counts (CD4), patients were classified in 3 categories: a) CD4 < 199/mm3, b) $199 \mathrm{CD} 4500 / \mathrm{mm} 3$, c) CD $4>500 / \mathrm{mm} 3$. The results showed that the apoptotic cell percentage (ACP) was lower in categorie b $(<30 \%)$, when in the others it reached the higher values $(30 \%)$. Furthermore, the higher IL-2 secretions ( $>300 \mathrm{pg} / \mathrm{ml}$ ) were found in categories $b$ and $c$. Then, we can point out the lack of correlation between IL-2 secretion and ACP. these two parameters can be used for patient monitoring, compared with clinical and therapeutical data. They could allow to appreciate the treatment effectiveness.
98 CORRELATED EXPRESSION OF SURFACE ANTIGEN AND THIAZOLE ORANGE STAINING DURING THE MATURATION OF HUMAN ERYTHROID PRECURSORS P. Gane, V. Bony, P. Bailly, J.-P. Cartron INTS and INSERM U76, Paris, France

A two phase liquid culture system was developped to study blood group antigens expression during the maturation of human erythroid cells. Up to $80 \%$ of erythroid cells were obtained in the second phase of culture (Epo-dependent) after 12 to 18 days. Erythroid specific (GPA and GPC) and non specific antigens expression (CD36, CD45 and CD71) as well as the binding of Thiazole Orange (TOr) to precursor's RNA (and DNA) were studied simultaneously. Different maturation stages, from CFU-E to mature red cells, were clearly defined combining TOr staining, the presence or absence of GPA and GPC and the quantitative determination of CD71 and CD36 expression.

Using these results it was possible to study the sequencial expression of blood group antigens during the proliferation and the maturation of human erythroid progenitors. In addition, TOr staining and surface antigen expression make possible the selection of the different maturation stages in order to examine genes and transcripts encoding these markers, particulary those involved in putative adhesive functions.

\section{MITOCHONDRIAL CONTROL OF APOPTOSIS}

P.X. Petit (1), G. Kroemer (2)

(1) CGM, CNRS-UPR 2420, 91198 Gif-sur-Yvette, France -

(2) CNRS-UPR 420, 19 rue Guy-Moquet, 94801 Villejuif, France

Programmed cell death (PCD) is commonly defined by alterations in nuclear morphology (apoptosis) and/or a characteristic stepwise degradation of chromosomal DNA.

However, major characteristic of PDC: loss of mitochondrial reductase activity or cytolysis can be induced in cytoblasts indicating cytoplasmic PCD control.

We have recently demonstrated that the first common biochemical alteration preceding nuclear apoptosis is a disruption of the mitochondrial membrane potential $(\Delta \mathrm{Cm})$. This apoptosis $\Delta \mathrm{Cm}$ dissipation is observed in independence of the cell type (including $r^{\circ}$ cells) and of the lethal stimulus and thus constitutes a general feature of early apoptosis. The mechanism by which the $\Delta \mathrm{Cm}$ is lost involves mitochondrial permeability transition (MTP) because well known inhibitors of MTP (mitochondrial cyclophilin-binding cyclosporin A derivatives, bongkretic acid) prevent this phenomenon. In a cell-free system of apoptosis, insolated mitochondria undergoing MTP become capable of inducing chromatin condensation and DNA fragmentation in purified nuclei. Inhibition of MTP abolishes the mitochondria-mediated transfer of apoptosis from on system to the other. In addition, bongkrekic acid can inhibit apoptosis in a variety of systems. These data indicate that MTP constitutes a critical event of the apoptotic cascade.
EVALUATION OF SENSITIVE AND CHEMO-RESISTANT CELL PROLIFERATION USING PKH26.

J. Boutonnat, X. Ronot, D. Seigneurin

Laboratoire de Cytologie Quantitative \& E.P.H.E., Institut Albert Bonniot, 38706 La Tronche Cedex, France

The major goals in tumor pathology are the determination of proliferation and multidrug resistance (MDR) status. $\mathrm{PKH} 26$ and UIC2 antibody were used to assess cell proliferation and glycoprotein 170 (PGP), respectively using flow cytometry on sensitive-resistant to Adriamycin K 562 cells. PKH26 did not modify cell proliferation. Labeling gave uniform fluorescence in both cell lines, as compared to Rhodamine 123 and Daunorubicin probes which are conventionally used to detect PGP activity. The joint staining of cells with PKH26 and UIC2 made it possible to detect the fraction of resistant and proliferating cells. The experimental procedure consisted in an incubation of a mixture of $\mathrm{K} 562 \mathrm{~S}$ and $\mathrm{K} 562 \mathrm{R}(1 / 1)$ with PKH26 at $10^{-5} \mathrm{M}$ during three days, then a labeling with IUC2 (revealed with Fab'2 FITC), and cells were analyzed using a FACScan. The Cell Proliferation Model program included in the Cell Census Plus System, was used to deconvolute histograms in order to extract the proliferation index. This appoach, which requires an optimization of PKH26 concentration depending on the cell type, is of interest to caracterize cell proliferation without prior cell selection. It could be applied to analyze sensitive and resistant acute myeloid leukemia cell populations.

The authors are indebted to Sigma BioSciences (Sigma-Aldrich, St-Quentin-Fallavier, France). 
101 DIFFERENTIAL EXPRESSION OF CYCLINS AND HGF OR MAJOR RESECTION

S. Masson (1), M. Scotté (1,2), F. Provot (1), M. Hiron (1), P. Ténière (2), J.P. Lebreton (1), M. Daveau (1)

(1) INSERM U78, 76230 Bois-Guillaume, France - (2) Service de Chirurgie Digestive, CHU, Rouen, France

Following partial hepatectomy $(\mathrm{PH})$, hepatocyte proliferation is controlled by a set of [cyclin/cyclin-dependent kinase (CDK)] complexes. The level of cyclin D1 mRNA is increased when isolated rat hepatocytes are stimulated with Hepatocyte Growth Factor (HGF), the most potent mitogen for hepatocytes. In the present study, we have compared the levels of mRNAs for cyclin D1, cyclin $\mathrm{B}, \mathrm{HGF}$ and HGF receptor (c-met) when $\mathrm{PH}$ is carried out to a variable extent $(33,66$ or $80 \%$ of total liver mass).

The mRNA levels for cyclins, HGF and c-met were measured by a quantitative RT/PCR method in livers from rats sacrificed at 2, 6 , $12,24,48$ or $144 \mathrm{~h}$ after $\mathrm{PH}$.

The expressions of cyclins D1 and B were delayed after major PH $(80 \%)$ as compared to that observed after a standard $66 \% \mathrm{PH}$. After a minor PH $(33 \%)$, the levels and timing of occurence of cyclin mRNAs were strongly decreased and delayed, respectively. Likewise, HGF and c-met expressions were modulated according to the extent of $\mathrm{PH}$.

Our results indicate that liver regeneration occurs whatever the extent of $\mathrm{PH}$. However, the time-course of this resection varies according to the PH extent as evaluated by cyclins and HGF that are acknowledged markers of hepatocyte proliferation.

103 CHROMATIN TEXTURE ANALYSIS IN HUMAN 3 LEUKEMIC CELLS TREATED BY NANOMOLAR OKADAIC ACID

S. Yatouji, F. Liautaud-Roger, J. Dufer

GIBSA, FR 53, UFR Pharmacie, 51100 Reims, France

Differential accessibility to DNA in tumor cell chromatin is important to growth, differentiation, apoptosis, and the targeting of DNA modifying drugs. It has been shown that non toxic nanomolar levels of okadaic acid could increase endonuclease accessibility to DNA within 2 hours (Rieber \& Rieber, Cancer Res., 1992, 52:6397-6399). In order to assess the effects of this treatment on chromatin structure, nuclear texture was analyzed by image cytometry on human leukemic CEM cells treated with $10 \mathrm{nM}$ okadaic acid for 0 to 3 hours. Endonuclease accessibility to DNA in chromatin was assayed by exposure of isolated nuclei to DNase I followed by electrophoretic analysis on $2 \%$ agarose. Image cytometry was performed on Feulgen stained cell smears using a SAMBA 2005 cell image processor. Data analysis indicate that DNA from CEM cells treated with okadaic acid shows an increased sensitivity to DNase I cleavage. Nuclei from treated cells display a progressive decrease in chromatin condensation as evidenced by contrast and run-lengths parameters changes. All these changes could not be observed in multidrug resistant CEM-VLB cells, known to present a cross resistance to okadaic acid. These data indicate that a low dose of okadaic acid can induce subvisual chromatin changes correlated with DNA accessibility.
102 REGENERATION OF CIRRHOTIC LIVER AFTER PARTIAL HEPATECTOMY: EXPRESSION OF MRNA FOR CYCLINS AND GROWTH FACTORS

F. Provot (1), M. Scotté (1,2), A. François (3), S. Masson (1) S. Lyoumi (1), J. Hemet (3), J.P. Lebreton (1), M. Daveau (1) (1) INSERM U78, 76230 Bois-Guillaume, France - (2) Service de Chirurgie Digestive - (3) Laboratoire d'Anatomie Pathologique, CHU, Rouen, France

There are conflicting data regarding the ability of the liver to regenerate after partial hepatectomy $(\mathrm{PH})$ in animals or humans with cirrhosis. In the present study, we have evaluated liver regeneration in cirrhotic rats undergoing $\mathrm{PH}$.

A cirrhosis was produced by weekly intragastric gavage with carbon tetrachloride $\left(\mathrm{CCl}_{4}\right)$ over a 16 weeks period. A histological analysis of each liver made at the time of $\mathrm{PH}$ allowed one to ascertain the cirrhosis stage. The mRNA levels for cyclins and growth factors were measured by a quantitative RT-PCR method in both parenchymal and non parenchymal hepatic cells at 6,12 hours or at $1,2,3$ or 6 days post $\mathrm{PH}$.

The expressions of cyclins D1 and B were significantly delayed in cirrhotic rats compared with control rats ( $\mathrm{PH}$ alone). Likewise, HGF, c-met and TGFa expressions were quantitatively impaired. Overall, our results indicate that, after $\mathrm{PH}$ in $\mathrm{CCl}_{4}$-treated rats, liver regeneration still occurs but is significantly delayed and impaired.

PHENOTYPIC CHARACTERIZATION OF ATYPICAL CELLS TRANSIENTLY OBSERVED WITHIN THE DAMAGED ORGAN OF CORTI OF RAT PUPS

N. Daudet, P. Vago, M. Lenoir INSERM U254, 34000 Montpellier, France

Previous morphological studies have shown that after rat pups are treated with amikacin during the period of cochlear supranormal sensitivity to ototoxic antibiotics, i.e. from post-natal day (PND) 9 to PND 16, atypical cells are transiently observed within the organ of Corti. These results suggest that sensory cells attempt to regenerate in vivo in the immature damaged organ of Corti. We thus investigated whether these atypical cells express some sensory or non-sensory cells cellular components. Whole mount cochlea apical turns of rats, aged from 21 to 55 days and previously amikacin treated between PND 9 and PND 16, were double stained for i) actin and ii) parvalbumin or cytokeratin, and observed using confocal microscopy. Actin, a component of sensory cell stereociliary bundles, was found in the apical region of the atypical cells; cytokeratins, some of the cytoskeletal proteins of nonsensory cells, were only expressed in their most peripheral zone; and parvalbumin, a cytoplasmic calcium binding protein found in mature hair cells of the rat apical turn cochlea, was absent from these cells. These results suggest that atypical cells transiently observed after sensory cell damage originate from non-sensory cells, and attempt to adopt certain immature sensory cell characteristics. 
105 IN SITU STUDY OF THE BCL-2/BAX INTERACTIONS DURING APOPTOSIS USING FLOW CYTOMETRY

M.A. Belaud-Rotureau, F. Belloc, F. Durrieu, F. Lacombe, P. Bernard

Laboratoire d'Hématologie, Hôpital Haut Lévèque, 33604 Pessac, France

Bcl-2 and Bax are two proteins with sequence homology which are implied in apoptosis. Bax-Bax homodimers are effectors of apoptosis but an excess of Bcl-2 can displace these dimers, forming Bax-Bcl-2 heterodimers and thus inhibiting apoptosis.

We studied by flow cytometry the evolution of the Bcl-2 and Bax content during the apoptosis of ceramide treated U937 cells. We performed indirect double labeling using murine anti-Bcl-2 and rabbit anti-Bax antibodies. The Bcl-2/Bax ratio was measured in each cell using flow cytometry. The Bcl-2/Bax ratio was found decreased in all the cells $30 \mathrm{~min}$ after the addition of $50 \mathrm{mM}$ ceramide while the percentage of apoptotic cells regularly increased during $20 \mathrm{hrs}$ of culture. The amount of Bax-Bcl-2 heterodimers was evaluated taking advantage of fluorescence resonance energy transfer (FRET) after double labelling with FITC-anti-rabbit-IgG and $\mathrm{Cy} 3$-anti-mouse-IgG antibodies as secondary reagents. The FRET from FITC to $\mathrm{Cy} 3$ which was observed in untreated cells was abolished after $30 \mathrm{~min}$ of ceramide treatment. These results suggest that the evolution of the Bax-Bacl2 dimers can be followed in situ by immuno-fluorescence and flow cytometry. 


\section{IMMUNOLOGIE ET HÉMATOLOGIE}

CLINIQUES (deuxième partie)

Présidents de séance : M.C. Béné, B. Lenormand

Résumés 106 à 109

Présentations orales : résumés 106 à 109 
106 A COMPARATIVE STUDY BETWEEN CELL MORPHOLOGY AND IMMUNOLOGICAL MARKERS IN B-CELL CHRONIC LYMPHOPROLIFERATIVE DISORDERS (B-CELL CLD)

V. Salaun, M. Malet, M. Macro, X. Troussard Laboratoire central d'Hématologie, CHU Côte de Nacre, 14033 Caen, France

The characterisation of the B-cell CLD ( $>4 \mathrm{G} / \mathrm{l}$ or $>20 \%$ atypic $\mathrm{B}$-cell) is usually based on cell morphology as proposed by the French-American-British (FAB) group, and 5 immunological markers (Igs, CD5, CD22, CD23, FMC7) as defined by Matutes.

Peripheral cells from 40 patients with B-cell CLD were analysed. The morphologic diagnosis was chronic lymphocytic leukemia (CLL) in 24 patients and other B-cell CLD in 16 cases.

For CLL, $88 \%$ have high scores ( 4 or 5), $4 \%$ a score 3 and a lower score 2 for $8 \%$. A score 0 or 1 was never found in CLL.

In contrast, the other B-cell disorders (16 cases) scored 1 or 2 , and any case with a score more than 2 was detected.

In conclusion, a high score (4 or 5 ) is always related to CLL and a low score $(0,1$ or 2$)$ to non CLL but other B-cell CLD.

In patients with score 3 , final diagnosis require morphologic and immunologic evaluation.

Comparative study between cell morphology and five immunological markers could improve the diagnosis and classification of the B-cell lymphoproliferative disorders with a discordance between both procedures of $5 \%$.
107 VALUE OF IMMUNOPHENOTYPING FOR THE DIAGNOSIS OF DIFFUSE SMALL B-CELL LYMPHOMA. V. Soumelis, J. Pagès, F. Berger, B. Coiffier, P. Felman Laboratoire d'Hématologie, Centre Hospitalier Lyon-Sud, 69495 Pierre-Bénite, France

114 cases of diffuse small B-cell lymphoma seen between 1987 and 1996 were retrospectively studied to assess the diagnostic value of CD5 and CD23. All the cases were recently reclassified in 28 small lymphocytic (SL), 34 SL with lymphoplasmacytoid differentiation (LP), 28 marginal zone (MZ) among which 6 splenic lymphoma with villous lymphocytes (SLVL), 22 mantle cell lymphoma (MCL) and 2 immunocytomas (both CD5-). 94 cases were typed by immunofluorescense ( 52 by flow cytometry) and 20 by immunocytochemistry. B-cell origin was confirmed by the presence of $\mathrm{CD} 19$ and/or CD20 antigen. CD5 antigen was positive in $25 \mathrm{SL}(89 \%), 30 \mathrm{LP}(88 \%), 4 \mathrm{MZ}(14 \%)$ (2 SLVL) and $20 \mathrm{MCL}(91 \%)$. Search for CD23 antigen was performed in 87 (76 $\%)$ cases and was positive in $18 \mathrm{SL}(81 \%), 21 \mathrm{LP}(84 \%), 3 \mathrm{MZ}$ (18\%) (2 SLVL) and 1 MCL (5\%). Of the cases typed for both CD5 and CD23, 3 subgroups can be identified: CD5+/CD23+ was the best predictor for SL or LP diagnosis [36 cases (77\%) in the SL/LP group, $1 \mathrm{MZ} \mathrm{(6 \% ),} 1 \mathrm{MCL}(5 \%)]$, CD5-/CD23- for MZ [0 SL/LP, 13 MZ (76\%), 2 MCL (9 \%)], CD5+/CD23- for MCL [8 SL/LP $(17 \%), 1 \mathrm{MZ}(6 \%), 19 \mathrm{MCL}(86 \%)]$. CD5 and CD23 phenotype was similar in SL and LP. This might be consistent with a common origin of SL, LP and B-CLL cells. However, LP subtype has a worse clinical prognosis which justifies its recognition from SL.
108 CORRELATIONS BETWEEN CLINICAL, BIOLOGICAL, MORPHOLOGICAL AND FLOW CYTOMETRY IMMUNOPHENOTYPING CRITERIA IN NEOPLASTIC CHRONIC LYMPHOID DISEASES.

M. Chouraqui (1), E. Delbeke (1), C. Chagnon (2), F. Mazzerbo (2), R. Quilichini (2), P. Chaffanjon (2), D. Baume (2) and PJM Philip (3)

(1) Lab. Biologie (2) Serv. Hématologie - CHITLS - 83000 Toulon (3) UEFCT- CHU Pasteur - Nice - France.

Clinico-biological as well as morphological and flow cytometry immunophenotypic analysis were simultaneously investigated in 120 neoplastic lymphoproliferative disorders including chronic lymphoid leukemia (CLL), Hairy Cell Leukemia (HCL), Prolymphocytic Leukemia (PLL) and non Hodgkinien Lymphoma (NHL). The aim of this study was to know wether $1 /$ correlations could be found between these clinical and biological criteria; $2 /$ some of these criteria could be used for following the evolution of the disease as new prognostic factors. Flow cytometry was performed by using a Coulter Profile II cytometer and MoAbs belonging to the following $\mathrm{CD}$ : $\mathrm{CD} 2, \mathrm{CD} 3, \mathrm{CD} 4, \mathrm{CD} 5, \mathrm{CD} 8$, CD10, CD14, CD16, CD19, CD20, CD22, CD23, CD25, CD38, CD56; 2/ MoAbs from the FMC7, BL7, BB4 clones, HLA-Class II and $3 /$ antibodies against the human kappa/lambda light chains. Chronic lymphoid leukemia were characterized from LNH by using the Binet's classification and the use of the conventional CD referred to the B-CLL, PLL and HCL ones. Our results showed in this preliminary retrospective and prospective study, the immunolological and morphological incidence of these parameters within the diagnosis citeria and for some patients, their impact as well as their potential prognostic factor for monitoring these neoplastic chronic lymphoid diseases.
APPLICATION OF THE SCORING SYSTEM TO CHRONIC B CELL LEUKEMIAS: A BELGIAN MULTICENTRIC STUDY

V. Deneys, O. Pradier, A.M. Mazzon, M. Bernier, T. Braechevelt, B. Cantinieaux, B. Chatelain, J.L. D'hautcourt, B. Husson, J.L. Rummens, N. Schaaf-Lafontaine, V. Thiry, P. Vandekerkhove UCL St Luc, Immunohématologie, 30 Clos Chapelle aux Champs, 1200 Bruxelles, Belgique

Matutes et al (Leukemia,8:1640,1994) have shown that some markers in chronic lymphocytic leukemia (CLL) (CD5, CD23, FMC7, expression of Smig and CD22) improved the diagnostic and classification of the B Lymphoproliferative disease. A preliminary study was first performed to establish the feasibility of this scoring system in different centres. Blood samples of 13 patients were investigated in 9 Belgian laboratories in order to compare the scores. Discrepancies were due to a "monoclonal antibody's effect" and a "centre's effect" (mostly concerning the interpretation of fluorescence intensity). The second part of the study, using the same MAbs in all centres $(\mathrm{n}=11)$ and after establishing rules for the fluorescence intensity interpretation (comparison with the intensity obtained in normal cells) improved greatly the results: $90 \%$ concordance (6 samples) and no more "centre's effect". Conclusion: (1) scoring system is an interesting immunological approach to improve diagnosis and classification of $\mathrm{B}$ lymphoproliferative disorders, (2) a good standardization of monoclonal antibodies and establishment of reference values for each centre are necessary to compare the results. 


\title{
IMMUNOLOGIE ET HÉMATOLOGIE
}

\author{
CLINIQUES (troisième partie)
}

Présidents de séance : F. Lacombe, O. Lees

Résumés 110 à 134

Présentations orales : résumés 110 à 115 
110 ECTOPEPTIDASES IN THE IMMUNOPHENOTYPING OF LEUKEMIAS

M.C. Béné, G.C. Faure and the GEIL

Secrétariat du GEIL, Laboratoire d'Immunologie, Faculté de Médecine de Nancy, B.P. 184, 54500 Vandoeuvre-les-Nancy, France

Flow cytometry has become a major tool for the identification of the immunophenotype of acute leukemias (AL), and consensual classifications are emerging, usually taking into account about 35 surface, cytoplasmic or nuclear markers. These classifications rely on what is known of the maturation of lymphoid cells or the immunophenotypic patterns of myeloid lineages. The nomenclature of clusters of differentiation (CD) has greatly contributed to simplify the use of a common language, especially needed in this complex domain. The suspected functions of the molecules identified however are seldom considered. This presentation will focus on a functional family interestingly involved in the identification of the three major lineages investigated for AL immunophenotyping. Indeed CD10, CD13 and CD26 all display ectopeptidase activities that could be related to the leukemogenic process. The expression of CD10, still considered a major B-lineage marker, is a highly discriminating factor, owing to the poor prognosis of CD10- B-I ALL. CD13, both intracytoplasmically and on the blast surface, is one of the most lineage-specific markers for the identification of AMLs. The expression of CD26, although not involved in AL subclassifications, could segregate specific T-ALL subsets. These three molecules will be described for their functional properties and through their involvement as diagnostic and prognostic tools for AL.

112 DETECTION OF INTRACYTOPLASMIC CD3 AND TCR BY FLOW CYTOMETRY IN THE DIAGNOSIS OF T ALL C. Mesguiche-Jabès, P. Le Tutour, E. Macintyre, F. Valensi Laboratoire d'Hématologie, Hôpital Necker, 75015 Paris, France

The expression of cytoplasmic antigens cCD3 (CD3 FITC Coulter, HIT3A), cTCRb (bF1 Bioadvance), cTCRd (Pangd Bioadvance), and surface antigens mbCD3 (Leu4 Becton Dickinson, SK3), mbTCRb (Panab Immunotech, BMA031) and mbTCRd (Pangd Bioadvance), were analysed by flow cytometry (Epics Profile II Coulter) in 14 cases of T ALL. The Seralab cell Permeabilisation Kit (Harlan) was used to allow detection of intracellular molecules. Results: cCD3 was detected in all T ALL (mbCD3+ or cCD3+ by immunoperoxydase), but was not detectable in B ALL and in myeloid leukemias. We classified the cases into four groups on the basis of the expression of mbCD3, mbTCRb, mbTCRd and the expression of cytoplasmic cTCRb:

- Group 1: cTCRb-, mbCD3-, mbTCRb-: four cases.

- Group 2: cTCRb+, mbCD3-, mbTCRb-: four cases.

- Group 3: cTCRb+, mbCD3+, mbTCRb+: four cases.

- Group 4: cTCRd-, mbCD3+, mbTCRd+: two cases.

Each subtype corresponds to different stages of $\mathrm{T}$ cell maturation, however no cTCR $d+$ cases were detected.

Conclusion: 1- This method is adapted to routine use. 2- This classification correlates well with the proposals of EGIL for immunological classification of AL: Group 1 corresponds to TII; Group 2 to TIII; Group 3 to TIVa; Group 4 to TIVb.
111 IMMUNOPHENOTYPIC CHARACTERISTICS OF 432 CYTOGENETICALLY DEFINED ACUTE MYELOID LEUKEMIA (AML) : A PROSPECTIVE MULTICENTRIC STUDY OF THE GEIL

R.O. Casasnovas (1), L. Campos (2), F. Mugneret (1), C. Sartiaux (3), C. Charrin (4), M. Bernier (5), M. Favre (6) R. Garand (7), I. Chaumarel (8), M.C. Bene (9), G. Faure (9), M. Maynadié (1), E. Solary (1) on behalf the GEIL (1) CHU Dijon, France - (2) CHU St Etienne, France - (3) CTS Lille, France - (4) CHU Lyon, France - (5) Institut Bordet Bruxelles, Belgique - (6) CTS Grenoble, France (7) CHU Nantes, France - (8) CHU Reims, France - (9) CHU Nancy, France

This study analyzed the relationships between immunophenotypic and cytogenetic features of blast cells in 432 AML at presentation. The immunophenotype was studied using a panel of 24 monoclonal antibodies with a $20 \%$ cut-off value for positivity. 232 AML ( $54 \%$ ) had at least one acquired clonal chromosome abnormality (Abn) Multivariate analysis identified CD34 and CD9 expression as independently predictive of the presence of at least one cytogenetic Abn ( $p<10^{-4}$ and $p<0.03$ respectively). CD9 was not related to any specific cytogenetic Abn. Conversely, recurrent cytogenetic Abn were classified into three groups according to the incidence of CD34 expression and related to characteristic immunophenotypic patterns. When combined with $\mathrm{FAB}$ and cytogenetic criteria immunophenotypic data identified new AML entities: M0 or M1 $\mathrm{t}(9 ; 22)$ or del(11)(q23) / B lineage antigen positivity ; $\mathrm{M} 2 / \mathrm{t}(8 ; 21)$ / CD13-; M4 / inv(16) / CD13+, CD34+, CD36+; M4 or M5/del(11)(q23) or $\mathrm{t}(9 ; 11) /$ lack of $\mathrm{B}$ lineage antigen.

SIMILARITY OF EXPRESSION OF CD28, CD38 AND HLADR ANTIGENS ON gd AND ab-RECEPTOR T CELLS IN HIV INFECTION

F. Jouen-Beades, D. Gilbert, E. Paris, F. Tron UPRES EAD Laboratoire d'Immunologie, CHU Charles-Nicolle, 76031 Rouen, France

During HIV infection, phenotypic analysis of CD4 and CD8 ab-T cells revealed an increased expression of activation markers CD38 and HLA-DR and a down regulation of the costimulation molecule CD28. The aim of this study is to determine if gd T cells that are predominantly CD4-CD8- exhibit the same alterations.

Subjects and Methods. PBMC from $37 \mathrm{HIV}+$ infected patients (32 males, 5 females) (17 stage II, 20 stage IV) and $24 \mathrm{HIV}$ - non infected controls (12 healthy male volonteers, 8 injecting drug users, 6 homosexual men) were studied by double or three colorflow analysis with CD3, TCR-g/d-1, CD28, CD38, DR, CD4, CD8, CD14 and CD45.

Results and Conclusion. During HIV infection: (i) the percentage of $\mathrm{gd} \mathrm{T}$ cells that express CD28 antigen was decreased; (ii) an increased expression of CD38 and/or HLA-DR molecules was found on gd T cells and ab T cells; (iii) these modifications were found on CD8+ and CD8- gd-T cells. Thus unique changes in the different T-cells subsets might be induced by substained activation of the immune system or by the rapid turnover of $\mathrm{T}$ cells and argue for a global dysregulation of T lymphocytes during HIV infection. 
114 ab AND gd TCR REPERTOIRE AFTER AUTOLOGOUS VERSUS ALLOGENEIC PERIPHERAL BLOOD STEM CELL TRANSPLANTATION (PBSCT)

C. Arnoulet, A. Necker (1), F. Romagné (1), M.J. Mozziconacci, D. Olive, C. Faucher, C. Chabannon, S. Oziel, D. Blaise, D. Sainty Dépt. Hématologie, Institut Paoli Calmettes, Marseille, France

(1) Société Immunotech, Marseille, France

The reconstitution of $\mathrm{ab}$ and gd TCR repertoire after autologous (19 patients) versus allogeneic (17 patients) PBSCT was studied using two-color flow cytometry ( $\triangle$ TCR FITC / CD3 PE) in graft, in blood before transplantation, at D15, 30, 60 and 120 posttransplant.

- gd cells, essentially g2 d9, were significantly higher in the allogeneic PBSCT group than in the autologous one at D30, 60, 120 post-transplant.

- $a b$ cells reemerged early in the two groups with complete diversity; all subsets (Vb 2, 3, 5.1, 5.2, 5.3, 8, 13.2, 13.6,14, 16, 17 , $18,20,21.3,22$ ) were already represented at D15 post-transplant. The pattern of reconstitution of 6 allogeneic PBSCT patients considering the genetic $\mathrm{Vb} 3$ and $\mathrm{Vb} 20$ polymorphism was of particular interest. In all cases, we found the donor pattern of $\mathrm{Vb} 3$ and Vb20 expression early at D15 post-transplant. However, 2 patients exhibited a change in Vb20 expression at D60 and D120 corresponding respectively to a relapse and to a probably partial chimerism.

Despite of the immunodeficiency, there is no "hole" in the T repertoire during the early post-transplant period. Study of $\mathrm{Vb} 3$ and $\mathrm{Vb} 20$ expression could provide, in some cases, information about the donor or recipient $\mathrm{T}$ reconstitution.

16 THREE-COLOUR IMMUNOLOGICAL STAINING OF PROGENITOR CELL SURFACE ANTIGENS: A NEW WAY FOR INVESTIGATED IN FLOW CYTOMETRY THE DISTRIBUTION OF THE CD34+ HEMATOPOIETIC PROGENITOR CELL SUB-POPULATIONS

P.J.M. Philip

Unité d'Exploration Fonctionnelle Cellulaire et Tissulaire (UEFCT) Laboratoire Central d'Hématologie, CHU, Nice, France

The discovery of CD34 as an hemopoietic cell surface antigen has transformed and accelerated studies into developmental hematopoiesis. The CD34bright population contains the majority of the immature hematopoietic progenitor cells, whereas the CD34dim population contain more lineage-commited progenitors, as assayed in vitro. CD34 is currently used to purify normal human stem/progenitor cells for hematopoietic rescue after high-dose myeloablative therapy in patients. Moreover, CD34+ selection may be used to concentrate stem cells for gene therapy or expansion of clinical transplant grafts. The aim of this study was to investigate by using three different three-colour immunological staining, the distribution of the different CD34 progenitor cell subpopulations observed between acute leukemia as well as apheresis. The 3 threecolour immunological staining combining CD34 vs HLA-class II vs CD13, CD38, or CD117, were analyzed with the Coulter system II - MCL - XL sofware, giving automatically 24 subpopulations for any sample. We here report this new flow cytometry concept in acute leukemia as in apheresis in order to characterize the distribution of the immature progenitor cell subpopulations as well as their fundamental and clinical incidences for the futur concentrate stem cells or the expansion of clinical transplant grafts.
115 FLOW CYTOMETRY AN EFFICIENT TOOL TO STUDY THROMBOCYTOPENIAS

D. Bakour, M. Rohr, P. Chretien

Laboratoire d'Hématologie et d'Immunologie, CHI Créteil, France

Idiopathic Thrombocytopenic Purpura (ITP) is characterized by an increased platelet surface-bound immunoglobulin level.

The aim of this study was to develop a technic specific, sensitive, simple and suitable for pediatric samples for the detection and the quantification of anti-platelet antidodies.

The use of a calibration system composed of microbeads chosen for their increasing ability to bind revelation antidody allowed quantitative results expressed in surface-bound immunoglobulin level. In order to determine the cut off value, we tested 40 samples from blood donors. The study of samples from acute and chronic ITP as well as from thrombocytopenic pregnant women revealed an increased platelet surface-bound IgG and sometimes IgM levels, in acute ITP but not in chronic disorder neither than in thrombocytopenic pregnant women. If the quantitative determination of platelet surface bound immunoglobulins is an efficient tool to explore an acute ITP, this assay seem insufficient for chronic disorders. Using flow cytometry we decided to develop the determination of anti-platelet antibodies in sera, the quantitation of reticulated platelets as well as the detection of platelet-derived microvesicles to complete thrombocytopenias assessment
117 COMPARISON OF 3 MONOCLONAL ANTIBODIES FOR HLA-B27 TESTING BY FLOW CYTOMETRY

G. Bonnaud, C. Jayat-Vignolles, M. Drouet

Laboratoire d'Immunologie, CHRU Dupuytren et Service Commun de Cytométrie, Faculté des Sciences, Limoges, France

HLA-B27 is strongly associated with ankylosing spondylitis; defining the presence or the absence of this allele can be a help in diagnosis. In this study we evaluated the application of 3 HLA-B27 specific monoclonal antibodies (mAb), using direct immunofluorescent staining on whole blood and flow cytometry analysis for the assignment of this allele, on 395 blood samples taken at random. All samples were typed as HLA-B27 positive or negative by PCR-SSP, which served of reference technic allowing determination of the cut offs of mean fluorescence for HLA-B27 + and HLA-B27 -

$\begin{array}{lcccc} & \begin{array}{c}\text { mean fluoresc } \\ \text { B27+ (min. maxi) }\end{array} & \begin{array}{c}\text { mean fluores } \\ \text { B27- (min. maxi) }\end{array} & \text { grey zone } & \begin{array}{c}\text { \% tests in } \\ \text { grey zone }\end{array} \\ & & & & \\ \text { ABC m3 } & 7.30(2.20 \text { to } 27.5) & 0.48(0.13 \text { to } 9.4) & 2.1-9.4 & 13.4 \\ \text { FD 705 } & 3.2(0.42 \text { to } 10.22) & 0.38(0.22 \text { to } 0.6) & 0.4-0.7 & 35 \\ \text { GS145.2 } & 2.20(1.3 \text { to } 6.7) & 0.25(0.1 \text { to } 1.4) & 0.3-1.5 & 25\end{array}$

The grey zone corresponds to mean fluorescence value with a risk of false positive; all samples in this zone have to be controlled by PCR-SSP. The differences of mean fluorescence of HLA-B27+ did not correlate with clinical status, lymphocytes counts or HLA-B27 subtypes determined by PCR-SSO. Two parameters were relevant: the existence of crossreaction (HLA-B7) and analysis the mean fluorescence on $\mathrm{T}$ cells rather than all lymphocytes population. 
118 REDOX STATUS OF MONOCYTES IN HIV-INFECTED PATIENTS

C. Elbim, S. Pillet, A. Preira, N. Israël, M.A. Gougerot-Pocidalo Laboratoire d'Immunologie-Hématologie, CHU X. Bichat, Paris

Several reports implicate oxidative stress in the regulation of HIV expression and in the progression of HIV infection to AIDS. Production of reactive oxygen species by monocytic cells, which serve as major reservoirs of HIV, may participate in viral replication and in lymphocyte $\mathrm{T}$ cell death in HIV-infected patients. We used flow-cytometry to study the redox status of whole-blood monocytes in $40 \mathrm{HIV}$-infected patients at different stages of the disease by evaluating $\mathrm{H}_{2} \mathrm{O}_{2}$ production by means of $\mathrm{DCFH}$ oxidation, apoptosis using a method derived from TUNEL assay and intracellular expression of the antioxidante molecules $\mathrm{Bcl} 2$ and thioredoxine. We found that unstimulated monocytes from HIVinfected patients express an increased $\mathrm{H}_{2} \mathrm{O}_{2}$ production which was correlated with the clinical stage. This impairment was associated with a decreased L-selectin expression, an increased CD11b/CD18 adhesion molecule expression and an increased actin polymerization, demonstrating that circulating monocytes were activated in vivo in HIV-infected patients. Moreover, we reported an increased apoptosis in all stages of patients and a decreased intracellular expression of $\mathrm{Bcl} 2$ and thioredoxin in asymptomatic and ARC patients. The dysregulation of expression of these molecules on patients monocytes may be involved at least in part in the increased $\mathrm{H}_{2} \mathrm{O}_{2}$ production by monocytes and may participate to the increase susceptibility of mononuclear cells to apoptosis, consequently contributing to AIDS pathogenesis.

\section{P24 AND Ki67 EXPRESSION ON PBMCs IN HIV PATIENTS I. Antonioli, G. Praz, E.Dayer} ICHV, Sion, Suisse

In this study, we analysed the proliferation (Ki67) of the CD4 lymphocytes, the P24 Ag expression, the CD4 cell count and the viremia of HIV patients. Plasma and peripheral blood were collected in $20 \mathrm{HIV}$ patients: 4 asymptomatics (CDC stage A1) and 16 patients at the beginning of a bitherapy antinucleoside/proteaseinhibitor (CDC stage A2-B-C). Five individuals negative for the HIV test served as the negative controls.

CD4 lymphocytes, purified on magnetic separation column (MiniMacs, Mitenyi Biotec $\mathrm{GmbH}$ ), were stained for intracytoplasmic P24 Ag (Coulter) and Ki67 (Dako) using Permeafix (Ortho). All test were performed using dual colour flow cytometry. The viremia was done with a commercial kit (HIV monitor, Roche)

Base line evaluation: Comparing the stage A1 with stages A2-B-C, we found a significant increase of 1$)$ the viremia $(p=0.047), 2)$ the percentage of the CD4 lymphocytes expressing the P24 $(p=0.05)$ or the Ki67 $(p=0.047)$. There was no significant increase between the stage A1 and the controls. Follow up at one month: A decrease of the CD4+ P24+ lymphocytes in absolute number correlate with the decrease in viremia $(r=0.61, p=0.042)$. The increase of the absolute count of CD4 correlate with the increase of CD4 + Ki67 + lymphocytes $(\mathrm{r}=0.58, \mathrm{p}=0.02)$.
119 LYMPHOCYTES BEARING THE gd T CELL RECEPTOR IN HUMAN LISTERIOSIS

E. Paris, F. Jouen Beades, F. Tron

Laboratoire d'immunopathologie clinique et expérimentale, UPRES EAD (CRI 950602), CHU Charles Nicolle, 76031 Rouen Cedex, France

Several studies have provided evidences for a role of $\mathrm{gd} \mathrm{T}$ cells in murine listeriosis. The aim of this study is to determine if human gd $\mathrm{T}$ cells are involved in immunity against this pathogenic intracellular bacteria. In vivo, a phenotypic analysis by two or three colour cytofluorometry in peripheral blood of 7 patients with Listeria monocytogenes infection revealed an increased percentage of circulating CD3 gd $+\mathrm{T}$ cells that mainly expressed the $\mathrm{Vg} 9 / \mathrm{V} d 2$ gene products. gd $\mathrm{T}$ cells were activated (CD38, HLA $\mathrm{DR}$ ) and displayed a memory phenotype (CD45RO high) Interestingly, gd T cells were still expanded 4-6 weeks after onset of infection, and in 1 patient, a long tem analysis revealed persistence of increased circulating gd $\mathrm{T}$ cells, though less markedly, over 6 months. In vitro, when PBMC from healthy individuals were cultured with $5.10 \% / \mathrm{ml}$ heat killed listeria, (i) gd T cells were early activated (CD25, CD38, HLA DR), most of them were $\mathrm{Vg} 9 / \mathrm{V} d 2+$; (ii) depletion of gd $\mathrm{T}$ cells before culture induced an inhibition of the cell proliferative response to Listeria. Taken together, our in vivo and in vitro results suggest that human gd $\mathrm{T}$ cells are involved in immunity against Listeria monocytogenes.

1 SURFACE ANTIGENS DISTRIBUTION ON LEUKEMIC LYMPHOBLASTS STUDIED BY FLOW CYTOMETRY

A.M. Dumitrescu, A.I. Motoiu, A.D. Moiceanu, D. Colita Immunology Laboratory, Fundeni Hospital, Bucharest, Romania

The surface antigen profile of leukemic cells of 45 untreated patients ( 32 children, 13 adults) was determined on fresh cells isolated from the bone marrow or peripheral blood using standard two-colours flow cytometric analysis with a large panel of monoclonal antibodies. Samples were analysed with a Becton Dickinson FACScan flow cytometer and CELLQuest Software.

39 of patients were assigned to the B lineage and 6 cases to the $T$ lineage. All cases of B lineage expressed CD19 and HLA-DR. CD10 was present in most cases (34). 26 cases were CD22+, 11 $\mathrm{CD} 20+$. Among the B-cell cases, 7 coexpressed one myeloid marker: CD 33 in 2 cases, CD13 in 2 cases and CD 15 in 3 cases. All cases of T lineage expressed CD5 antigen. 4 cases were CD7+, 2 $\mathrm{CD} 1 \mathrm{a}+, 2$ - $\mathrm{CD} 3+$. CD4 and CD8 were coexpressed in one case; 2 cases were CD4+, 2 cases CD8+, one case was CD4-CD8-. The haemopoietic progenitor cell marker, CD34, was detected in 19 cases with B lymphoid markers being absent in $\mathrm{T}$ - lineage cases. The leukocyte common antigen, CD45, was present in all cases of $\mathrm{T}$ - lineage and only in 17 cases of B - lineage.

Regarding to age of the patients, the $\mathrm{T}$ group is more frequent in the adults. The pre-B ALL CD10+ group was most frequently observed in children. Concerning the phenotypic abnormalities, we found no difference between children and adults. 
122 HEPATOSPLENIC T GAMMA/DELTA LYMPHOMA: A CLINICOPATHOLOGIC ENTITY

J.F. Lesesve, A. François, C. Fruchart, B. Lenormand, F. Tron, C. Bastard, Ch. Duval, M. Monconduit, H. Tilly

Hématologie Clinique et Biologique, Immunologie, AnatomoPathologie, Cytogénétique, CHU, CHB, CRTS, Rouen, France

Peripheral T-cell lymphoma is characterized by hepatosplenic presentation and $\mathrm{g} / \mathrm{d}$ T-cell receptor phenotype on malignant cells. Consistent cytogenetic features (loss of chromosome 7p, trisomy 8) have been recently mentionned.

Two patients with proliferation of $\mathrm{T} g / \mathrm{d}$ cells are reported. One had received prior chemotherapy for Hodgkin's disease. Both were young men who presented with severe fatigue and fever. Marked hepato-splenomegaly was found. Biological findings showed normal leucocyte count, thrombocytopenia, and abnormal liver function tests. Histologic investigations demonstrated interstitial neoplastic proliferation of T-cells involving the bone marrow, spleen, liver, and lymph nodes. Phenotype was CD3+, CD4-, CD8+/-. Isochromosome $7 \mathrm{q}$ was observed in both patients. Rearrangement of the $\mathrm{g}$ locus was demonstrated by Southern blotting. Both patients were treated with intensive chemotherapy, but the disease remained evolutive. Prognostic was severe with death 5 and 8 months after diagnosis. These two patients showed characteristic clinical and biological presentation of $\mathrm{g} / \mathrm{d}$ lymphoma. As the rule, clinical outcome was very poor. These features emphasized on the fact that $\mathrm{g} / \mathrm{d}$ lymphoma is a rare but distinct entity of peripheral T-cell lymphoma.

GRANULOCYTE COLONY-STIMULATING FACTOR (GCSF) RECEPTOR EXPRESSION IN PEDIATRIC ACUTE LYMPHOBLASTIC LEUKEMIAS (ALL)

P. Le Moine, G. Renier, A. Chevailler, I. Dobo, L. Perroux-Goumy, D. Hurez

Laboratoire d'Immunologie, CHU, 49033 Angers, France

Since G-CSF has been introduced into several ALL treatment protocols, we investigated the expression of its receptor on blast cells. After purification, recombinant glycosylated G-CSF was biotinylated using a biotinyl N-hydroxysuccinimide ester. This bG-CSF retained its ability to modify phagocytosis of neutrophils as demonstrated by flow cytometry, and to stimulate granulocyte colony formation by normal bone marrow cells in collagen. Biotinylated-G-CSF binding to cells was detected by flow cytometry using streptavidin-phycoerythrin. Granulocytes from healthy donors were used as control. Ten pediatric ALL, with no myeloid surface antigen, were tested. Blast cells were characterized by either CD7 or CD10 surface antigen. One ALL clearly expressed the G-CSF receptor: $41 \%$ positive events remained after substraction of non specific binding, and 15-fold excess of unlabeled G-CSF led to $34 \%$ decrease in mean fluorescence intensity. Four patients were negative (no competition). Five samples presented with 9 to $12 \%$ decrease by competition, and 8 to $15 \%$ specific positive events. Until investigation of the functional significance of G-CSF receptor expression on blast cells is completed, clinical use of G-CSF should be avoided in pediatric ALL
123 FLOW CYTOMETRIC MEASUREMENT OF THE RETICULATED PLATELET INDEX IS NOT PREDICTIVE OF ACCELERATED PLATELET DESTRUCTION

J. Feuillard, Z. Azgui, M. Raphael, G. Le Roux

Service d'Hématologie Biologique, Hôpital Avicenne, Bobigny, France

Increased levels of free thrombopoietin is directly due to the decrease of platelet levels, and is responsible for an increase of both megakaryopoïesis and reticulated platelet index (RPI), which is used for diagnosis of thrombocytopenia with accelerated destruction.

The aim of this study was to optimise the determination of the RPI by flow cytometry using thiazole orange, then to compare RPIs of both thrombocytopenia with accelerated destruction or with bone marrow infiltration, i.e with a deficient production and functionally normal megakaryopoiesis. Results are given in the following table:

\begin{tabular}{|l|c|c|c|c|}
\hline & $\begin{array}{c}\text { Mean } \\
\text { of RPI }\end{array}$ & $\begin{array}{c}\text { Standard } \\
\text { deviation }\end{array}$ & Range & $\begin{array}{c}\text { t-test/ } \\
\text { control }\end{array}$ \\
\hline Control (n=61) & $7.9 \%$ & $4.6 \%$ & $1 \%-18 \%$ & $\mathrm{X}$ \\
\hline $\begin{array}{l}\text { Bone marrow infiltration } \\
(\mathbf{n}=\mathbf{1 4})\end{array}$ & $32 \%$ & $15 \%$ & $18 \%-65 \%$ & $<10^{-4}$ \\
\hline $\begin{array}{l}\text { Accelerated destruction } \\
(\mathbf{n}=\mathbf{1 3})\end{array}$ & $31 \%$ & $15 \%$ & $19 \%-66 \%$ & $<10^{-4}$ \\
\hline
\end{tabular}

These results show that the RPI is increased in thrombocytopenia due to both accelerated destruction or dramatic decrease of functionally normal bone marrow. Therefore, RPI is not predictive of the thrombocytopenia with accelerated destruction of platelets.

\section{EXPRESSION OF C-KIT IN A RARE CASE OF ACUTE} BASOPHILIC LEUKEMIA

E. Kuhlein, N. Dastugue, C. Demur, E. Duchayne, A. Blancher Laboratoire d'Immunologie, CHU Purpan, Toulouse, France

In this study, we investigated changes in the expression of c-Kit in a case of acute leukemia presenting clinical features of hyperhistaminemia syndrome, morphologic signs of basophilic differentiation on $20 \%$ of blasts by light and electron microscopy, and a translocation $\mathrm{t}(\mathrm{X} ; 6)(\mathrm{p} 11, \mathrm{q} 23)$ as sole chromosomal abnormality.

Blasts from blood and bone marrow were analyzed, by flow cytometry in direct immunofluorescence with a large panel of monoclonal antibodies. Freshly purified blasts represented a unique population expressing only low levels of c-Kit (CD117). After 7 days culture with IL3, CSF and GM-CSF, two phenotypically and morphologically distinct populations could be observed: a first large immature blast population (1), expressed a higher level of c-Kit without any other markers while a second more granular blastic population (2) expressed new markers, CD34, CD13 and CDw65 associated with the same low level of c-Kit as in the native blasts.

The morphologic heterogeneity of blasts within this case suggests that the maturation process is not blocked even though the blast population derives from a single precursor, identified by the $t(X$; 6) (p11, q23). Moreover, the phenotype of immature blasts (c-Kit High, CD34-) recently described by others as possible erythroblasts or mast cell precursors could also contained immature basophilic precursors, as observed in our study. 
126 CD38 + CD8 + T LYMPHOCYTE COUNTS IN LATE HIV INFECTION DURING A TWO YEARS FOLLOW UP A. Schandelong

Laboratoire d'Hématologie, CHG du Havre, France

Objective: Double positive CD8 CD38 may account for activated lymphocytes and plasmocytes and quantified at a very low level in normal blood except in case of viral infection and hypersensitivity to drug. These subsets of lymphocytes disappear in a few days or week while remain stable or increase in HIV patients. To assess the correlation with CD3, CD8, CD16, CD56, CD19, and CD38 alone we measured those categories of cells in a study population, look at serial profiles over more than a year and compare the average of results of each patient to the normal results.

Moreover this could be an evaluation of our laboratory practice by noting the regression curves of these subsets to total lymphocyte counts.

Patients: Out of 120 out and hospitalized patients referred by pneumology units over a period of 27 months, only 38 were sampled more than three times and taken for the survey: 5 women for 33 men, the average of age is 35.2 years ( 16-70) and the CD4 count at the start is $278,4 / \mathrm{mm} 3$ (2- 1037), the period 18 months (4-30).

Results: A strong correlation is found between CD38+ CD8+ population and $\mathrm{CD} 8+, \mathrm{CD} 38+, \mathrm{CD} 16+$ in single marquage, a less acute correlation with CD56 and a poor one with CD4 and CD19. The absolute expression of the results is more representative than the pourcentage because of some cases of lowering of $\mathrm{CD} 8$
127 AUTOLOGOUS STEM CELL TRANSPLANTATION: FLOW CYTOMETRICAL QUANTITATION OF CIRCULATING CD34+ CELLS

P. Moskovtchenko (1), S. Pignon (1), M. Maynadié (1), F. Girodon (1), D. Caillot (2), O. Casanovas (2), M. Domy (3), E. Racadot (4) C. Coffe (3), P.M. Carli (1)

(1) Laboratoire d'Hématologie - (2) Service d'Hématologie Clinique - (3) ETS - CHU, 21000 Dijon - (4) Laboratoire d'Immunologie, CRTS, 25000 Besançon, France

Flow cytometrical determination of $\mathrm{CD} 34+$ cells was realised in duplicate with CRTS of Besançon on 88 apheresis products and 130 peripheral blood samples during 6 months.

Using the same HPCA-2-PE MoAb (Becton Dickinson, France), CD34 quantitation was statistically correlated between the 2 centers $(r=0.97, n=151, p<0.01)$. In our center, CD34 determination was realised with 2 MoAbs, HPCA-2-PE and 581-PE (Immunotech, France) with excellent correlation $(\mathrm{r}=0.99, \mathrm{n}=207$, $\mathrm{p}<0.01)$

No statistical correlation was found with leucocytosis nor with mononuclear cells and $\mathrm{CD} 34$ apheresis product $(\mathrm{r}=0.58$ and 0.31 ; $\mathrm{n}=82$ ). However, we find a significant threshold of 30 CD $34+$ cell $/ \mu \mathrm{l}$ in peripheral blood sample predictive of an apheresis $1.10^{6}$ CD34/kg $(\mathrm{p}<0.001 ; \mathrm{n}=87)$.

Our datas show excellent CD34 quantitation correlation between the 2 centers, and between HPCA-2-PE and 581-PE antibodies. The peripheral blood threshold of $30 \mathrm{CD} 34 / \mu \mathrm{l}$ should be very helpful to guide apheresis procedure, instead of leucocyte number.
28 AGE-RELATED DECREASE IN CD69 EXPRESSION BY MITOGEN-ACTIVATED T CELLS

D. Brohée, B. Kennes, M. Vanhaeverbeek, P. Nève

Laboratoire de médecine expérimentale (ULB), CHU Vésale, 6110 Montigny-le-Tilleul, Belgium

An age-wise decrease in T-cell response to mitogens or antigens is well known. Classically, mitogenesis is evaluated by tritiated thymidine (Tdr) incorporation into DNA. Flow cytometry and fluorescent monoclonal antibodies provide unique tools for identifying functional lymphocyte subsets and replacing radioactive methods. Expression of CD69 occurs early in T-cell activation but does not reflect some of the late signals for proliferation such as IL2R expression. CD69 expression by CD3+ $\mathrm{T}$ cells after 3 -days culture is now routinely used in our laboratory for evaluation of possible drug allergy. As a control test, T cells are also stimulated by $1 \mu \mathrm{g} / \mathrm{ml}$ of phytohemagglutinin-A.T-cell response is evaluated by the percentage of FITC/Leu23-positive T cells (PE/Leu4+) measured in a FACScan flow cytometer (BDIS). We have reviewed our first 100 patients ( 7 to 89 y-old). A highly significant decrease in CD69 expression with age has been found. The regression equation is $\mathrm{y} \%=97-0.3$ age (Pearson $\mathrm{r}=-0.54, \mathrm{p}$ $<0.001)$. No sex effect exists. Although Tdr incorporation and CD69 expression involve different events in T-mitogenesis, they are similarly affected by age. The rapid kinetics and transient expression of CD69 do not preclude its use in 3-days cultures. About $100 \%$ of PHA-stimulated T cells from our youngest patients are CD69-positive at $72 \mathrm{~h}$.
EFFECT OF AGE ON LYMPHOCYTE CELL SIZE IN

\section{HUMANS}

D. Brohée, P. Nève

Laboratoire de médecine expérimentale (ULB), CHU Vésale, 6110

Montigny-le-Tilleul, Belgium

An age-wise increase in cell size has been well documented in various cell lines, in vitro or in vivo. The age-effect on human lymphocytes is more controversial. In 2 different experimental settings, we could demonstrate an increase in cell size but restricted to some subsets. In the first group, there were 17 subjects aged 21 to 76 , in the second group, 29 aged 1 to 86 . Whole blood samples were analysed. Cell size was evaluated by forward light scatter (mean channel) after RBC lysis and cell fixation (FACS Lysing solution TM) in a FACScan flow cytometer. The subsets were determined using different FITC/PE fluorescent couples of monoclonal antibodies (BDIS).

$\mathrm{B}$ cells, CD19+, CD20+CD5- (B2) or CD20+CD5+ (B1), were unaffected by age. A trend for cell enlargement existed with $\mathrm{CD} 3+$ $\mathrm{T}$ cells (regression coefficient $\mathrm{b}=0.12, \mathrm{p}=0.08$ ). CD5+ T cells increased in size $(b=0.24, p<0.01)$ but not the large CD5+CD20+ T cells. The size of the CD4+ and the dull CD8+ lymphocytes was constant, while the bright CD8+ lymphocytes increased in size with advancing age $(b=0.23, p=0.001)$. Although these observations are in good keeping with other ones in gerontology, the mechanisms of cell swelling remain to be determined, as related for example to changes in cell membrane permeability, cytoplasmic accumulation of osmolytes, or distension of cell organelles. 
130 EXPRESSION OF CD34, CD2 AND CD13 ANTIGENS IN ACUTE PROMYELOCYTIC LEUKEMIAS : CORRELATION WITH HYPERLEUCOCYTOSIS

F. Zassadowski, M.L. Menot, N. Balitrand, I. Gouin, C. Chomienne et les protocoles APLs

Laboratoire de Biologie Cellulaire Hématopoïétique, UF 414, EA316 et EP 107 CNRS, Hôpital Saint Louis, Paris, France

Acute promyelocytic leukemias are characterized cytologically (AML3 subtype of the FAB classification), cytogenetically (15;17 translocation), molecularly by the PML-RAR fusion gene (type Bcr1, Bcr2 and Bcr3), and by a cell surface antigen pattern (HLA-Dr -, CD34- and CD33+). Recently the expression of CD2 and CD13 on APL cells were correlated to an increased WBC count at diagnosis. This study was performed on 31 PML-RAR positive cases $(B C R 1=16, B C R 2=11, B C R 3=4) .11$ cases expressed CD2 (med: $40 \%$ pos cells), 8 cases expressed CD13 (med: $50 \%$ pos cells) and 6 cases expressed both CD2 and CD13. 18 patients had a WBC $>5.10^{9} / \mathrm{mm} 3$. No correlation was observed between either the CD2 and CD13 expression and the WBC nor with the different type of PML-RAR transcripts. Interestingly, 16 cases were CD34 pos (5476; med: $48 \%$ ), suggesting that CD34 typing is necessary for bone marrow autografting with purified CD34 cells.
131 DETERMINATION OF FLOW CYTOMETRY CD4 SUBPOPULATIONS IN BRONCHO-ALVEOLAR LAVAGE FLUID FROM PATIENTS WITH SARCOIDOSIS AND VARIOUS PULMONARY DISEASES

F. Baudouin (1), PJM. Philip (2), A. Ducailar (1), A.Goguel(1)

(1) Laboratory of Hemato-Immunology, Hôpital Ambroise Paré, Université de Paris V, (2) UEFCT, Hôpital Pasteur, CHU Nice, France

Sarcoidosis is a chronic non malignant systemic disorder associated with an interstitial lung disease; the etiology being unknown. T cells play an important role in its physiopathology i.e T-helper found increased in Broncho-Alveolar Lavage Fluid (BALF). These T-cells have been demonstrated to express activation antigens such as HLA-DR and CD25. In this study, we analyzed the phenotype of lymphocytes in BALF from various pulmonary diseases i.e sarcoidosis $(n=15)$, tuberculosis $(n=2)$ and interstitial pulmonary fibrosis $(\mathrm{n}=3)$. The $\mathrm{CD} 2, \mathrm{CD} 3, \mathrm{CD} 4, \mathrm{CD} 8$, CD 16CD 56+CD3-, CD4+CD45R0+, CD4+CD29+, and CD4+CD45RA+ T-cell subset mean values were $94 \pm 6 \%$, $91 \pm 6 \%, 74 \pm 12 \%, 16 \pm 11 \%, 3 \pm 2 \%, 69 \pm 14 \%, 71 \pm 13 \%$ and $3.5 \pm 3.2 \%$ respectively. These T-cell subset percentages did not differed significantly between these three pulmonary diseases. Ratios of CD4/CD8, CD4 CD29 / CD4 CD45 RA and CD4 CD45 RO/CD4 CD45RA were $7.8 \pm 6,35.5 \pm 23$ and $35 \pm 24$ respectively. We confirm that the increased CD4+ T-cell subsets were mainly CD4 "memory" cells, expressing CD45RO and CD29 like in the other non sarcoidosis pulmonary lesions. CD4+ T-cells may be thus activated and involved in the pathogenesis of sarcoidosis.
132 EVOLUTION OF PERIPHERAL BLOOD LYMPHOCYTE SUBSETS FOLLOWING BONE MARROW OR BLOOD PROGENITOR CELL TRANSPLANTATION

P. Portalès (1), C. Exbrayat (2), N. Fégueux (2), J.F. Rossi (2), J. Clot (1)

Immunologie (1), Maladies du sang B (2), CHU, 34295 Montpellier Cedex 5, France

We studied lymphocyte peripheral subsets by flow cytometry (FACScan, Becton Dickinson) in 50 patients following allogenic bone marrow transplantation (allo BMT $\mathrm{n}=21$ ), autologous BMT (auto BMT $\mathrm{n}=15$ ) and peripheral blood progenitor cell tranplantation (PBPC $\mathrm{n}=14$ ). Different combinaisons of monoclonal antibodies were used (all from Immunotech, France). Median follow-up was 12 months. We found a profound and durable lymphopenia in allo BMT patients. Lymphocyte count was increased during the first 6 months following PBPC. It remained low and stable in auto BMT. An early and transient T CD3 DR increase after auto BMT and PBPC was shown. A profound T CD4 decrease after allo BMT which was less marked after auto BMT was noticed. CD4 count was increased in PBPC as compared to low pre-graft value and remained > 200/ $\mu$ l. T CD8 increased after auto BMT and PBPC. They remained stable after allo BMT. The CD4/CD8 ratio decreased in the 3 groups but a normal value at 6 months in auto BMT and PBPC was observed. NK cell population after allo BMT increased but were stable and normal in auto BMT and PBPC. A short decrease in B cells with an early recovery and a further increase in the 3 groups was noted. High grade acute GvHD and $\mathrm{ABO}$ mismatch were associated with lymphopenia and durable CD4 and B cell count decrease. In PBPC the hematologic recovery was rapid whereas the $\mathrm{CD} 4$ recovery was delayed.
133 ANTITHYMOCYTE GLOBULINS (ATG) IN RENAL TRA NS PLA NTATION: DAILY (DATG) VS INTERMITTENT (IATG) ADMINISTRATION. A FLOW CYTOMETRY STUDY

A. Djamali (1), P. Portalès (1), G. Mourad (2), J. Clot (1)

Immunologie (1), Néphrologie (2), CHU, 34295 Montpellier Cedex 5, France

Ideal doses of ATG in renal transplantation have not been adequately defined. Two therapeutic regimens were studied: DATG (Thymoglobulines, Mérieux Institute) and IATG, in which ATG were given only when the CD3 T lymphocytes were $>10 / \mathrm{mm}^{3}$. Seventeen cadaveric renal transplant recipients were studied $($ DATG $=10 /$ IATG $=7$ ). The DATG group received a significantly higher total dose of ATG. Peripheral blood T cells were evaluated daily by flow-cytometry (FACScan, Becton Dickinson) using respectively anti-CD2-FITC and anti-CD3-PE monoclonal antibodies (Immunotech, France). ATG-induced T cell depletion was identical in the 2 groups; it began at day 2 posttransplant, reached maximum intensity at day 4 (total lymphocyte $100 \pm 67\left(\right.$ Mean \pm SEM) and $179 \pm 101 / \mathrm{mm}^{3} ;$ CD2 $10 \pm 10$ and $19 \pm 15 / \mathrm{mm}^{3}$, CD $37 \pm 5$ and $10 \pm 8 / \mathrm{mm}^{3}$ in group DATG vs IATG respectively) and persisted until day 12. After stopping ATG, lymphocytes count increased and reached pretreatment values at day 20. The number of rejection episodes as well as infectious complications were not statistically different between the 2 groups. Our study demonstrates that intermittent administration of ATG, based on $\mathrm{T}$ cell depletion is as efficient as daily administration of them, concerning the intensity of $\mathrm{T}$ cells depletion and the number of acute rejection episodes. IATG has the advantage of a reduction in cost of treatment and possibly in the number of infectious complications. 
134 SEQUENTIAL ASSESSMENT OF CELL CYCLE S-PHASE
IN FLOW CYTOMETRY TO MEASURE LYMPHOCYTE ACTIVATION IN VITRO

Ch. Kohler, M.N. Kolopp-Sarda, A. De March-Kennel, M.C. Béné, G.C. Faure

Laboratoire d'Immunologie, Faculté de Médecine, B.P. 184 54505 Vandoeuvre les Nancy Cedex, France

Proper signals of lymphocyte activation induce the proliferation of these cells, both in vivo and in vitro. This multiplication can be induced in vitro by mitogens or specific antigens and is usually measured using methods involving tritiated thymidin. Cellular proliferation can also be analyzed by flow cytometry techniques based on cell cycle analysis through the measurement of DNA content after staining with intercalants or DNA dyes. We applied this method to lymphocytes from 113 individuals to evaluate lymphocyte proliferation after stimulation in vitro by a mitogen (Phytohaemagglutinin, PHA) or a recall antigen (tetanus toxoid), using a kinetic approach with 4 points sequential measurements of the $S$ and $G_{2}$ phases over 6 days of culture. The proportion of cells in $\mathrm{S}$ phase after PHA stimulation was significantly higher than in controls overall and as early as on day 3 of the culture. Activation with a recall antigen induced significantly increasing S-phase cell proportions up to day 6 . These data suggest that flow cytometric assessment of the $\mathrm{S}$ phase could be a useful alternative to isotopic methods measuring lymphocyte reactivity in vitro.
135 MOLECULAR COMBING: A NEW APPROACHE TO MOLECULAR CYTOGENETICS AND PHYSICAI MAPPING

A. Bensimon, X. Michalet, C. Schurra and J. Herrick.

Laboratoire de Biophysique de l'ADN, Institut Pasteur, Paris, France

In a process called "molecular combing" DNA molecules attached at one end to a solid surface are extended and aligned by a receding air-water interface and left to dry on the surface.

It turns out that the force the interface exerts on the DNA is strong enough to extend the molecule but to weak to break the bond between the molecule and the surface. The local action of the interface is the same on each of the molecules in solution: they are identically stretched.

Simple, controlled and reproducible optical mapping on purified DNA molecules, individual sorted chromosomes and total genomic DNA is made possible by applying Fluorescence in situ hybridisation (FISH) to combed DNA. The utility and accuracy of FISH on combed molecules are illustrated by several examples. (i) mapping of lambda DNA restriction fragments along linearized $49 \mathrm{Kbp}$ long lambda phage DNA molecules with $1 \mathrm{Kbp}$ precision, (ii) mapping of cosmid clones along a $470 \mathrm{Kbp}$ yeast artificial chromosome (YAC) with $5 \mathrm{kbp}$ precision and estimation of the gaps and the overlaps between them, and (iii) ultrahigh resolution comparative nucleic acid hybridisation to combed DNA molecules. This has allowed us to study, in a relatively simple manner, chromosomal rearrangements, insertions and deletions of different genetic disorders with high precision.

\section{FISH ON CHROMOSOMES: SOME INTRODUCTORY \\ REMARKS}

Dr Alain Bernheim

Laboratoire de Cytogénétique et Génétique Oncologiques (URA 1967 CNRS), Institut Gustave Roussy, 36 rue Camille Desmoulins 94805 Villejuif Cedex, France

Morphological cytogenetics has been transformed in molecular cytogenetics by the introduction of FISH techniques. The nucleus content and organisation can be analysed during all the cell cycle, either on condensed chromosome, intact nuclei, section of nuclei, whole DNA, streched DNA.

The FISH techniques are rapidly expanding with various probes:

- unique DNA segments from few hundred base pair to several megabase; - repeat sequences for centromeric probes, telomeric allowing even the use of oligonucleotides for PRINS;

whole or partial chromosome for painting:

- Total DNA for comparative in situ hybridization which allows to demonstrate chromosomal losses or gains from tumoral DNA

- stretched DNA or chromatin which allows a resolution as low as few $\mathrm{kb}$. Digital imaging by cooled single or color CCD cameras and image processing are more and more used. Recently Schrock et al (Science 1996) used an interferometer to determine the full spectrum of light emited by each stained chromosome. If a combinatorial approach is used by labeling the painting probes for each chromosome with a different assortment of fluochromes, as few as five dyes can give enough combinations to give one for each human chromosome type.

Among an exponentialy growing amount of applications, determination of the very complex chromosomal abnormalities in cancer cells are one which which may help to understand the genetic change leading to cancer and may provide roads to therapy. 
Gosset P. - $73-74$

Goubern M. - 41

Gougerot-Pocidalo M.A. - 30 - 118

Govin I. - 130

Goujon N. - 78

Guyotat D. - 94

Hamon S. -42
Hardy E. - 15

Healy J.C. -96

Hebbache A. - 49b

Hemet J. - 79 - 102

Herlin P. - 3 - 7 - 8 - 9 - 10 - 11 - 12 - 13 - 14 - 16 - 72 -

Herrick J. - 135

Hiron M. - 101

Hurez D. - 124

Husson B. - 109

Israël N. - 118

Jacquey S. -67

Jaloustre C. - 95

Janossy G. - 31

Jayat-Vignolles C. - 47 - 117

Jbilo O. - 24

Jeanne-Pasquier C. - 76

Jeannin P. - 25

Joret J.B. - 3

Jouen Beades F. - 34 - 119

Julien R. - 47

Jung G. -67

Kahn E. - 63 - 65 - 66

Kennes B. - 128

Keriel C. - 37

Klein C. - 61

Klijanienko J. - 83

Kohler Ch. - 134

Kolopp-Sarda M.N. - 134

Kroemer G. - 99

Kuhlein E. - 12

Kujas M. - 6

Lacombe F. - 95 - 105

Lacoste L. - 95

Laquerrière A. - 79

Laudier B. - 84

Laurent J.L. - 70

Le Moine P. - 124

Le Roux G. - 123

Le Tessier D. - 87 - 91

Lebarr A. - 87

Lebeau C. - 76

Lebreton J.P. - $101-102$

Leclerg N. - 76

Lecomte-Houcke M. - 73

Lefebvre J.L. - 74

Lenoir M. - 104

Lenormand B. - 34 - 122

Leonard C. - 84

Leprat P. - 47

Leprêtre S. - 34

Lequeux N. - 80 - 8

Lescoarnec J. - 88

Lesesve J.F. - $34-122$

Lesty C. -6

Leverve X. - 37

Liautaud F. - 69

Liautaud-Roger F. - 103

Linares-Cruz G. - 65

Lizard G. - 63

Lorenzato M. - 71

Louarn J. - 42

Louarn J. -

Lu H. -48

Lyoumi S. - 102

Maciorowski Z. - 83

Macro M. - 106

Malcus C. - 53 - 97

Malcus-Vocanson C. - 97

Malet M. - 106

Mandard A.-M. - 3 - 76

Mandy F. - 50

Manfait M. - 33 - 62
Marchand J. - 24

Marion S. - 53

Marnay J. - 76

Martin E. - 20

Martin P.M. - 18

Masson E. - 3

Masson S. - 101 - 102

Maubon I. - 70

Maynadié M. - 111 - 127

Mazzerbo F. - 108

Mazzon A.M. - 109

Mendel I. - 88

Menet A. - 35

Menot M.L. - 130

Mercadier A. - 53

Mercier B. - 15

Meunier O. - 39 - 46

Meyer J.J. - 67

Michalet X. - 135

Michel P. - 79

Michels J.-J. - 72 - 76

Miet S. - 26

Mishal Z. - 2

Moiceanu A.D. - 121

Monconduit M. - 122

Monteil H. - 39 - 46

Morjani H. - 33

Moskovtchenko P. - 127

Mosnier-Damet M. - 78

Motoiu A.I. - 121

Mourad G. - 133

Mousseau M. - 27 - 32

Mozziconacci M.J. - 114

Mugneret F. - 111

Muirhead K. - 36

Mutin M. - 31

Necker A. - 114

Nève P. - $128-129$

Noirot M. - 42

Ohlsson-Wilhelm B. - 36

Olive D. - 114

Osmont A. - 13 - 14

Oziel S. - 114

Pagès I. - 56

Pagès J. - 107

Pagniez M. - 58

Paillasson S. - 40

Palmari J. - 18 - 19

Parésy M. - 79

Paris E. - 119

Paschoud N. - 21

Pelegrini M. - 66

Pellestor F. - 85 - 90

Penel C. - 19

Perek N. - 94

Peries L. - 92

Perroux-Goumy L. - 124

Petit P.X. - 41 - 99

Petitprêtre G. - 24

Philip P.J.M. - 52 - 55 - 108 - 116

Philippe C. - 66

Pignon S. - 127

Pillet S. - 118

Piriou L. - 29

Plancoulaine B. - 3 - 13 - 14

Pléau-Varet J. - 6

Ploton D. - 60 - 6

Poitevin-Later F. - 97

Poncelet P. - 26 - 28 - 31

Portalès P. - $132-133$

Pouchelet M. - 48

Pradier O. - 57 - 109

Praz G. - 120

Preira A. - 118

Prévost G. - 39 - 46

Provot F. - $101-102$

Puchelle E. - 45

Quereux C. - 71

Quilichini R. - 108

Rabineau D. - 87 - 91

Racadot E. - 127
Radal M. - 80 - 81

Raphael M. - 123

Réclar V. - 80 - 81

Réglier H. - 30

Renier G. - 44 - 124

Revenu M. - 7 - 16

Rigaut J.P. - 20

Robert-Nicoud M. - 40 - 43

Rocchi E. - 38

Roger P. - 45

Rohr M. - 115

Roignot P. - 63

Romagné $F .-114$

Ronot X. - $27-32-37-40-43-100$

Rossi J.F. - 132

Rotagnon M.O. - 97

Rougereau O. - 13

Roy L. - 86

Rummens J.L. - 109

Saadi A. - 62

Sabido O. - 70 - $94-96$

Sainty D. - 114

Salaun V. - 106

Salmon J.M. - 38

Sampol J. - $26-31$ - 54

Sanchez M. - 44

Sartiaux C. - $55-111$

Schaaf-Lafontaine N. - 109

Schandelong A. - 126

Schiavon V. - 23

Schmitt D. - 63

Schoëvaërt D. - 20 - 48 - 49b

Schüpp S. - $8-10$

Schurra C. - 135

Scotté M. - $101-102$

Seigneurin D. - 27 - 32 - 100

Sibille B. - 37

Signolle J.P. - 3 - 13 - 14

Simony J. - 80 - 81

Sire S. - 39

Sohm E. - 48

Sola B. - $11-12$

Solary E. - 111

Somerjai R. L. - 50

Sorokine-Durm I. - 86

Soumelis V. - 107

Soussaline F. - 86

Spyratos F. - 51

Staali L. - 39

Stoltz J.F - 4

Talabard J.N. -96

Tchernia G. -84

Tchernia G. - 84

Tertian G. - 84

Teyssier F. - 96

Thiry V. - 109

Tilly H. - 122

Touraine-Moulin F. - 97

Tracqui P. - 43

Triboulet J.P. - 73

Tron F. - $34-119-122$

Troussard X. - 106

Truong K. - 83

Ts Li - 92

Vago P. - 51 - 58 - 68 - $80-81-104$

Vandekerkhove P. - 109

Vandenhaute B. - 73

Vanhaeverbeek M. - 128

Vendrell JP - 56

Vergne M. - 47

Viallet P. - 38

Vielh P. - 83

Vigo J. - 38

Visseaux-Coletto B. - 71

Voisin P. - 86

Wallet F. - 17 - 18

Wattez N. - 74

Weber P. - 21

Xu C. - 67

Yatouji S. - 103

Zassadowski F. - 130 


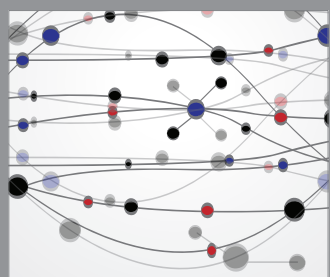

The Scientific World Journal
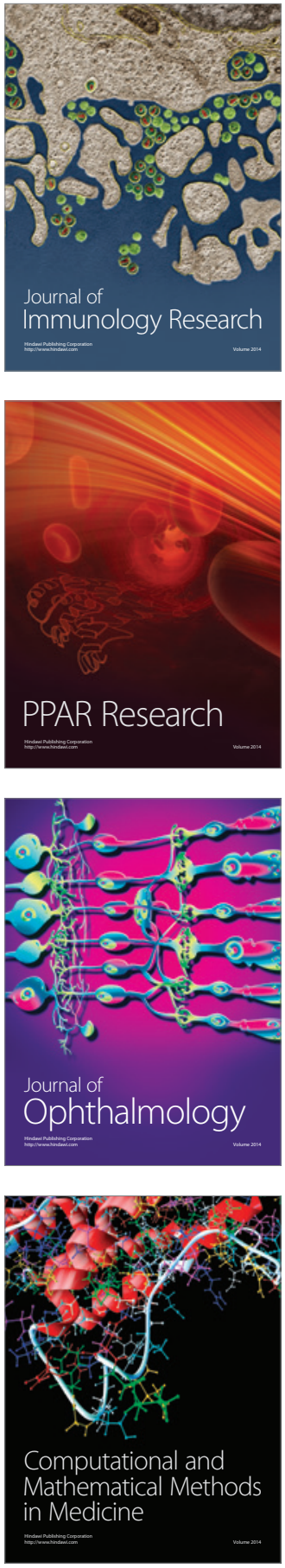

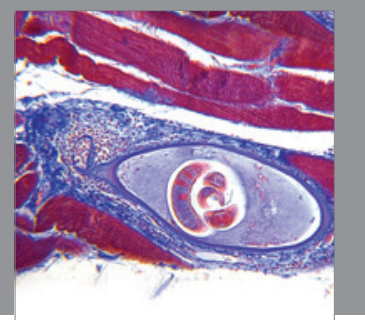

Gastroenterology

Research and Practice
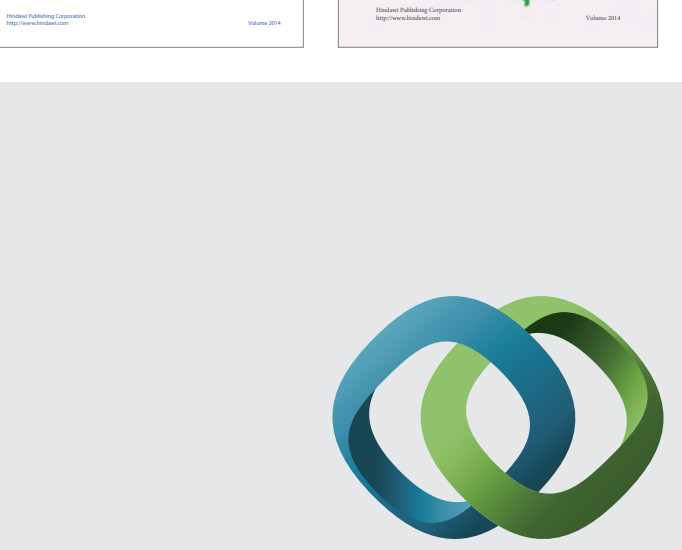

\section{Hindawi}

Submit your manuscripts at

http://www.hindawi.com
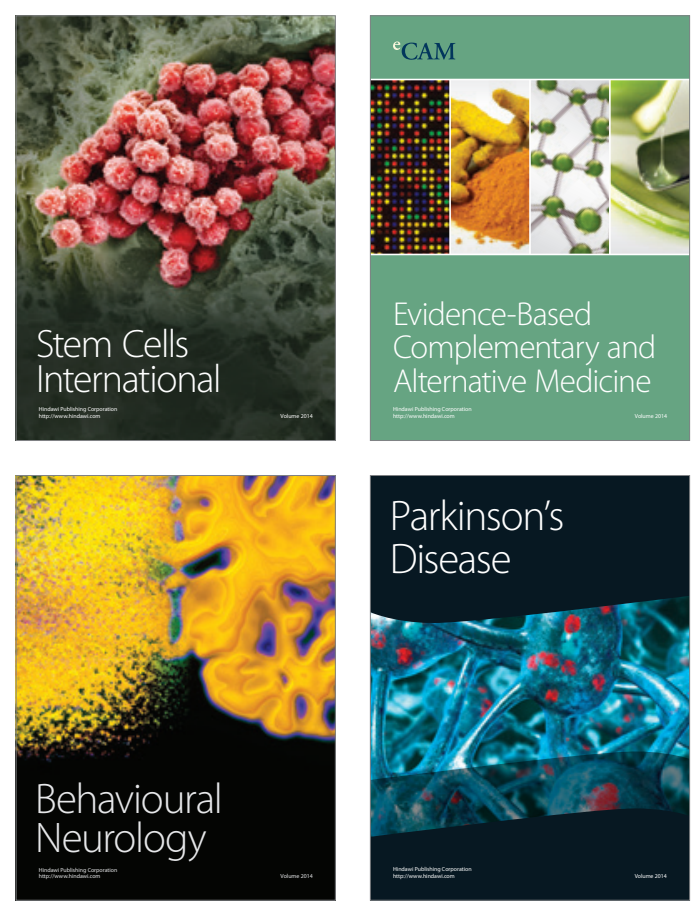

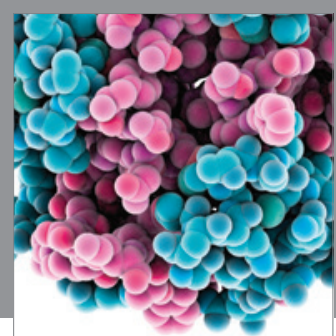

Journal of
Diabetes Research

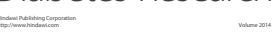

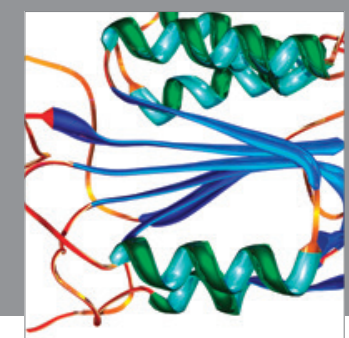

Disease Markers
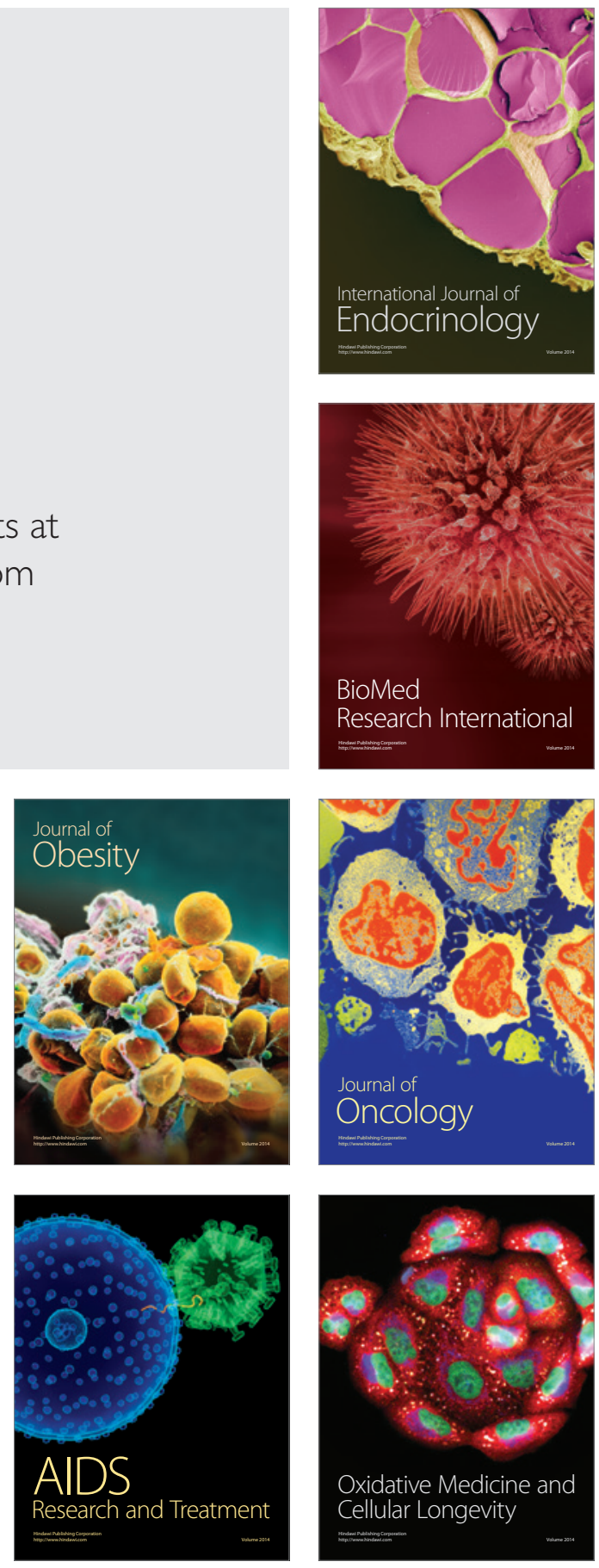